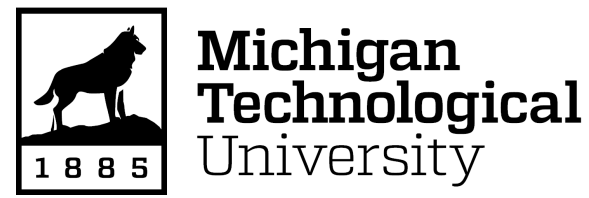

Michigan Technological University Digital Commons @ Michigan Tech

Dissertations, Master's Theses and Master's Reports

2017

\title{
Utilizing RepRap Style 3D Printers for the Manufacturing of Composite Heat Exchangers
}

John Laureto

Michigan Technological University, jjlauret@mtu.edu

Copyright 2017 John Laureto

\section{Recommended Citation}

Laureto, John, "Utilizing RepRap Style 3D Printers for the Manufacturing of Composite Heat Exchangers", Open Access Master's Thesis, Michigan Technological University, 2017.

https://doi.org/10.37099/mtu.dc.etdr/346

Follow this and additional works at: https://digitalcommons.mtu.edu/etdr

Part of the Heat Transfer, Combustion Commons, Manufacturing Commons, and the Materials Science and Engineering Commons 
UTILIZING REPRAP STYLE 3D PRINTERS FOR THE MANUFACTURING OF COMPOSITE HEAT EXCHANGERS

By

John J. Laureto III

\begin{abstract}
A THESIS
Submitted in partial fulfillment of the requirements for the degree of MASTER OF SCIENCE

In Materials Science and Engineering
\end{abstract}

MICHIGAN TECHNOLOGICAL UNIVERSITY

2017

(C) 2017 John J. Laureto III 
This thesis has been approved in partial fulfillment of the requirements for the Degree of MASTER OF SCIENCE in Materials Science and Engineering.

Department of Materials Science and Engineering

\author{
Thesis Advisor: Joshua M. Pearce \\ Committee Member: $\quad$ Paul G. Sanders \\ Committee Member: Julia A. King \\ Department Chair: $\quad$ Stephen A. Kampe
}




\section{Table of Contents}

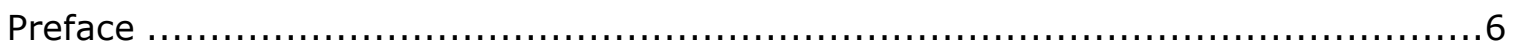

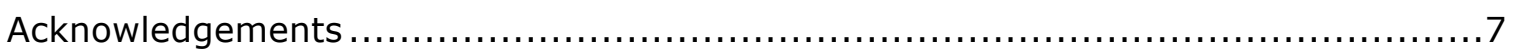

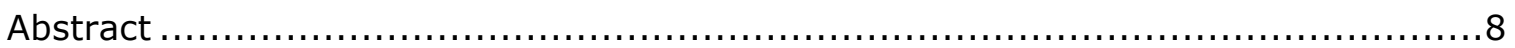

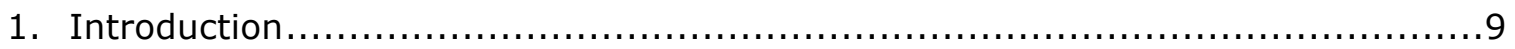

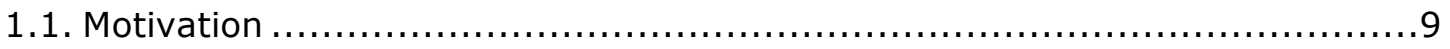

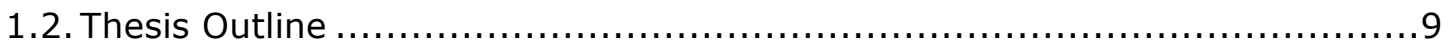

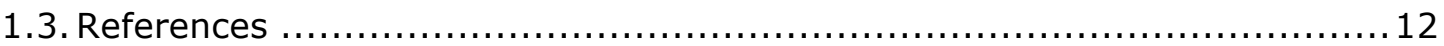

2. Open Source Laser Polymer Welding System: Design and Characterization of

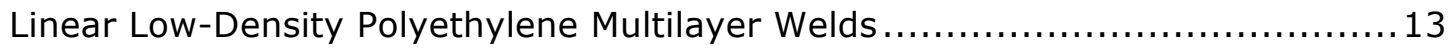

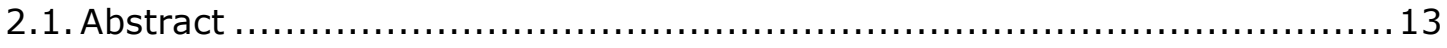

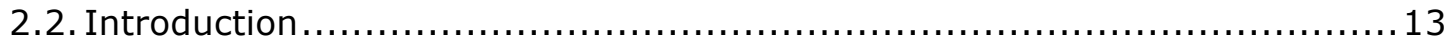

2.3. Materials and Methods..................................................... 15

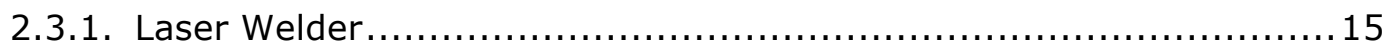

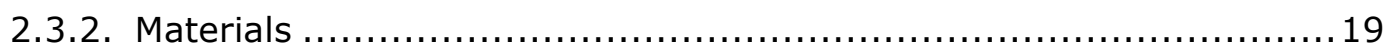

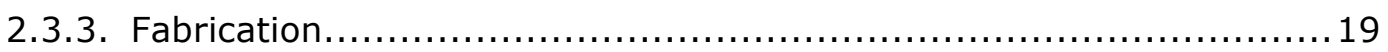

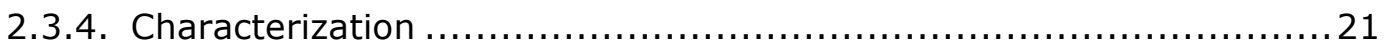

2.3.4.1. Peak Load Determination .................................... 21

2.3.4.2. Weld Width $(\mathrm{mm})$ and Resultant Energy Density

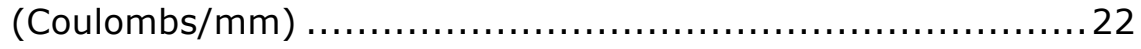

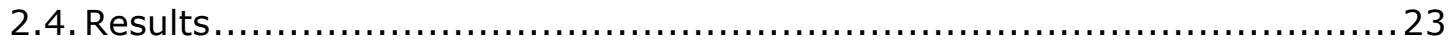

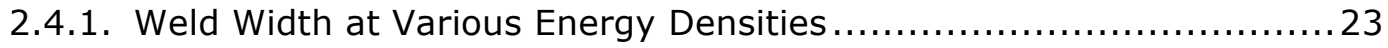

2.4.2. Polymer Weld Adhesion of Two and Three Layered LLDEP System ....27

2.4.3. Mechanical Testing - Peak Load (Ibf) ................................ 29

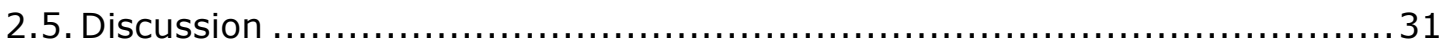

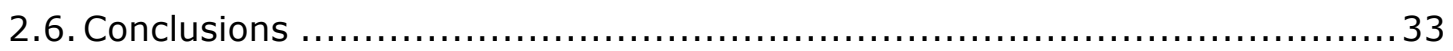

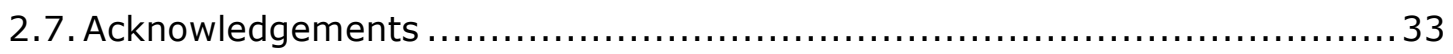

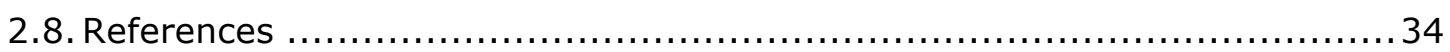

3. Thermal Properties of 3-D Printed Polylactic Acid - Metal Composites ..............39

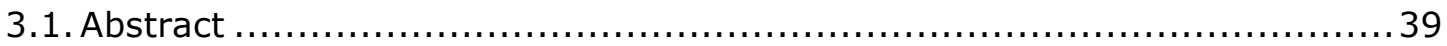

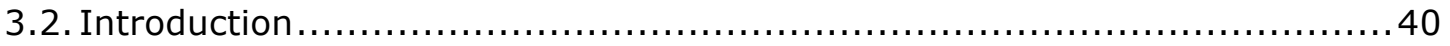

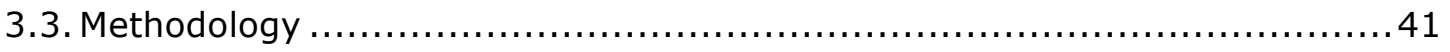

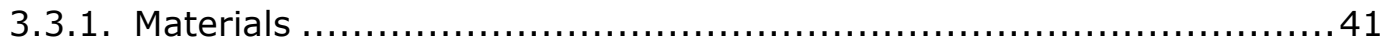




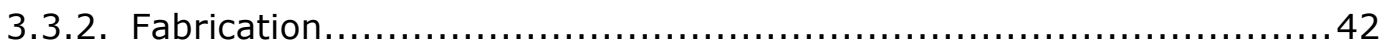

3.3.3. Characterization ................................................. 43

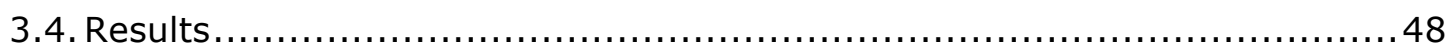

3.4.1. Density and Constituent Wt./Vol. Percentage Determination ...........48 48

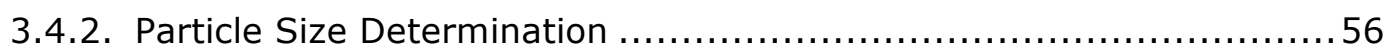

3.4.3. Composite Thermal Conductivity $(\mathrm{W} / \mathrm{m} \cdot \mathrm{K})$ Determination ..............6 61

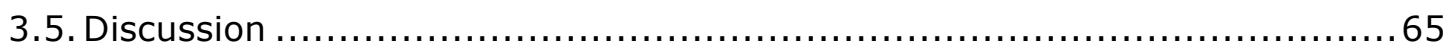

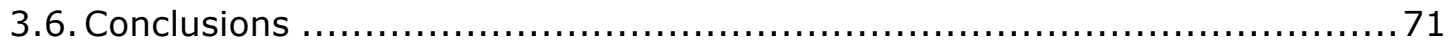

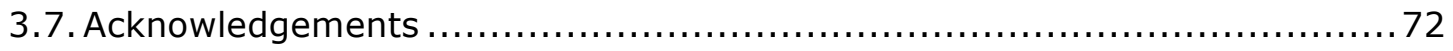

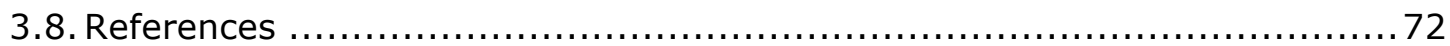

4. Open Source Multi-head 3-D Printer for Polymer-Metal Composite Component

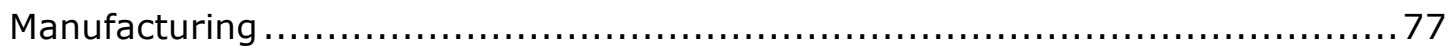

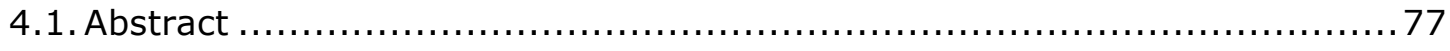

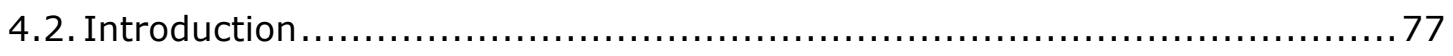

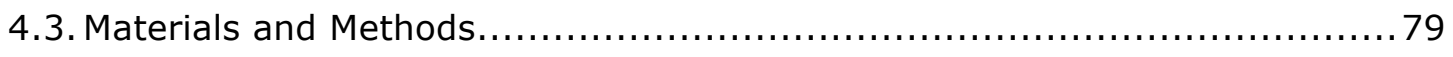

4.3.1. Fabrication of the Gigabot for Multihead Metal-Polymer Composite

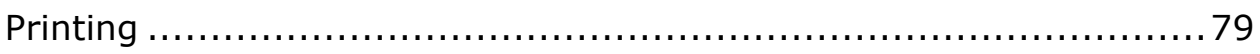

4.3.2. Circuit Assembly and Printer Control............................... 87

4.3.3. Modification of Extruder $A_{E}$ for Wire-Feeding ........................ 93

4.3.4. Composite Printing - Utilizing Wire-Feed Guide and Standard Brass 1.0mm Extruder Nozzle

4.3.5. Polymer Filament Material Selection and Printing Parameter

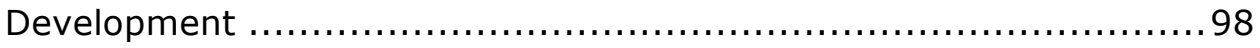

4.3.6. Composite Printing Tests for Metal-Polymer Gigabot ................. 99

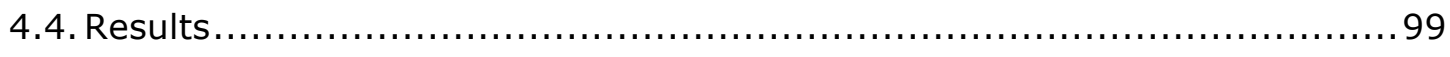

4.4.1. Resultant print quality and power consumption measurements ........99

4.4.2. Printing parameter and material development ..................... 103

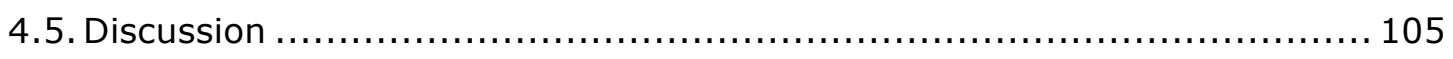

4.5.1. Practical Applications............................................. 105

4.5.2. Areas of improvement and comparison to other technologies ........ 106

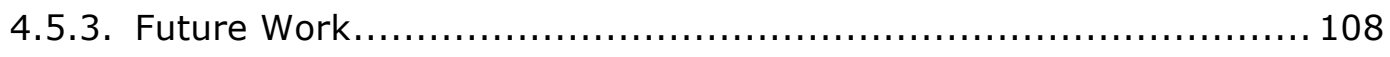

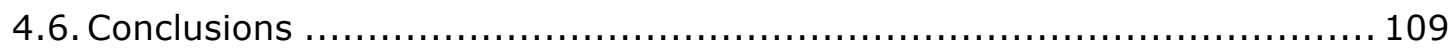

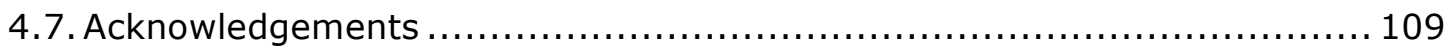

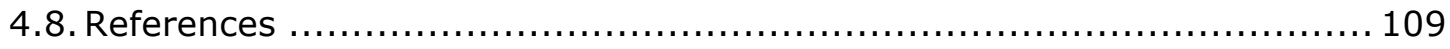




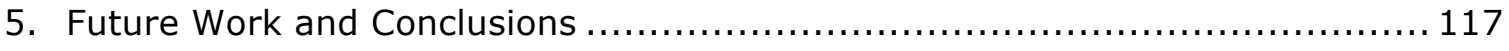

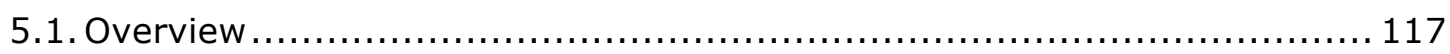

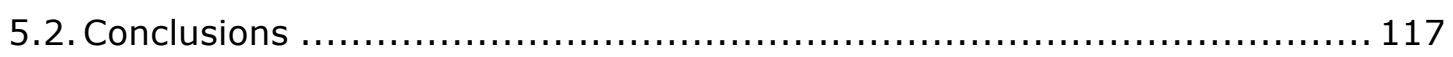

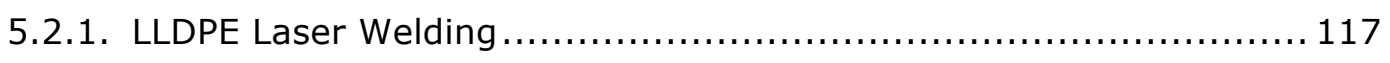

5.2.2. Polymer - Metal Composite Materials ............................. 118

5.2.3. Polymer - Metal Composite Gigabot Printer ....................... 119

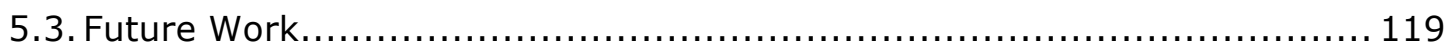

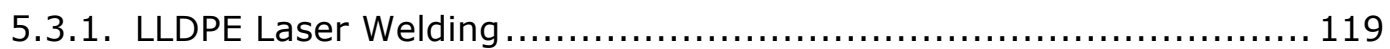

5.3.2. Polymer - Metal Composite Materials .............................. 120

5.3.3. Polymer - Metal Composite Gigabot Printer ......................... 120 


\section{Preface}

The author of this thesis has utilized a collection of previously published work and manuscripts submitted for academic review. The author's contributions to each section of research are as follows:

Chapter 2: John J. Laureto, Serguei V. Dessiatoun, Michael M. Ohadi and Joshua M. Pearce. Open Source Laser Polymer Welding System: Design and Characterization of Linear Low-Density Polyethylene Multilayer Welds. Machines 2016, 4(3), 14; doi: 10.3390/machines4030014. J.J. Laureto performed and designed welding experiment methods, data analysis and interpretation. S.V. Dessiatoun contributed materials selection guidance. M.M. Ohadi functioned as project manager and collaborative effort of all parties. J.M. Pearce developed the application along with the design of experiments and data analysis. All authors contributed to writing and editing the final published manuscript.

Chapter 3: Laureto, J., Tomasi, J., King, J.A., Pearce, J.M. Thermal Properties of 3-D Printed Polylactic Acid - Metal Composites. Progress in Additive Manufacturing (in press). This article was written by J. J. Laureto, J. Tomasi, J. A. King and J.M. Pearce. J.J. Laureto's contribution was development of printing parameters, printed samples, data collection / analysis and microscopy. J. Tomasi aided with experimental methods processes and data analysis. J. A. King provided research guidance via data interpretation and literature review. J.M Pearce conceived the application and proposed original research idea. All authors contributed to writing and editing the submitted manuscript.

Chapter 4: John J. Laureto, Joshua M. Pearce. Open Source Multi-head 3-D Printer for Polymer-Metal Composite Component Manufacturing. Technologies (in review). J. J. Laureto constructed the composite 3D printer, designed operational procedures, developed printing parameters, performed data collection and analysis. J.M Pearce proposed the research idea analyzed produced samples. All authors contributed to writing and editing the submitted manuscript. 


\section{Acknowledgements}

I would like to take the opportunity to thank my graduate research advisor Dr. Joshua M. Pearce who provided intellectual discussion, guidance, motivation and a keen sense of research methods over the past year and a half of our collaboration.

I would also like to thank Dr. Julia A. King and Dr. Paul G. Sanders for serving as my committee members and providing guidance when requested.

Finally, I want to extend my gratitude towards Gerald Anzalone, Dr. Bas Wijnen, fellow graduate students and all members of the Michigan Tech Open Sustainability and Technology (MOST) research group for their aid, encouragement and friendly banter. 


\section{Abstract}

The low cost 3D printing market is currently dominated by the application of RepRap (self-replicating rapid-prototyper) variants. Presented in this document are practical utilizations of RepRap technology. Developed are innovative processes to manufacture composite materials systems for thermal management solutions.

First, a laser polymer welder system is validated by quantifying maximum peak load and weld width of linear low density polyethylene (LLDPE) lap welds as a function of linear energy density. The development of practical engineering data, in this application, is critical to producing mechanically durable welds. Developed laser and printer parameter sets allow for manufacturing of LLDPE multi-layered heat exchangers

Second, newly introduced metal-polymer composite materials (e.g. copper-PLA, bronze-PLA, iron-PLA and stainless steel-PLA) were shown to influence the thermal conductivity $(\mathrm{W} / \mathrm{m} \cdot \mathrm{K})$ of the composite matrix. Increased volume percentage of metallic constituent was shown to increase thermal conductivity. Air void fraction, a resultant of the manufacturing process, reduced the bulk composite 3D printed component. No significant effects were realized dependent upon the metallic constituent morphology (i.e. flake-like vs. spherical).

Third, development and fabrication of a large format multi-head RepRap 3D printer displays the ability of large-scale manufacturing potential. Energy efficiencies are realized upon utilization of all hot-ends (i.e. the embodied energy of each printer movement ( $\mathrm{X}, \mathrm{Y}$ and $\mathrm{Z})$ ) and are simultaneously shown at each hot-end.

Furthermore, multi-head format printers are proven to develop composite components. Utilizing a novel weaving and layering method 1000-series aluminum wire is embedded into a polyethylene terephthalate glycol modified (PETG) matrix. Parametric customized gcode commands allow for innovative manufacturing.

In total, laser parameter development, material characterization, custom machine fabrication and printing process development are quantified. The three presented projects demonstrate the engineering advancement of RepRap technology in application to thermal management solutions and composite material development. 


\section{1 - Introduction}

\subsection{Motivation}

The ultimate goal of these academic endeavors are to increase practical applications of RepRap 3D printer technology. Specifically, the research conducted expands upon the RepRap's ability to manufacture composite material systems (e.g. polymer and metallic materials) and be able to use novel variations of a traditional RepRap [Bowyer] to manufacture single material thermal management solutions. Thus, the proposition is to utilize developed thermal solutions in industrial settings, including automotive and power generation.

\subsection{Thesis Outline}

The conducted research will be deconstructed into three main chapters. Beginning with Chapter 2, the audience will be introduced to a polymer laser welder system developed and published by the author. As to be described further, expanded microchannel heat exchangers can be developed with functional mechanical weldments. This initial work is key to the development of laser processed all-polymer heat exchangers. Preliminary heat exchanger designs will derive from the principles and methods described by Dekenberger et al. Multi-channel parallel co-current flow path computational models are to be utilized to design preliminary concept designs. Figure 1.1 describes a generalized cross-section of a multi-channel heat exchanger in relation to a manufactured sample. Flow channels are realized through laser welding successive sheets of polymer material via incident fiber laser current energy density. 
(A)

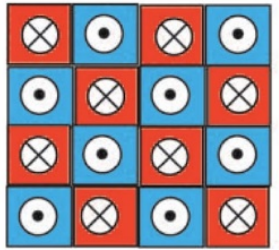

KEY

Hot

Cold

Flow into page

○ Flow out of page

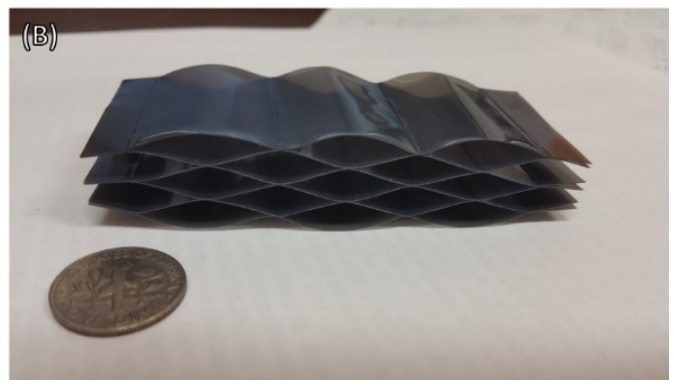

Figure 1.1. (a) Qualitative heat exchanger model utilizing multiple co-current flow paths, (b) Laser welded / processed sample component representing the design in (a) $[1]$

Low cost expanded microchannel heat exchangers utilize hydraulic diameters less than $1 \mathrm{~mm}$ and offer economic advantages as result of decreased material cost and an open source laser welding manufacturing system [1]. Furthermore, overcoming the significant thermal barrier associated with a polymers intrinsically low thermal conductivity (e.g. $\sim 0.02 \mathrm{~W} / \mathrm{mK}$ vs. metallic/composite materials $\sim 100-1000$ $\mathrm{W} / \mathrm{mK}$ ) is achievable with thin $(<1 \mathrm{~mm}$ ) polymer sheets. Figure 1.2 describes the negligible variances in polymer vs. metallic/composite materials where wall thickness (i.e. sheet thickness) is less than $1 \mathrm{~mm}$. The relationship derived suggests that fluid (convective heat transfer mediums) heat transfer coefficients $\left(\mathrm{W} / \mathrm{m}^{2} \mathrm{~K}\right)$ less than $10^{4}$ for polymer sheets less than $1 \mathrm{~mm}$ are equivalently effective at providing a total heat exchanger thermal transfer coefficient, $U\left(\mathrm{~W} / \mathrm{m}^{2} \mathrm{~K}\right)$, relative to metallic materials of similar thickness. 


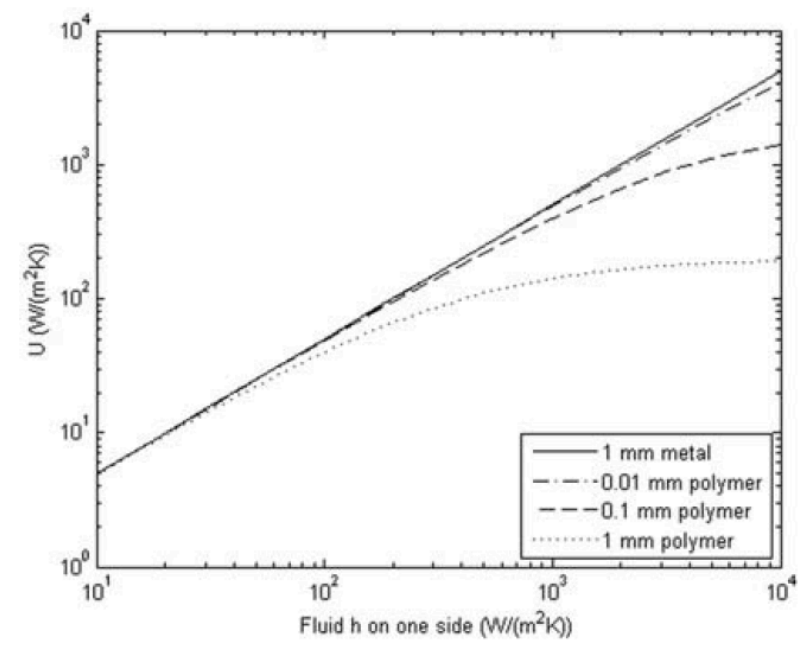

Figure 1.2. (a) Qualitative heat exchanger model utilizing multiple co-current flow paths, (b) Laser welded / processed sample component representing the design in (a) $[1]$

Chapter 3 introduces the audience to the thermal characterization analysis, performed by the author, of polymer-metal composite fused filament fabrication (FFF) materials readily available for purchase on the open market. Additionally, the study investigates the ability of metallic filler concentration to the bulk polylactic acid (PLA) composites for potential applications to control of heat transfer. Specifically, the thermal conductivity $(\mathrm{W} / \mathrm{mK})$ of the polymer-metal composite will be determined via thru-plane heat transfer analysis abiding by parameters specified in ASTM F43302 [2]. Theoretical models, commonly accepted in literature, are utilized for comparison to experimental results including Mamunya et al., Smith et al., and Landauer describing metallic filler volume fraction dependency, air void volume fraction corrections and Lichtendecker prediction factors, respectively $[3,4,5]$. Chapter 4 describes a large format RepRap printer to be utilized for multi-head printing and composite component manufacturing. The operational procedures and experimental processes, developed by the authors, are proven by manufacturing of PETG and aluminum composites, dimensional characterization and electrical requirements of the designed system. This system has the potential for industrial scale manufacturing of heat exchangers among other applications. Specifically, cross flow media heat exchangers containing an additively manufactured polymeric material encapsulating a 2-D array of 1100 series aluminum wires. The cross flow 
methodology enables reduced heat exchanger wall/fin thermal contact resistance, provides the shortest available thermal flow path and provides mechanically adequate thru-thickness joint converse to common brazing manufacturing methods of full metal heat exchangers [6]. Furthermore, metal wire embedment is characterized by burst pressure measurements and thermal management effectiveness. Chapter 5 identifies to the audience where the author believes the next steps of this research are to occur. Chapter 6 finalizes the author's findings and offers conclusions onto the conducted research presented in this work.

\subsection{References}

[1] Denkenberger, D.C.; Brandemuehl, M.J.; Pearce, J.M.; Zhai, J. Expanded microchannel heat exchanger: Design, fabrication, and preliminary experimental test. Proc. Inst. Mech. Eng. Part A J. Power Energy 2012, 226, 532-544.

[2] "Evaluating Thermal Conductivity of Gasket Materials," ASTM Test Method F43302 (Reapproved 2014)

[3] Mamunya, Y. P., Davydenko, V. V., Pissis, P., \& Lebedev, E. V. (2002). Electrical and thermal conductivity of polymers filled with metal powders. European polymer journal, 38(9), 1887-1897. doi: 10.1016/S0014-3057(02)00064-2

[4] Smith, D. S., Alzina, A., Bourret, J., Nait-Ali, B., Pennec, F., Tessier-Doyen, N., Otsu, K., Matsubara, H., Pierre, E., Gozenbach, U. T. (2013) Thermal conductivity of porous materials. Journal of Materials Research, 28(17), 22602272. doi: $10.1557 / j m r .2013 .179$

[5] Landauer, R. (1952). The electrical resistance of binary metallic mixtures. Journal of Applied Physics, 23(7), 779-784.

[6] "Novel Polymer Composite Heat Exchanger for Dry Cooling Of Power Plants", ARPA-E: ARID Project Proposal, University of Maryland, College Park, MD, 2016. 


\section{2 - Open Source Laser Polymer Welding System: Design and Characterization of Linear Low-Density Polyethylene Multilayer Welds ${ }^{1}$}

\subsection{Abstract}

The use of lasers to weld polymer sheets provides a means of highly-adaptive and custom additive manufacturing for a wide array of industrial, medical, and end user/consumer applications. This paper provides an open source design for a laser polymer welding system, which can be fabricated with low-cost fused filament fabrication and off-the-shelf mechanical and electrical parts. The system is controlled with free and open source software and firmware. The operation of the machine is validated and the performance of the system is quantified for the mechanical properties (peak load) and weld width of linear low density polyethylene (LLDPE) lap welds manufactured with the system as a function of linear energy density. The results provide incident laser power and machine parameters that enable both dual (two layers) and multilayer (three layers while welding only two sheets) polymer welded systems. The application of these parameter sets provides users of the open source laser polymer welder with the fundamental requirements to produce mechanically stable LLDPE multi-layer welded products, such as heat exchangers.

\subsection{Introduction}

Focused laser radiation absorbed into a polymer interface produces an elevated temperature, which can be used for inter-layer bonding. A contact free manufacturing method, such as laser welding, provides increased flexibility and further application than its conventional joint bonding processes [1]. Advancement in the field of polymer welding has expanded applications to microfluid polymer packages [2], aseptic packaging [3], hermetic sealing of an electronic car key [4],

\footnotetext{
${ }^{1}$ The material contained in this chapter was previously published in Machines
} 
microfluidic channels [5], and additively manufactured and complex microchannel heat exchangers $[6,7]$.

Characterization of polymer welds and in-process monitoring techniques have been explored with acoustic, optical, thermal, ultrasonic, and emission techniques [8, 9 ]. Thus, the application of polymer sheet material(s) for lap-joint laser welding applications is not uncommon. Ghorbel et al. characterized the thermal and mechanical behavior of some thermoplastic polymers [10]. They successfully welded polypropylene sheets by diode-laser transmission welding [11] and selected soundness variables for the diode laser welding of polypropylene thermoplastic polymers by experimental and numerical analysis [12]. Also, Torrisi et al. characterized the adhesion susceptibility of polyethylene sheet materials $[13,14]$. The work described indicates that efficient welding of polymer materials is the result of not only thermally induced melting effects, but also the development of ions near the laser-polymer interface. Subsequently, pulsed laser radiation allows for adequate polymer weld adhesion, through photo-chemical and ion implantation effects, while not elevating the polymer beyond its melting temperature. All work described suggests that the resultant weld seam quality correlates to diode laser process parameters (laser power $(\mathrm{W})$ and cross-head speed $(\mathrm{mm} / \mathrm{s})$ ) and the optical/absorption properties of the incident polymer [11]. Dowding et al. successfully demonstrated the production of viable adhesive bonds between LLDPE (linear low density polyethylene) on PP (polypropylene) at an appropriate laser line energy $(\mathrm{J} / \mathrm{m})$, similar to a linear energy density (Coulombs/mm). In this study, maximum peel force was used for quantification [15]. The response behavior of the material system is constant in regard to incident laser line energy. Specifically, the linear energy density delivered to the polymer system requires, at a minimum, a critical value to induce bonding.

This paper provides open source designs for a laser polymer welding system and then explores the mechanical properties and weld width appearance of LLDPE lap welds manufactured with the system. Specifically, apparent peak load (Ibf) and linear energy density (coulombs/mm), corresponding to weld width $(\mathrm{mm})$, are quantified. The designed, open-source, system is meant to provide a reliable manufacturing tool to be readily adapted to a multitude of polymer welding applications. Available 
source code and the provided component build files allow a multitude of users the ability to utilize the technology as they see appropriate.

\subsection{Materials and Methods}

\subsubsection{Laser Welder}

An open-source computer numeric control (CNC) laser welder [16] was modified for this experiment. The apparatus is a gantry device with NEMA17 motors driving 20 tooth GT2 pulleys, one set for the X-axis and one for $Y$. The frame is constructed with 20-20 extruded aluminum with accommodating fittings and fixtures. Utilized bearings and guide rods are readily available standard equipment for purchase.

Printed members (Table 2.1) were redesigned in OpenSCAD [17], an open source parametric scripting computer aided design (CAD) program, and printed on a standard RepRap [18-21] using polylactic acid (PLA). Parts were designed so as to maximize rigidity while minimizing plastic consumption to minimize printing time, embodied energy, environmental impact, and economic cost. All SCAD files are available for free [22] under the GNU GPLv3 [23] along with operational instructions [24].

Boxed idler ends were designed to maximize rigidity and to assure proper belt tracking under tension. $624-\mathrm{ZZ}$ roller bearings on $4 \mathrm{~mm}$ shafts were used as idlers. Belt tension was applied and maintained through the use of large nylon wire ties stretched between belt terminators previously designed for the MOST delta RepRap [25].

The $x$-carriage can adjust the position of the laser in the $z$-direction to assist in focusing. A pair of printed thumbscrews clamp the position of a threaded rod upon which they ride to the $x$-carriage. The laser mount is fixed to one end of the threaded rod and additionally constrained in the $x$ and $y$-directions by a $6 \mathrm{~mm}$ smooth rod that is press-fit into the mount and passes through the $x$-carriage. The assembled $\mathrm{x}$-carriage and $\mathrm{z}$-adjustment system are shown in Figure 2.1. 
Mechanical snap-action switches to eliminate the need for a $5 \mathrm{~V}$ power supply and to simplify the design. A Melzi controller [26] was mounted to the frame with three dimensional (3-D) printed components and this is driven by a Raspberry Pi [27] with custom Franklin firmware [28,29], Arroyo Instruments 432020 A LaserSource, and 5305 5A/12V TECSource. Gcode, for the laser profile scans, was user-generated and imported into Franklin. As designed, the 432020 A LaserSource and X/Y laser-head movement is controlled by commands the user prescribed, while the 5305 TECSource is a standalone unit. The $432020 \mathrm{~A}$ LaserSource provides the incident laser source while the 5305 TECSource is the cooling system for the laser apparatus. The 432020 A LaserSource is a laser diode driver. Connected to the controller is a JDSU High-Power 10W 9xxnm Fiber Diode Laser [30]. The diode laser provides 10W of power from a $105 \mu \mathrm{m}$ fiber thus providing a typical mean wavelength $(\lambda) 917-$ $974 \mathrm{~nm}$ [30]. Operating at a current of $\sim 11.6 \mathrm{~A}$ a conversion efficiency $(\eta)$ of $48 \%$ is realized [30]. Further operational performance data for the JSDU Diode Laser is available in [30].

Table 2.1. Three-dimensional (3-D) printed parts.

\begin{tabular}{|c|c|c|c|c|c|}
\hline Part Name & Count & $\begin{array}{c}\text { Rendered } \\
\text { Image }\end{array}$ & Part Name & Count & $\begin{array}{c}\text { Rendered } \\
\text { Image }\end{array}$ \\
\hline $\begin{array}{l}\text { Controller } \\
\text { standoff for } \\
\text { attaching } \\
\text { controller to } \\
\text { frame }\end{array}$ & 1 & i & $\begin{array}{l}\text { Laser carriage } \\
\text { for mounting } \\
\text { laser to holder } \\
\text { apparatus }\end{array}$ & 1 & \\
\hline $\begin{array}{l}\text { Limit switch } \\
\text { mount for } \\
\text { mechanical } \\
\text { switches to } \\
\text { appropriate } \\
\text { guide rods }\end{array}$ & 2 & a & $\begin{array}{l}\text { M8 } \\
\text { thumbscrew } \\
\text { for adjusting } \\
\text { z-position of } \\
\text { laser carriage }\end{array}$ & 2 & \\
\hline $\begin{array}{l}\text { X-carriage } \\
\text { cable mount } \\
\text { for attaching } \\
\text { a cable } \\
\text { carrier to the } \\
\text { x-carriage }\end{array}$ & 1 & & $\begin{array}{l}\text { X-carriage for } \\
\text { connecting } \mathrm{X} \text { - } \\
\text { axis linear } \\
\text { bearings to } \mathrm{x} \text { - } \\
\text { axis drive belt, } \\
\text { laser carriage, } \\
\text { and cable } \\
\text { carrier }\end{array}$ & 1 & \\
\hline
\end{tabular}




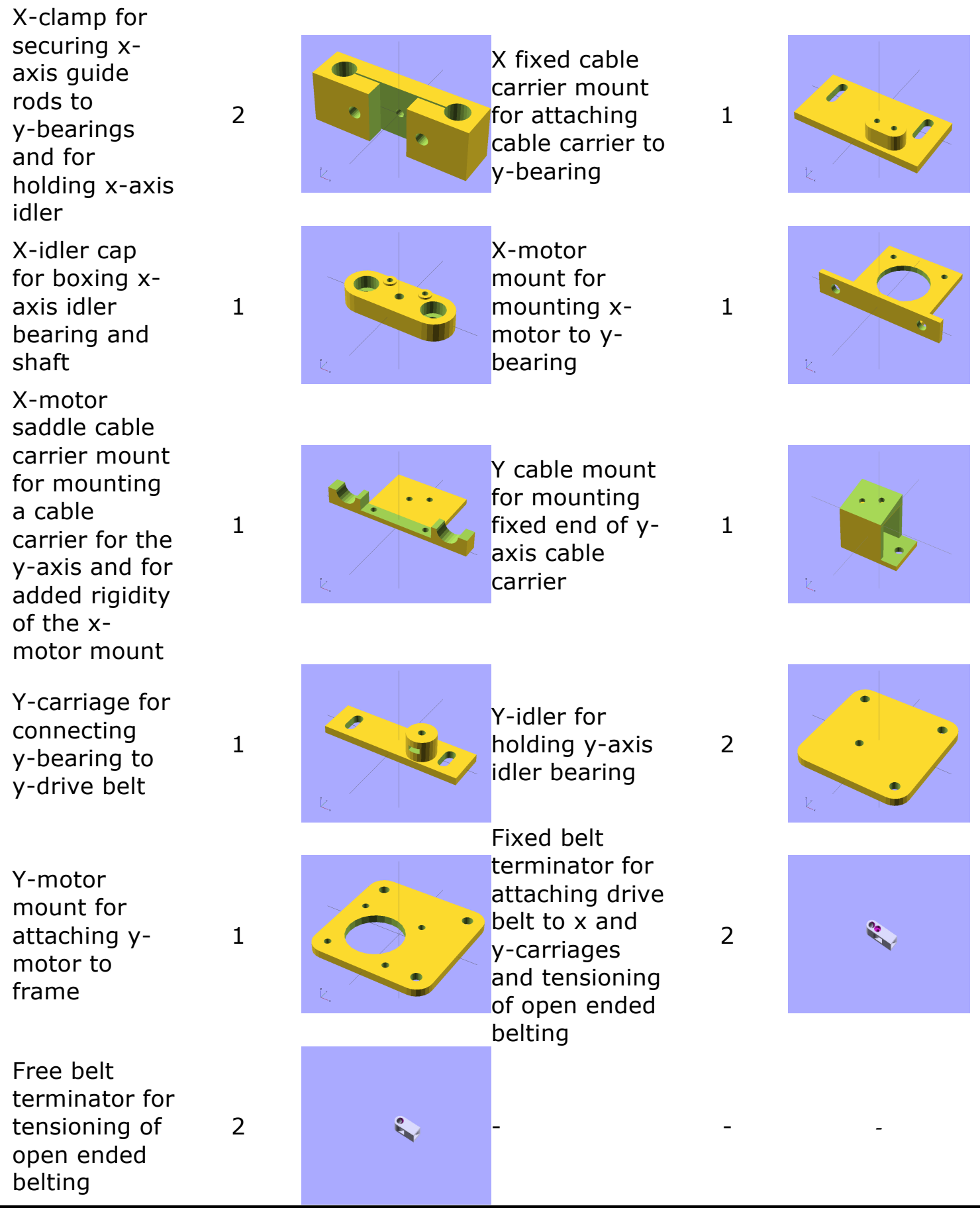




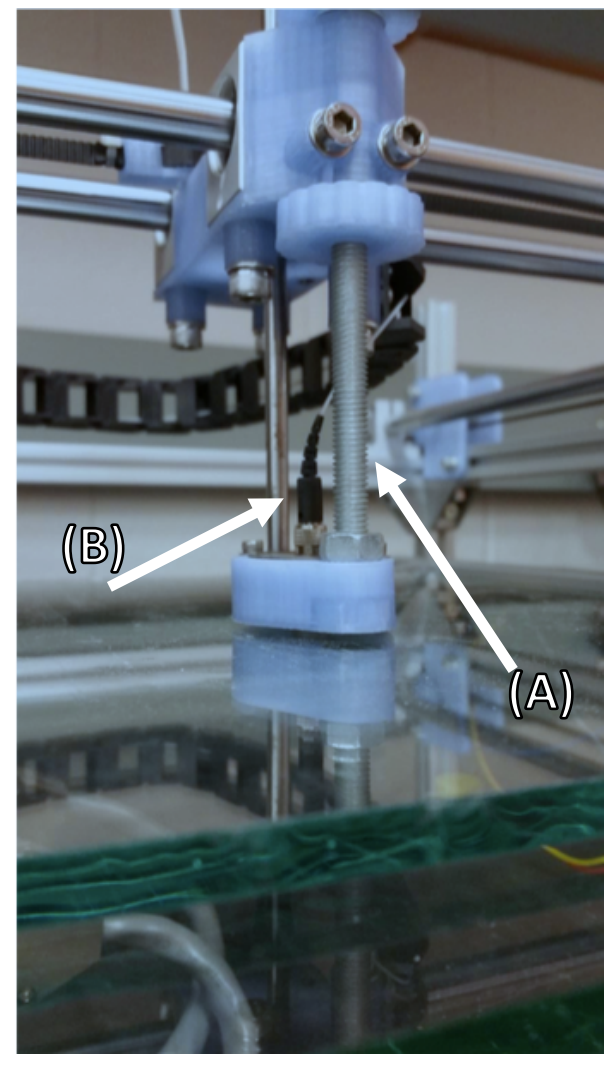

Figure 2.1. Close up of the $X$-carriage Z-axis adjustment assembly: (a)Focal length adjustment lead screw, (b) JDSU 10W fiber laser connection point

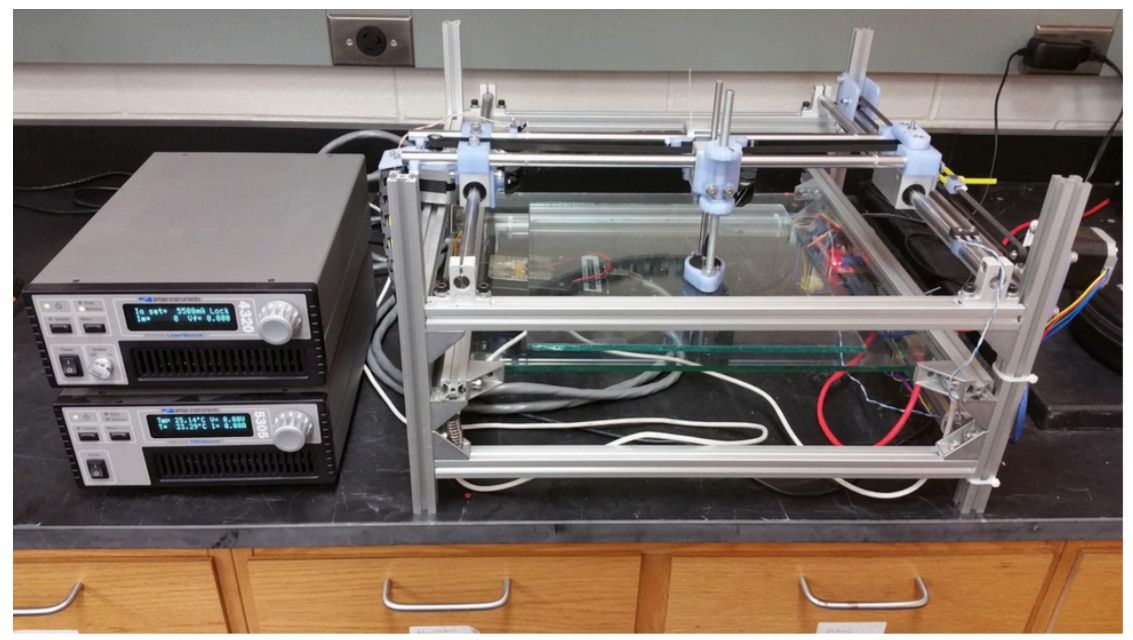

Figure 2.2. Completed open-source laser welder apparatus. 


\subsubsection{Materials}

Liner low-density polyethylene (LLDPE), which is typically utilized as an underground encasement of ductile iron pipes per ANSI/AWWA C105/A21.5, is analyzed. Large industrial LLDPE rolls are readily available [31]. Material was obtained in a continuous length measuring 16 in $(406.4 \mathrm{~mm}) \pm 0.5$ in $(12.7 \mathrm{~mm})$ in width and manufactured to a minimum thickness of 0.008 in $(0.203 \mathrm{~mm})$. The supplier's technical data sheets indicate a density of 0.910 to $0.935 \mathrm{~g} / \mathrm{cm}^{3}$ and a carbon black additive of no less than $2 \%$ [32].

\subsubsection{Fabrication}

The LLDPE sheeting was sectioned into dimensions $2.25 \times 4.5$ in $(57.15 \times 114.3 \mathrm{~mm})$ \pm 0.5 in $(12.7 \mathrm{~mm})$. The specified dimensions allow for sufficient bonding area to be analyzed while fitting into the tensile testing grips used for analysis. Prior to all welding operations, foreign particulate (e.g., dust and debris) was removed from the surface with a wet cloth then allowed to dry. Contaminates, as described, may depreciate the validity of the analysis.

A single sample component is comprised of two to three layers of LLDPE, to dimensions specified prior, depending upon testing conditions. Three individual samples are placed inside the polymer welder at a time, thus providing three samples per testing condition. Multiple testing conditions were analyzed beyond variable layer count. Incident current (I) and cross-head speed were intentionally varied throughout the analysis. Specifically, the incident current was incremented $0.5 \mathrm{~A}$ per analysis within the range of $5 \mathrm{~A}-20 \mathrm{~A}$, and all collected data was done in two scenarios: one using a $10 \mathrm{~mm} / \mathrm{s}$ cross-head speed, and the other using a 20 $\mathrm{mm} / \mathrm{s}$ cross-head speed. Laser scan patterns proceeded linearly across the sample component, parallel to the rolled direction, near mid length $\sim 2.25$ in $(57.15 \mathrm{~mm})$. Table 2.2 describes the test parameters in further detail. 
Table 2.2. LaserSource $20 \mathrm{~A} 4320$ Set Up Values.

\begin{tabular}{|c|c|c|}
\hline Variable & Value & Units \\
\hline Mode & $I_{0}(A C C)$ & - \\
\hline $\mathrm{I}_{0}$ Limit $^{2}$ & $5.5-20$ & Amps (A) \\
\hline$I_{m}$ Limit & 20,400 & Microamps $(\mu \mathrm{m})$ \\
\hline$V_{f}$ Limit & 5.1 & Volts (V) \\
\hline$V_{f}$ Sense & Internal & - \\
\hline Cable R & 0.0 & Ohms $(\Omega)$ \\
\hline Tolerance $\mathrm{I}_{\mathrm{o}}$ & 100 & Milliamps (mA) \\
\hline On Delay & 0.0 & Milliseconds (ms) \\
\hline
\end{tabular}

Low-iron glass plates, $0.6 \mathrm{~cm}$ thick, were utilized to ensure sample stability and flatness during the welding operation. The experimental setup involved layering three samples adjacent to one another, along their $4.5 \mathrm{~mm}$ length, followed by another secondary low-iron glass plate placed on top. Second, the laser head, modifiable with a set screw, was placed adjacent to the top glass surface. Figure 2.3 describes the set-up involved during all experimentation.

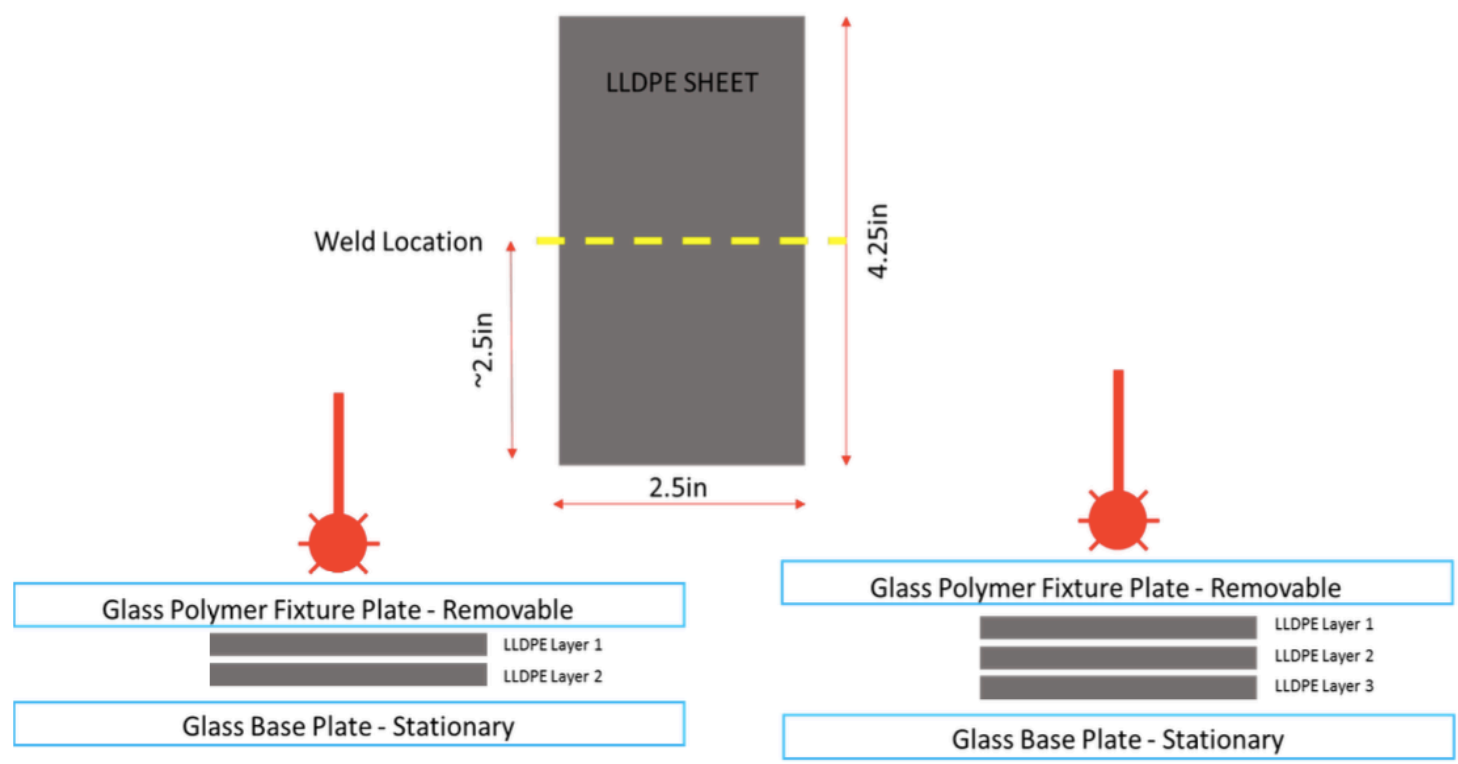

Figure 2.3 Sample dimensions are two/three layered experimental set up. Linear low density polyethylene (LLDPE), linear low density polyethylene.

\footnotetext{
${ }^{2}$ Variable in experimentation
} 


\subsubsection{Characterization}

\subsubsection{Peak Load Determination}

Procured materials for this analysis are assumed to not be anisotropic. Specifically, all tensile tests performed induce force normal to the rolled direction of the manufactured LLPDE and/or normal to the weld line. Baseline analysis of "virgin" LLDPE samples (e.g., no weld line specimens) can be directly compared to their welded counterparts. An Instron 4206 tensile tester with testing procedures modeled after ASTM D2990-01 and D638-02a allowed for determination of peak load (lbf) for all sample conditions $[33,34]$. Specimens comprised of two and three layers were subjected to this analysis. All two layered components exhibiting adequate layer-tolayer adhesion were deemed adequate. If visual analysis post-welding determined any delamination and/or lack of weld cross section, the sample was omitted from the analysis. Similar inspection criteria were employed on the three layer samples. Ideally, the bottom layer (third layer-Figure 2.3) will not bond to the near-adjacent first and second layers, which enables complex 3-D geometries to be fabricated with this system (e.g., heat exchangers). Graphical representation of the testing conditions are shown in Figure 2.4. Tensile load is subject to the exterior LLDPE layers in 2 and 3 layer welding conditions as represented independently. 


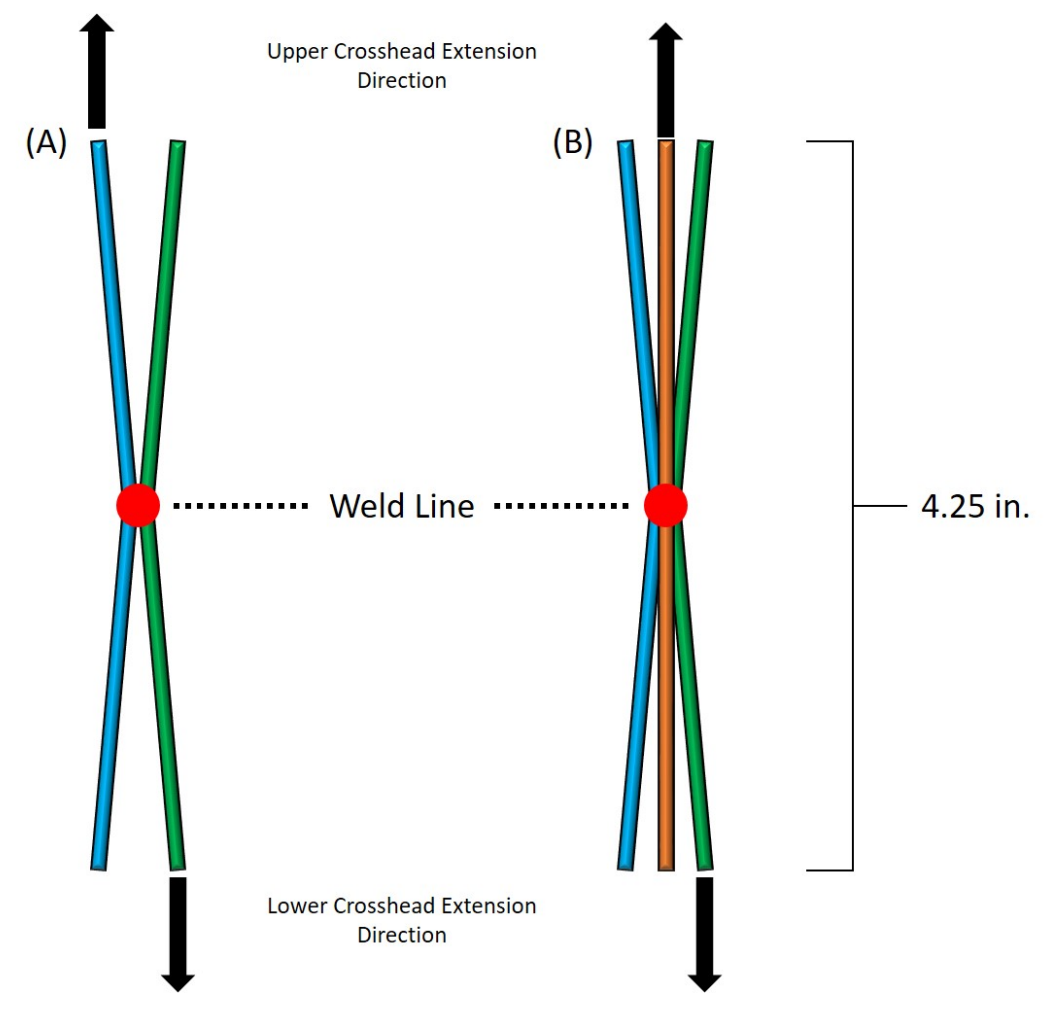

Figure 2.4. Instron 4206 peak load determination protocol / experimental set up: (a) describes a 2 layer pull test, (b) describes a 3 layer test where weld quality of incident layer and $2^{\text {nd }}$ layer is tested independently of the $3^{\text {rd }}$ layer

Thus, the near-adjacent layers can be welded independently of the previous bottom layers of LLDPE. Fabrication methods, as described prior, are aimed to ensure this. Thus, tensile testing on three layered specimens was performed pending the observation that the first and second layers are adequately bonded while the third has not.

\subsubsection{Weld Width ( $\mathrm{mm}$ ) and Resultant Energy Density (Coulombs/mm)}

The application of imaging software Image] 1.49 [35] allowed for the quantitative analysis of each respective weld width. Images selected for analysis were captured utilizing a standard digital camera. The image frame (i.e., contained in the image(s)) were a representative top-down view of each weld line. Each image frame contained a ruler with 0.5 and $1.0 \mathrm{~mm}$ resolution/gradations. The ruler provided the ability to 
utilize Image] 1.49 to properly scale the captured images. This is accomplished by the software measurement correlation to the "real" measurements using a "pixels/in" determination. An average of three distinct line profile length measurements ensured statistical confidence in operator measurement(s). Figure 2.5 displays a representative weld width photograph used for width determination.

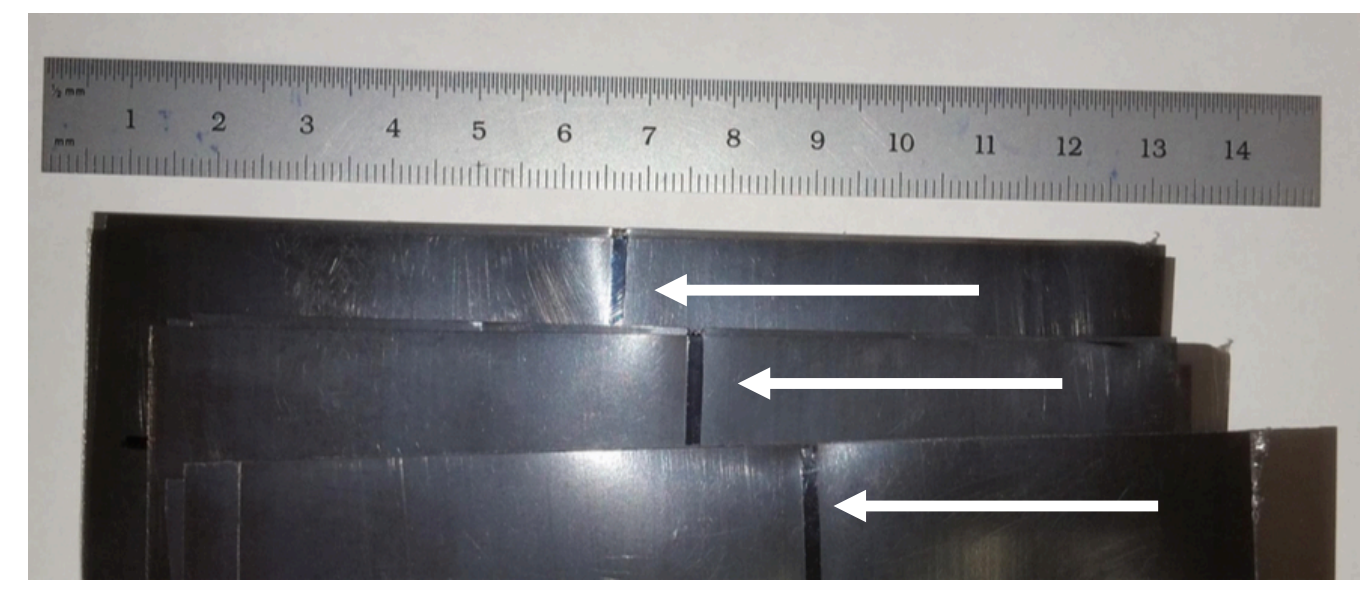

Figure 2.5. Representative weld width analysis photograph. Line profile measurements in ImageJ 1.49 occur near areas indicated

Correlating laser cross-head speed to incident laser current derives an expression for linear energy density (Coulombs $(A \cdot s) / \mathrm{mm}$ ). Thus, linear energy density, weld width, and peak load can be characterized.

\subsection{Results}

\subsubsection{Weld Width at Various Energy Densities}

Linear regression analysis of measured weld width vs. linear energy density data show that weld width increases with increased linear energy density. Figures 2.6-2.9 describe the correlation. Directly comparing the regression analysis of Figures 2.6 and 8 (two layered systems) shows that the slopes are near equivalent and greater than one. Conversely, Figures 2.7 and 2.9 (three layered systems) also display a similar slope, although at a different magnitude of $\sim 0.5$. Weld width data was recorded for linear welds with, at a minimum, incident laser appearance. Specifically, 
solid linear welds to observable faint heat lines were recorded. Significant data spread, in reference to the trend line, is apparent in Figure 2.6 at a range of $0.5-1.3$ (Coulombs $/ \mathrm{mm}$ ). At relatively low linear energy densities the resultant weld width is a gradient (e.g., a thin linear indication that gradually fades at distances normal to the weld direction). Conversely, relatively high linear energy density welds develop weld seams with a visible finite width. Thus, upon measurement with ImageJ, the identification of the apparent weld is subjective as some zone within the gradient is selected as the edge. The deviation in operator measurement, which is identified as the edge of the weld, causes the spread shown in the Figure 2.6 data set.

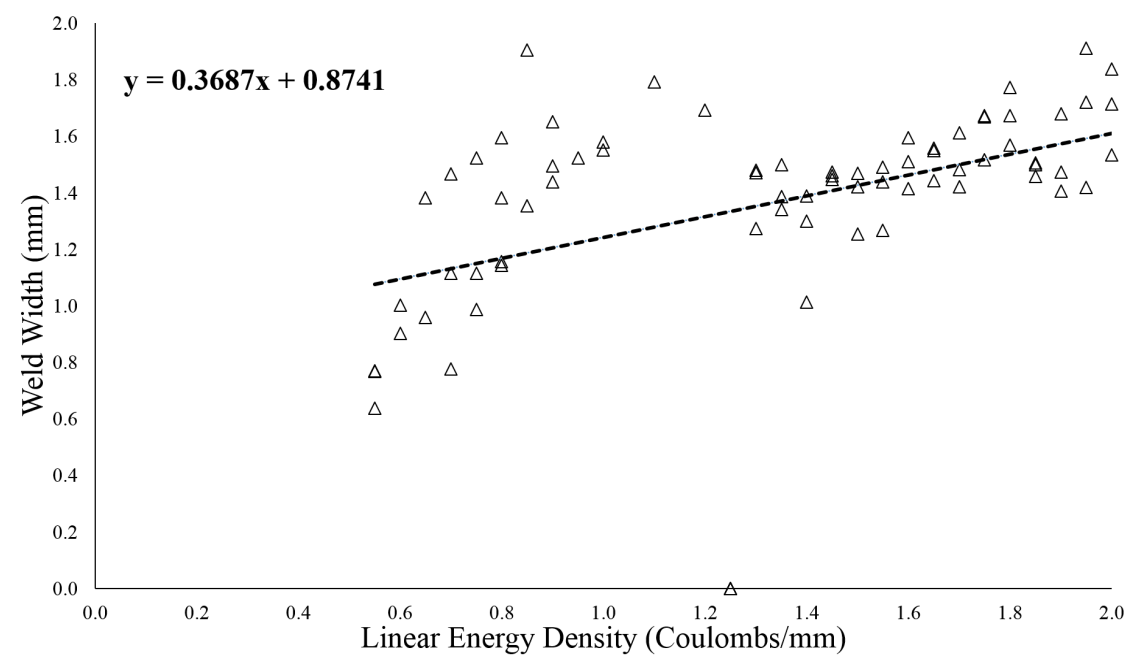

Figure 2.6. Weld width as a function of linear energy density for $10 \mathrm{~mm} / \mathrm{s}$ on two layers of LLDPE. 


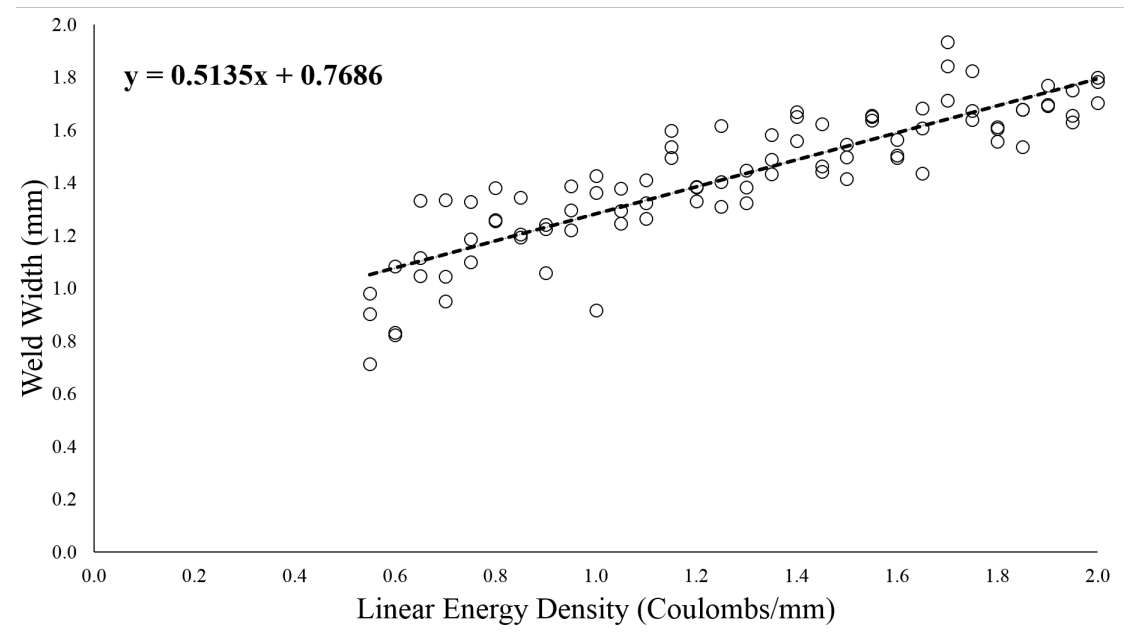

Figure 2.7. Weld width as a function of linear energy density for $10 \mathrm{~mm} / \mathrm{s}$ on three layers of LLDPE

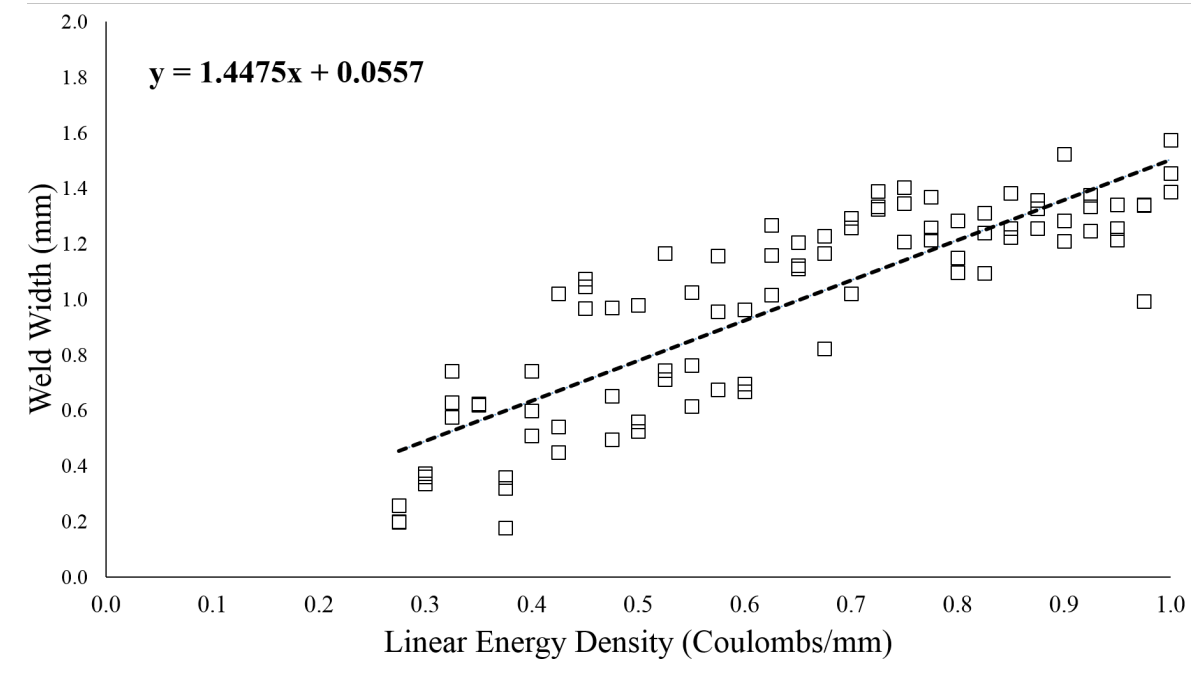

Figure 2.8. Weld width as a function of linear energy density for $20 \mathrm{~mm} / \mathrm{s}$ on two layers of LLDPE 


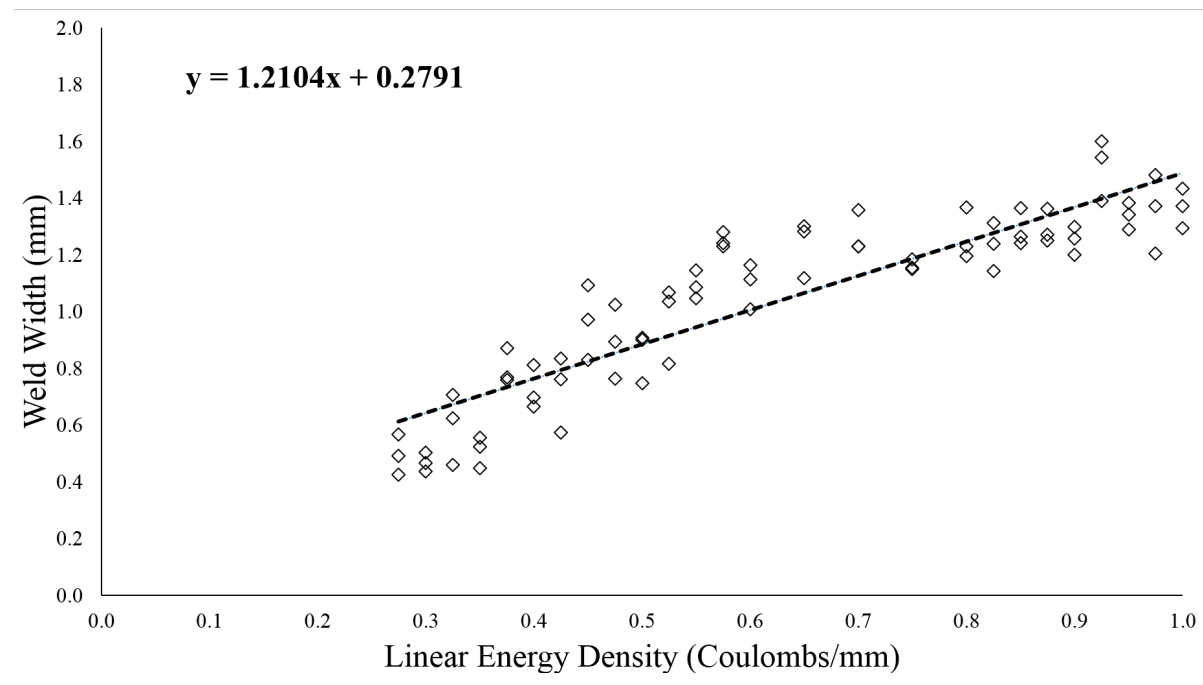

Figure 2.9. Weld width as a function of linear energy density for $20 \mathrm{~mm} / \mathrm{s}$ on three layers of LLDEP

Typical weld cross sections are as shown in Figures 2.10 and 2.11. Figure 2.10 demonstrates a quality weld, while Figure 2.11 demonstrates a delaminated failed weld.

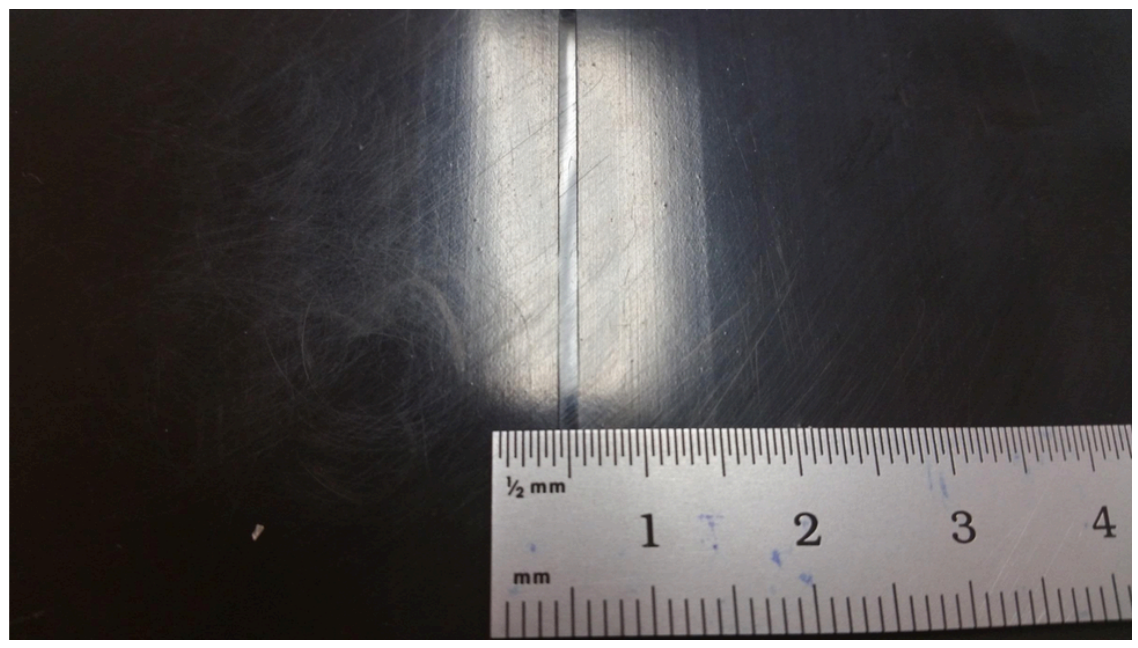

Figure 2.10. Representative photograph of a quality two layer LLDPE polymer laser weld. Similar surface topology, as shown, is apparent the three layered LLDPE weld systems. 


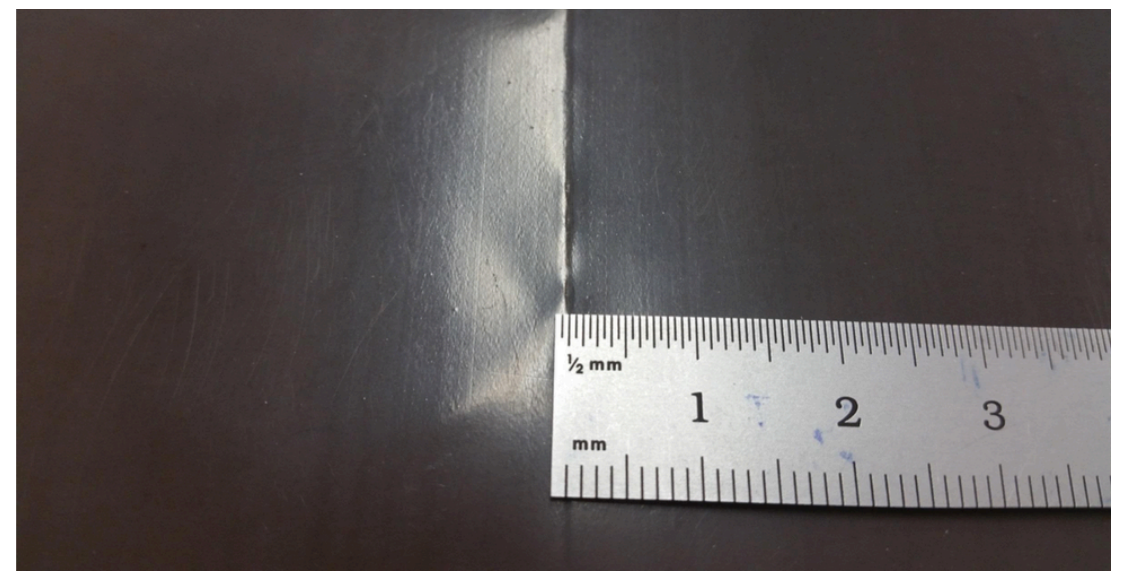

Figure 2.11. Representative photograph of a degraded two layered LLDPE polymer laser weld. Similar line width decrease is apparent in the three layered LLDPE weld systems.

\subsubsection{Polymer Adhesion of Two and Three Layered LLDPE System}

Adhesion susceptibility due to an increase in linear energy density was analyzed qualitatively. Post welding operations/attempts, operators would analyze generated welds and exert a small pull force (by hand) in attempts to shear the weld zone. Welds requiring minimal effort (e.g., tackiness) were deemed unacceptable for further analysis. Welds exhibiting greater adhesion (i.e., greater than minimal force) were subjected to further mechanical testing. Laser welds requiring further mechanical testing and those sheared are shown in Figures 2.11 and 2.12, respectively. The linear line indication in Figures 2.12 and 2.13 represent solid weld regions. A proper weld contains a solid line (Figure 2.12). Conversely, a poor weld (Figure 2.13) will have dashed indications displaying improper adhesion. It is to be concluded that the ideal weld appearance will be a solid uninterrupted line. 


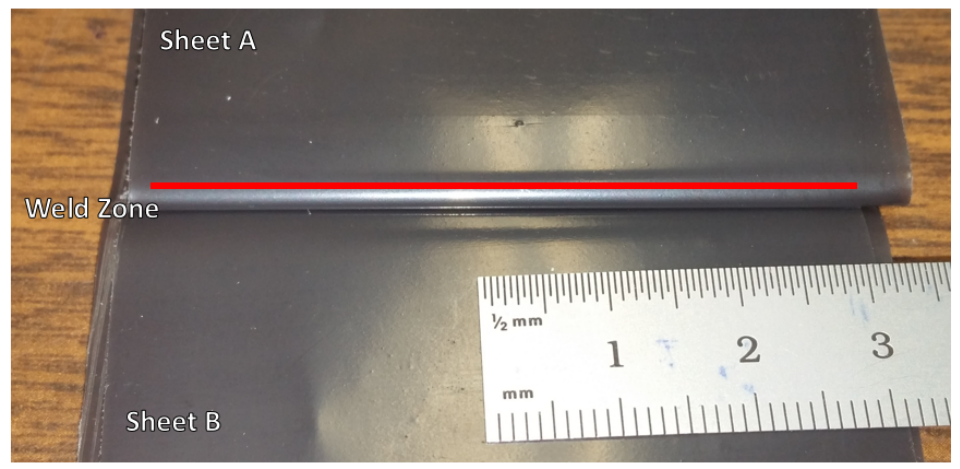

Figure 2.12. Laser weld subjected to further mechanical testing. Linear indications signify proper adhesion at the weld interface of the LLDPE sheeting.

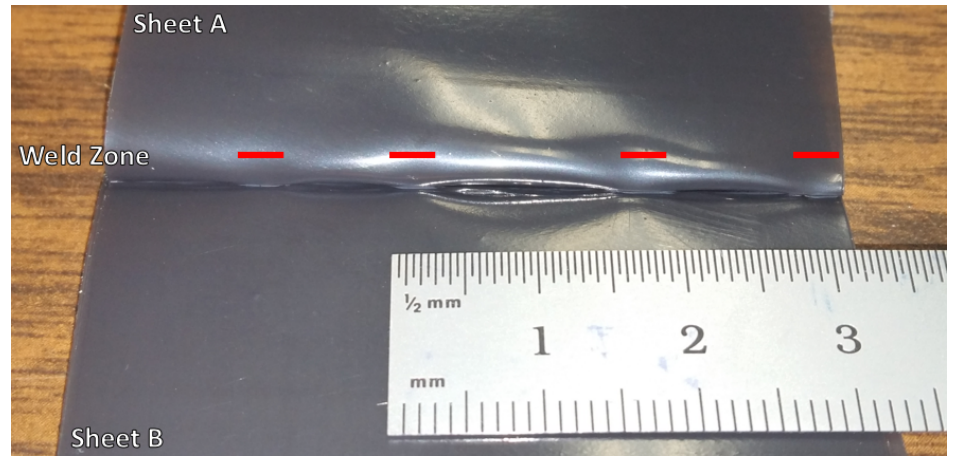

Figure 2.13. Laser weld not subjected to further mechanical testing. Broken/dashed linear indication represented a degraded weld seam between the LLDPE sheeting.

Figure 2.14 describes each testing scenario and their respective shear point(s) (e.g., where mechanical testing is not required for quantification). 


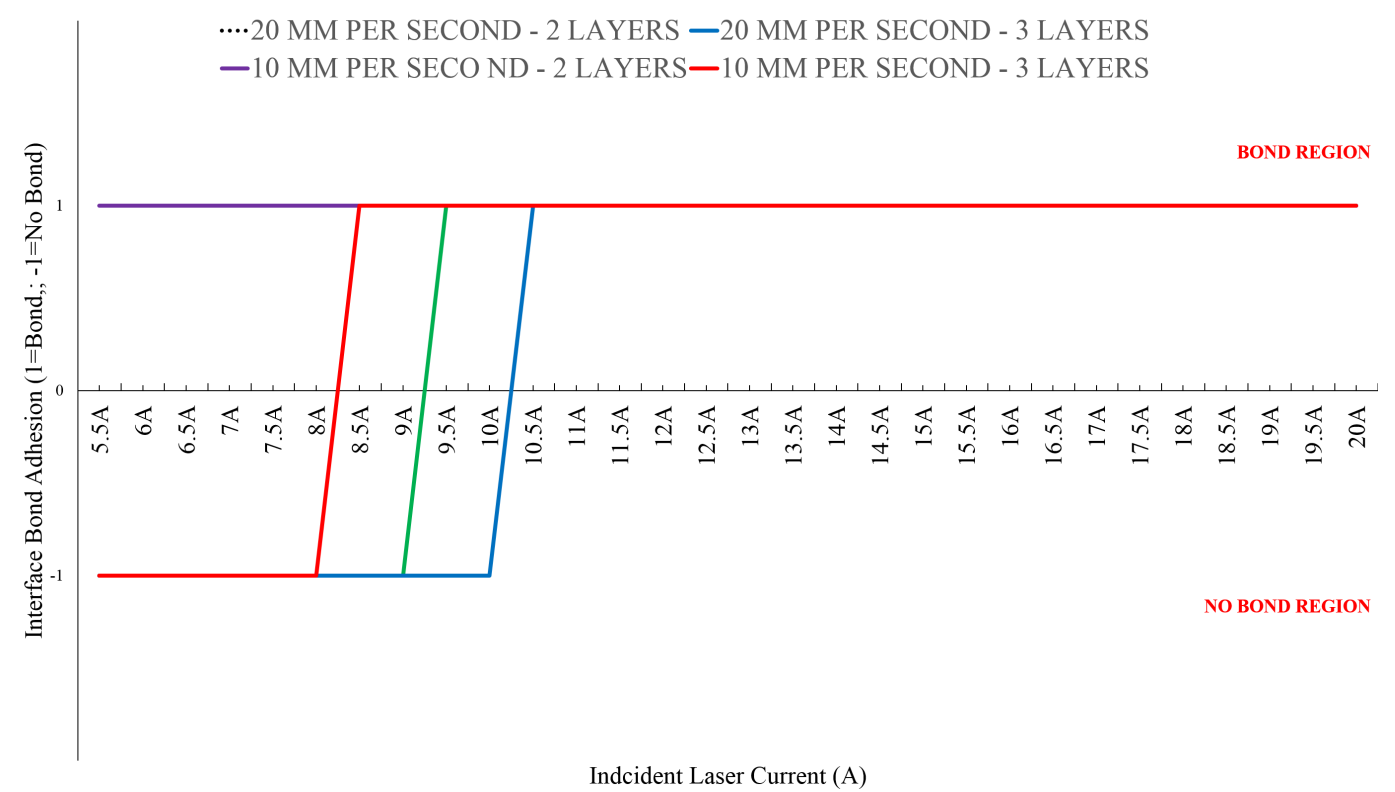

Figure 2.14. Shear and Bond Zone comparisons of 10 and $20 \mathrm{~mm} / \mathrm{s}$ cross-head speeds at variable incident laser current (A).

In application of three layered based systems a delaminated (i.e., un-bonded) third layer is ideal. Specifically, the information described in Figure 2.13 indicates that multilayered systems are applicable to this technology. By proper control of the linear energy density (vector speed $x$ incident current (i.e., laser power)) the overall depth of penetration can be controlled. Thus, providing an adequate system to develop multichannel and multi-layered laser welded LLDPE polymer systems. Specifically, in the developed system for three layered manufacturing processes at 10 and $20 \mathrm{~mm} / \mathrm{s}$ are to be set at 8.5 and $10.5 \mathrm{~A}$, respectively. At these specified zones, the laser system has successfully welded two layers of the three layered systems. Amperage settings greater than those recommended will yield completely welded three layered components. Conversely, amperages settings below the recommendations may fail to allow the top two layers to bond.

\subsubsection{Mechanical Testing - Peak Load (lbf)}

Mechanical testing was performed on all sample components abiding similar criteria, to the energy density determination, were met. Typically, recorded mechanical data is resultant of an average of three different peak load determinations. Specifically, all 
mechanically tested samples resemble those described in Figure 2.3 (i.e. the samples utilized for linear energy density determination (Coulombs/mm) are tested in tensile). Samples were subjected to a cross-head displacement rate of $1 \mathrm{in} / \mathrm{min}$ with the maximum allowable extension set at 1 in. The test was completed if a break/rupture was measured at the weld and/or the maximum cross-head displacement was reached equivalent to methods described in Figure 2.4. Raw (i.e., non-welded LLDPE) samples set the baseline for the analysis. Maximum sustained peak loads for each experimental condition $(10 \mathrm{~mm} / \mathrm{s}$ - two layers, $10 \mathrm{~mm} / \mathrm{s}$-three layers, $20 \mathrm{~mm} / \mathrm{s}$-two layers, and $20 \mathrm{~mm} / \mathrm{s}$-three layers) are displayed in Table 2.3. Representative values shown indicate maximum peak load at the experimental setting just after the shear zone (no-bond region). Thus, any incident current greater than the critical shear zone limit amperage will provide, at a minimum, this corresponding peak load. Furthermore, for comparative purposes, typical loadextension curves are displayed in Figure 2.15.

Table 2.3. Maximum sustained peak load above shear point of LLDPE weld(s).

\begin{tabular}{ccccc}
\hline $\begin{array}{c}\text { Sample } \\
\text { Material }\end{array}$ & $\begin{array}{c}\text { Condition/Speed } \\
(\mathbf{m m} / \mathbf{s})\end{array}$ & $\begin{array}{c}\text { LLDPE } \\
\text { Layers }\end{array}$ & $\begin{array}{c}\text { Peak Load } \\
(\mathbf{+ \sigma})(\mathbf{l b f})\end{array}$ & $\begin{array}{c}\text { Incident Current } \\
\text { Setting (A) }\end{array}$ \\
\hline LLDPE & RAW & - & $26.6(2.1)$ & - \\
LLDEP & 10 & 2 & $19.6(3.8)$ & 5.5 \\
LLDPE & 10 & 3 & $25.3(3.4)$ & 8.5 \\
LLDPE & 20 & 2 & $25.7(1.4)$ & 9.5 \\
LLDPE & 20 & 3 & $25.4(2.8)$ & 10.5 \\
\hline
\end{tabular}




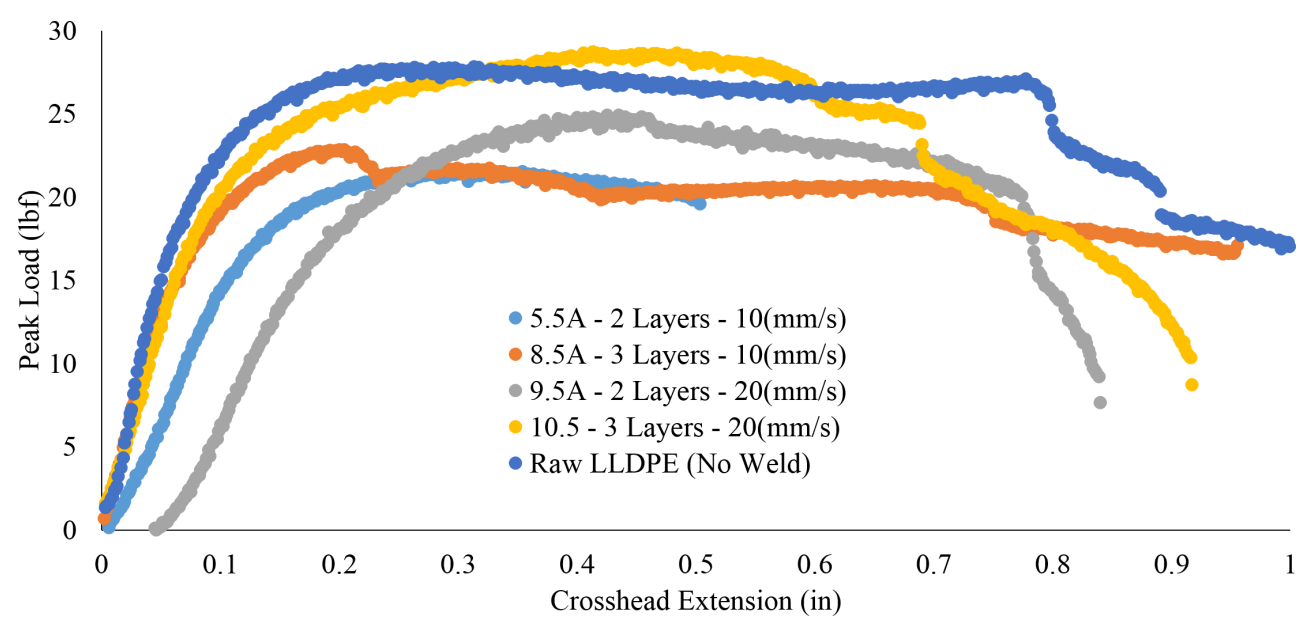

Figure 2.15. Typical load-elongation curves for sample conditions described in Table 2.3. Samples were subjected to a cross-head displacement of $1 \mathrm{in} / \mathrm{min}$.

\subsection{Discussions}

The proposed welding system was shown to adhere multi-layered systems.

Sustained peak load measurements of the resultant weld width(s) are equivalent to a virgin/raw LLDPE sample sheet. The experimental trials have identified shear zones of the particular weld systems (e.g., 10 and $20 \mathrm{~mm} / \mathrm{s}$ cross-head speeds coupled with variable incident beam current). Quantification of the rigidity of two layered LLDPE systems, specifically the shear zone, allows for confirmation of a quality lap weld seam. Furthermore, shear zone identification in three layered systems determines the appropriate linear energy density for a given multi-layered system.

Mechanical property results describe a system in which a welded interface will perform similarly to that of its not welded raw/virgin counterpart. Comparison of the representative data in Table 2.3 shows, at a maximum, the overall degradation in sustain peak load (lbf) is $26.32 \%$ (10 mm/s and two layers of LLDPE). Collected mechanical data (peak load (lbf)) is representative of a weld just beyond the potential shear zone. These data points described are theoretical operating minimums of the polymer welding system. Thus, an adequate safety factor is to be applied to further manufacturing operations to ensure, at a minimum, the peak load of the theoretical minimum is achieved. For example, in a three layer $20 \mathrm{~mm} / \mathrm{s}$ 
condition the incident current setting should be $10 \%-20 \%$ larger than the recommended minimums of $9.5 \mathrm{~A}$. The clustering of the mechanical property results suggest that a weld interface does not significantly impact the mechanical performance of the polymer in this test scenario. Various energy densities have been shown to produce quality welds. Refer to Table 2.3, a LLDPE polymer weld at 10 $\mathrm{mm} / \mathrm{s}$ with $8.5 \mathrm{~A}$ current $(0.425$ Coulombs $/ \mathrm{mm})$ produces a peak sustained load of 25.3 lbf. Comparatively, a LLDPE polymer weld at $20 \mathrm{~mm} / \mathrm{s}$ with $10.5 \mathrm{~A}$ current ( 0.525 Coulombs $/ \mathrm{mm}$ ) produced a peak load of $25.4 \mathrm{lbf}$. Therefore, a linear energy variance of $21.95 \%$ produces a LLDPE weld seam where the average mechanical property variance is relatively small at $0.39 \%$.

Larger scaled application(s) are possible with large X-Y build platforms. Increased productivity (i.e., speed of manufacturing) is achievable by implementation of multiple laser head systems. Situations and models described in these experiments utilize a single laser source head, whereas multiple systems would allow for a similar part (laser paths) to be replicated during the same manufacturing cycle. Similarly, increased laser power allows for increased manufacturing speed [36]. High power laser systems have been shown to be valuable in the current scope in laser welding applications [4]. Thus, quick-high power systems are achievable. In addition, largescale mass manufacturing is possible with this process using roll-to-roll technology [7].

Furthermore, numerous direct applications are available for implementation of the proposed system. For example, the system can be used for additive manufacturing of vehicle heat recovery ventilators for the automotive industry [37], industrial heat exchangers $[6,38]$, heat exchangers for solar water pasteurization [39], hermetic thermoplastic medical device encapsulation [40], bio-microfluidic channels in transparent polymer materials [41], and consumer goods packaging [42]. The polymer laser welder described is ideal for rapid prototyping. For example, the new floating photovoltaics (FPV) can be combined with aquaponics to make aquavoltaics $(A V)$, which use thin film flexible substrate based solar photovoltaic (PV) modules to float on water, yet designs have largely been untested $[43,44]$. The low mass allows a significantly diminished supporting structure and the flexible nature of the system allows for designed yield to oncoming waves while maintaining electrical performance 
[45]. This enables FV to take advantage of the superior net energy production of thin film PV materials like amorphous silicon $[46,47]$. To maintain the flexibility and long term structural integrity of the module, thin-films should be encapsulated by a polymer with high transparency, low rigidity, and be waterproof [43], and during the encapsulation process air pockets or voids can be purposefully introduced to increase buoyancy without increasing mass [45]. The system described in this article can be used to test various thin-film FPV designs by prototyping them at minimal costs.

\subsection{Conclusions}

Modification of a standard RepRap system has allowed for the development of a novel laser welding system and weld protocol. Previously custom developed Franklin firmware has provided an intuitive graphical user interface in which to control the welding system. Mechanical property analysis and weld width characterization of representative LLDPE polymer welds have shown applicability to multiple industrial, medical, and end user/consumer systems. Results have shown success in both dual (two layer) and multilayer (three layer) systems. Proper incident laser power and machine parameters (i.e., linear energy density) have been determined. Application of these parameter sets will provide user(s) with the fundamental LLDPE requirements to produce adequate mechanical polymer welds. Incident laser current (A) has been shown to display a positive linear relationship with relative weld width data. Thus, weld width increases as incident laser current increases. However, increased laser current did not show any increase and/or degradation to the LLDPE weld mechanical properties.

\subsection{Acknowledgements}

Financial support of this work by U.S. Department of Energy ARPA-e, Award \# DEAR0000507 is greatly acknowledged. The authors would also like to acknowledge technical assistance from Gerald Anzalone and Paul Fraley and helpful discussions with David Denkenberger, James Klausner, and Geoffery Short. 


\subsection{References}

[1] Becker, F.; Potente, H. A step towards understanding the heating phase of laser transmission welding in polymers. Polym. Eng. Sci. 2002, 42, 365-374.

[2] Garst, S.; Schuenemann, M.; Solomon, M.; Atkin, M.; Harvey, E. Fabrication of multilayered microfluidic 3D polymer packages. Proc. Electron. Compon. Technol. 2005, 1, 603-610.

[3] Brown, N.; Kerr, D.; Jackson, M.; Parkin, R. Laser welding of thin polymer films to container substrates for aseptic packaging. Opt. Laser Technol. 2000, 32, 139-146.

[4] Bachmann, F. Industrial applications of high power diode lasers in materials processing. Appl. Surf. Sci. 2003, 208-209, 125-136.

[5] Tsao, C.-W.; DeVoe, D.L. Bonding of thermoplastic polymer microfluidics. Microfluid. Nanofluid. 2009, 6, 1-16.

[6] Arie, M.A.; Tiwari, R.; Shooshtari, A.H.; Dessiatoun, S.V.; Ohadi, M.M.; Pearce, J.M. Experimental Characterization of Heat Transfer in an Additively Manufactured Polymer Heat Exchanger (to be published).

[7] Denkenberger, D.C.; Brandemuehl, M.J.; Pearce, J.M.; Zhai, J. Expanded microchannel heat exchanger: Design, fabrication, and preliminary experimental test. Proc. Inst. Mech. Eng. Part A J. Power Energy 2012, 226, 532-544.

[8] Shao, J.; Yan, Y. Review of techniques for on-line monitoring and inspection of laser welding. J. Phys. Conf. Ser. 2005, 15, 101-107.

[9] Norman, P.; Engström, H.; Kaplan, A.F.H. Theoretical analysis of photodiode monitoring of laser welding defects by imaging combined with modelling. J. Phys. D Appl. Phys. 2008, 41, 195502, doi:10.1088/0022$3727 / 41 / 19 / 195502$.

[10] Ghorbel, E.; Hadriche, I.; Casalino, G.; Masmoudi, N. Characterization of thermo-mechanical and fracture behaviors of thermoplastic polymers. Materials 2014, 7, 375-398.

[11] Ghorbel, E.; Casalino, G.; Abed, S. Laser diode transmission welding of polypropylene: Geometrical and microstructure characterisation of weld. Mater. Des. 2009, 30, 2745-2751. 
[12] Hadriche, I.; Ghorbel, E.; Masmoudi, N.; Casalino, G. Investigation on the effects of laser power and scanning speed on polypropylene diode transmission welds. Int. J. Adv. Manuf. Technol. 2010, 50, 217-226.

[13] Torrisi, L.; Caridi, F.; Visco, A.M.; Campo, N. Polyethylene welding by pulsed visible laser irradiation. Appl. Surf. Sci. 2011, 257, 2567-2575.

[14] Torrisi, L.; Visco, A.M.; Campo, N.; Caridi, F. Pulsed laser treatments of polyethylene films. Nucl. Instrum. Methods Phys. Res. Sect. B Beam Interact. Mater. Atoms 2010, 268, 3117-3121.

[15] Dowding, C.; Dowding, R.; Franceschini, F.; Griffiths, J. The effect of laser power, traverse velocity and spot size on the peel resistance of a polypropylene/adhesive Bond: Non-contact laser based technique of polymer bonding. Packag. Technol. Sci. 2015, 28, 621-632.

[16] Pearce, J.M. Open-Source Lab: How to Build Your Own Hardware and Reduce Research Costs; Elsevier: Waltham, MA, USA, 2014.

[17] OpenSCAD. Available online: http://www.openscad.org/ (accessed on 21 April 2016).

[18] Jones, R.; Haufe, P.; Sells, E. Reprap-The replicating rapid prototype. Robotica 2011, 29, 177-191.

[19] Bowyer, A. 3D printing and humanity's first imperfect replicator. 3D Print. Addit. Manuf. 2014, 1, 4-5.

[20] Sells, E.; Bailard, S.; Smith, Z.; Bowyer, A.; Olliver, V. RepRap: The replicating rapid prototyper-maximizing customizability by breeding the means of production. In Handbook of Research in Mass Customization and Personalization, Volume 1: Strategies and Concepts; Pillar, F.T., Tseng, M.M., Eds.; World Scientific: Hackensack, NJ, USA, 2009; pp. 568-580.

[21] Rundle, G.A. Revolution in the Making: 3D Printing, Robots and the Future; Affirm Press: South Melbourne, Australia, 2014.

[22] Open Science Framework. Available online: https://osf.io/r7hn6/ (accessed on 11 April 2016).

[23] GNU Operating System. Available online: http://www.gnu.org/licenses/gpl3.0.en.html (accessed on 22 May 2016).

[24] Laser Welding Protocol (MOST). Available online: http://www.appropedia.org/Laser_welding_protocol:_MOST (accessed on 4 April 2016). 
[25] Irwin, J.; Pearce, J.M.; Opplinger D.; Anzalone, G. The RepRap 3-D printer revolution in STEM education. In Proceedings of the 121st ASEE Annual Conference and Exposition, Indianapolis, IN, USA, 15-18 June 2014; Paper ID \#8696.

[26] RepRap. Available online: http://reprap.org/wiki/Melzi (accessed on 4 April 2016).

[27] Raspberry Pi. Available online: https://www.raspberrypi.org/ (accessed on 4 April 2016).

[28] Wijnen, B.; Anzalone, G.C.; Haselhuhn, A.S.; Sanders, P.G.; Pearce, J.M. Free and open-source control software for 3-D motion and processing. J. Open Res. Softw. 2016, 4, doi:10.5334/jors.78.

[29] Github "Franklin". Available online: https://github.com/mtu-most/franklin (accessed on 15 March 2016).

[30] JDSU High-Power 10W 9xx nm Fiber-Coupled Diode Laser: Available online: http://pdf.datasheet.live/datasheets-1/jds_uniphase/L4-9897510-100M.pdf (accessed on 17 May 2016).

[31] AWWA C105-10 Polyethylene Encasement for Ductile Iron Pipe Systems. Available online: http://awwa.org/store/productdetail.aspx?productid $=25362$ (accessed on 17 May 2016).

[32] Infinity Plastics Datasheet. Available online: http://www.infinityplastics.net/downloads/PollyWrap.pdf (accessed on 17 May 2016).

[33] ASTM International. Standard Test Method for Tensile, Compressive, and Flexural Creep and Creep-Rupture of Plastic; ASTM Test Method D2990-01 (Superseded by ASTM Test Method D2009-09); ASTM: West Conshohocken, PA, USA, 2001.

[34] ASTM International. Standard Test Method for Tensile Properties of Plastics; ASTM Test Method D638-02a (Superseded by ASTM Test Method D838-14); ASTM: West Conshohocken, PA, USA, 2002.

[35] Rasband, W.S. Image]; U.S. National Institues of Health: Bethesda, MD, USA, 1997-2015. Available online: http://imagej.nih.gove/ij/ (accessed on 17 March 2016).

[36] McGrath, G.C.; Cawley, W.H. Devloping Cost Effective Laser Welding Parameters for Weldable Resins and Application to the Medical Segment. 
Available online:

http://www.clearweld.com/edufiles/Developing\%20Cost\%20Effective\%20Las er\%20Welding\%20Parameters\%20For\%20Weldable\%20Resins\%20And\%20A pplication\%20To\%20The\%20Medical\%20Segment.pdf (accessed on 20 March 2016).

[37] Denkenberger, D.; Parisi, M.; Pearce, J.M. Towards low-cost microchannel heat exchangers: Vehicle heat recovery ventilator prototype. In Proceedings of the 10th International Conference on Heat Transfer, Fluid Mechanics and Thermodynamics (HEFAT), Orlando, FL, USA, 14-16 July 2014.

[38] Ohadi, M.M. Heat transfer enhancement in heat exchangers. ASHRAE J. 1991, $33,6-50$

[39] Denkenberger, D.C.; Pearce, J.M. Compound parabolic concentrators for solar water heat pasteurization: Numerical simulation. In Proceedings of the 2006 International Conference of Solar Cooking and Food Processing, Granada, Spain, 12-16 July 2006; p. 108.

[40] Amanat, N.; James, N.L.; McKenzie, D.R. Welding methods for joining thermoplastic polymers for the hermetic enclosure of medical devices. Med. Eng. Phys. 2010, 32, 690-699.

[41] Khan Malek, C.G. Laser processing for bio-microfluidics applications (part II). Anal. Bioanal. Chem. 2006, 385, 1362-1369.

[42] Coelho, J.P.; Abreu, M.A.; Pires, M.C. High-speed laser welding of plastic films. Opt. Lasers Eng. 2000, 34, 385-395.

[43] Trapani, K.; Redón Santafé, M. A review of floating photovoltaic installations: 2007-2013: A review of floating photovoltaic installations. Prog. Photovolt: Res. Appl. 2015, 23, 524-532.

[44] Pringle, A.M.; Handler, R.R.; Pearce, J.M. Aquavoltaics: Synergies for Dual Use of Water Area for Solar Photovoltaic Electricity Generation and Aquaculture. (to be published).

[45] Trapani, K. Flexible Floating Thin Film Photovoltaic (PV) Array Concept for Marine and Lacustrine Environments. Doctoral Dissertation, Laurentian University of Sudbury, Sudbury, CA, USA, 16 May 2014. Available online: https://zone.biblio.laurentian.ca/dspace/handle/10219/2199 (accessed on 25 May 2016). 
[46] Pearce, J.M.; Lau, A. Net energy analysis for sustainable energy production from silicon based solar cells. ASME 2002, 181-186, doi:10.1115/SED20021051.

[47] Kim, H.C.; Fthenakis, V.; Choi, J.K.; Turney, D.E. Life cycle greenhouse gas emissions of thin-film photovoltaic electricity generation. J. Ind. Ecol. 2012, 16 (Suppl. 1), S110-S121 


\section{3 - Thermal Properties of 3-D Printed Polylactic Acid - Metal Composites ${ }^{3}$}

\subsection{Abstract}

Standard fused filament fabrication (FFF)-based 3-D printers fabricate parts from thermopolymers, such as polylactic acid (PLA). A new range of metal based PLA composites are available providing a novel range of potential engineering materials for such 3-D printers. Currently, limited material data, specifically thermal property characterization is available on these composites. As a result, the application of these materials into functional engineered systems is not possible. This study aims to fill the knowledge gap by quantifying the thermal properties of CopperFill, BronzeFill, Magnetic Iron PLA, and Stainless Steel PLA composites and provide insight into the technical considerations of FFF composite 3-D printing. Specifically, in this study the correlation of the composite microstructure and printing parameters are explored and the results of thermal conductivity analysis as a function of printed matrix properties are provided. Considering the relative deviation from the filament raw bulk analysis, the results show the printing operation significantly impacts the resultant component density. Experimentally collected thermal conductivity values, however, do not correlate to the theoretical models in the literature and more rigorous quantitative exercises are required to determine true percent porosity to accurately model the effect of air pore volume fraction on thermal conductivity. Despite this limitation, the thermal conductivity values provided can be used to engineer thermal conductivity into 3-D printed parts with these PLA-based composites. Finally, several high-value applications of such 3-D printed materials that look metallic, but have low thermal conductivity are reviewed.

\footnotetext{
${ }^{3}$ The material contained in this chapter is currently in press with Progress in Additive Manufacturing
} 


\subsection{Introduction}

Adrian Bowyer's release of the open-source RepRap (self-Replicating Rapid prototyper) 3-D printer [1-3] greatly accelerated the adoption of 3-D printing [4]. Standard RepRap 3-D printers fabricate parts using fused filament fabrication (FFF $)^{4}$ and such open-source designs now constitute the majority of deployed 3-D printers [5]. As the costs for RepRap components have dropped below $\$ 500$ [6] and highquality commercial RepRaps can be purchase assembled for $\$ 1000-\$ 2200$ [7], the potential for decentralized manufacturing with 3-D printing both in the developing [8] and developed countries [9] is feasible. Such decentralized digital fabrication leads to radical reductions in the cost of printing low quantity speciality items [10]. For instance, small production runs are suited for 3D printing; highly customizable objects [11], functional prototypes [12] and maintence/replacement components [13]. Previous studies have shown that such manufacturing not only allows for a lower cost of even simple products for the consumer [14], but a lower impact on the environment as well [15].

Conventional FFF 3-D printers printed in primarily hard thermopolymer of ABS (acrylonitrile butadiene styrene) and PLA (polylactic acid), however, there are many other materials available on the market for consumer FFF 3-D printing including nylon, polycarbonate, high-density polyethylene, high impact polystyrene. In addition, there are a number of new functional materials including glow in the dark, flexible (ninjaflex and semiflex and other elastomers), water soluble (PVA), electrically conductive PLA, HIPS, INVOA-1800, Laybrick, Laywoo-D3, CopperFill, BronzeFill, magnetic iron PLA and stainless steel PLA.

One functionality is the use of metal/polymer matrix composites for thermal applications. For example, an iron/nylon feed stock material, manufactured using FFF printing technology, has shown to be applicable to rapid tooling die inserts [12]. Thermal conductivity of the matrix was found to be proportional to that of the metal filler additive. Similarly, the implementation of iron powder into an ABS matrix will increase the glass transition temperature of the polymer base, thus decreasing the

\footnotetext{
${ }^{4}$ FFF is material extrusion by ASTM Standard F2792-12a. It should be noted that FFF is the generalized not registered trade mark of fused deposition modeling (FDM)
} 
softening point of a potential injection molding material [16]. 3-D printed fabrication of metal/polymer composites has been shown to promote dimensional stability, while simultaneously reducing the cost of manufacturing as compared to conventional methods [17]. Enhanced thermal conductivity polymer/metal composites have been proposed; hybrid filler [18], nanoporous particle embedding [19], polypropylene composite with graphite and carbon black [20] and polymeric composites utilized for heat dissipation, are expanding in many fields of engineering [21].

A new range of open metal based PLA composites have been introduced to the market, providing a new range of potential engineering materials. Currently, limited material data, specifically thermal property characterization is available. As a result, the application of these materials into functional engineered systems is not possible. This study aims to fill the gap by quantifying the thermal properties of CopperFill, BronzeFill, magnetic iron PLA, and stainless steel PLA composites and provide insight into the technical considerations of FFF composite 3-D printing. Specifically, composite microstructure and correlation of printing parameters to resultant performance will be understood. This paper describes the results of thermal conductivity analysis as a function of printed matrix properties.

\subsection{Methodology}

\subsubsection{Materials}

Four metal/polymer composites are analyzed: CopperFill, BronzeFill, stainless steel PLA and magnetic iron PLA. ColorFabb (CopperFill and BronzeFill) and ProtoPasta (Stainless Steel PLA and Magnetic Iron PLA) are the only major suppliers of these composite filament types. The composite filaments are blends of PLA/PHA with metal powder additives e.g. copper, bronze, ferritic iron and stainless steel. Filament material for this analysis was obtained in $0.75 \mathrm{~kg}$ spools per standard packaging requirements of the respective vendors. Due to $3-D$ printer design, a nominal filament diameter of $2.85 \mathrm{~mm}(0.112 \mathrm{in}) \pm 0.05 \mathrm{~mm}$ ( $\pm 0.001 \mathrm{in}$ ) was selected for development. Further relevant technical material data, mechanical properties and supplier recommended printing parameters are described in Table 3.1[22-25]. ColorFabb's technical data sheets indicate a maximum tensile strength of $25 \mathrm{MPa}$ and 
$30 \mathrm{MPa}$ for CopperFill and BronzeFill, respectively. Furthermore, flexural strength and flexural modulus are reported as $40 \mathrm{MPa}$ and 7.0 GPa for CopperFill and $40 \mathrm{MPa}$ and 9.0 GPa for BronzeFill. ProtoPasta does not report mechanical property information, however, it would be expected that due to a similarity in formulation and material type the maximum tensile strength, flexural strength and flexural modulus relatively similar to ColorFabb's reported values. Moreover, manufacturing condition and/or processing methods are not reported on ColorFabb's technical data sheets. Thus, correlating processing parameters to these mechanical properties should be empirically determined relative to an operators manufacturing conditions.

Table 3.1. Supplier Recommended Printing Parameters and Basic Material Properties

\begin{tabular}{|c|c|c|c|c|}
\hline Filament & $\begin{array}{c}\text { Hot End } \\
\text { Temperature } \\
\left({ }^{\circ} \mathbf{C}\right)\end{array}$ & $\begin{array}{c}\text { Bed } \\
\text { Temperature } \\
\left({ }^{\circ} \mathbf{C}\right)\end{array}$ & $\begin{array}{c}\text { Print Speed } \\
(\mathbf{m m} / \mathbf{s})\end{array}$ & $\begin{array}{c}\text { Density } \\
\left(\mathbf{g} / \mathbf{c m}^{\mathbf{3}} \mathbf{)}\right.\end{array}$ \\
\hline CopperFill & $190-210$ & $55-60$ & 50 & 4.0 \\
\hline BronzeFill & $195-220$ & $50-60$ & 50 & 3.9 \\
\hline $\begin{array}{c}\text { Magnetic } \\
\text { Iron PLA }\end{array}$ & $185-195$ & 50 & Not Specified & 1.8 \\
\hline $\begin{array}{l}\text { StainlesS } \\
\text { Steel PLA }\end{array}$ & $195-220$ & 50 & Not Specified & 2.4 \\
\hline
\end{tabular}

\subsubsection{Fabrication}

The utilization of an open-source architecture allowed for rapid development of digital build files and physical samples. Applying the testing methodology described in ASTM F433, thermal conductivity samples were modeled in OpenSCAD 2015.03. Dimensional requirements, as stated in ASTM F433, require symmetric cylinders produced to a diameter of $50.8 \mathrm{~mm}(2 \mathrm{in}) \pm 0.25 \mathrm{~mm}(0.010 \mathrm{in})$ and a thickness of 2.29-12.7mm (0.090-0.50in) [26].

Slicing, i.e. the digital fabrication of a volumetric shape into two-dimensional vectors paths, was performed with Cura 15.04.4 utilizing the supplier recommended parameter sets (summarized in Table 3.2) as a baseline. The parameters that determine slicing conditions were developed in effort to produce $100 \%$ dense samples. Thus, effective 'fill' stripe, 'contour' offset alignment, extrusion temperature and flow percentage were critical. However, during initial parameter development 
understanding the space void between each vector path is difficult to quantify without further analysis $[27,28]$. Therefore, fabricated samples were expected to contain microscopic air voids. The resultant Cura profiles for the quantitative parameter development are displayed in Table 3.2.

Table 3.2. Cura Profiles Utilized for Manufacture of Component Samples

\begin{tabular}{|c|c|c|}
\hline \multirow{2}{*}{ Quality } & Layer Height & 0.25 \\
\cline { 2 - 3 } & Shell Thickness & 1 \\
\hline \multirow{2}{*}{ Fill } & Bottom/Top Thickness & 1 \\
\cline { 2 - 3 } $\begin{array}{c}\text { Speed and } \\
\text { Temperature }\end{array}$ & Fill Density & 100 \\
\hline & Print Speed $(\mathrm{mm} / \mathrm{s})$ & 50 \\
\cline { 2 - 3 } & Printing Temperature $\left({ }^{\circ} \mathrm{C}\right)$ & 190 \\
\hline \multirow{2}{*}{ Filament } & Bilament Diameter $(\mathrm{mm})$ & 60 \\
\cline { 2 - 3 } & Flow $(\%)$ & 2.85 \\
\hline Machine & Nozzle Size $(\mathrm{mm})$ & 100 \\
\hline
\end{tabular}

A single Lulzbot TAZ 3.0 printer coupled with a $0.5 \mathrm{~mm}$ diameter extruder nozzle was employed. Use of a single printer removes variability observed in FFF 3-D printers [27]. A Budaschnozzle 2.0 extruder modification was required as the standard $3.0 \mathrm{~mm}$ polytetrafluoroethylene (PTFE) filament guide required an increase of $0.5 \mathrm{~mm}$ to account for excessive dimensional expansion of metal/polymer composite flow through the hot end. One print cycle/build yielded four composite samples. Four samples provided adequate statistical relevance to the analysis while minimizing material waste. The printing systems utilized a singled extruder nozzle/head. Thus, four distinct build set-ups were required as described in Table 3.1. The build platform/surface was prepared with a mechanical cleaning operation prior to each print cycle.

\subsubsection{Characterization}

Printed component fracture surfaces, transverse to the build orientation were imaged using a Philips XL 40 Environmental Scanning Electron Microscope (ESEM) for qualitative elemental analysis and back-scattered electron imaging. ESEM fracture surfaces provide information on metallic particle morphology that optical microscopy cannot. Captured back-scattered electron images highlight average atomic number 
of matrix constituents, thus providing a qualitative elemental analysis. Excessive charge build up on the sample as a result of the PLA constituent affected the SEMBSE (scanning electron microscope back-scattered electron) images. Thus a low vacuum water atmosphere was required for analysis. The low vacuum mode limited the available incident keV from the electron source. As a result of this limiting condition, elemental mapping with EDS (energy dispersive spectroscopy) proved to be inadequate.

ImageJ 1.49 software was used for the conversion of SEM-BSE micrographs into an 8-bit image files [29]. From the converted image, a binary representation is created and a relative percentage of 'white' vs. 'black' is formulated allowing for volume percentages to be measured. By comparison, weight percentage is calculable from an Archimedes density analysis. Equation 3.1 equates a relationship between dry sample weight and wet sample weight to yield a density analysis that measures apparent porosity within the metal polymer matrix [30].

$$
\rho_{S}=\frac{A}{A-B} \rho_{L}
$$

Where:

$$
\begin{aligned}
& \rho S=\text { Density of Solid Body } \\
& A=\text { Weight of solid body in air } \\
& B=\text { Weight of solid body when immersed in test liquid } \\
& \rho L=\text { Density of test liquid at a given temperature } T
\end{aligned}
$$

Thermal conductivity measurements of the printed materials utilized the guarded heat flow method of ASTM F433 using a Holometrix TCA300 Through-Plane Thermal Conductivity Tester. Prior to each analysis thermal paste, Dow Corning (Dow Dupont) 340 silicon heat sink compound, was applied to each sample [31]. Thermal conductivity measurements were taken at $55^{\circ} \mathrm{C}$ providing a temperature measurable near ambient while also producing a sufficient temperature gradient within the 
Holometrix TCA300 [32]. The heat flow through a disk specimen between two solid flat surfaces is modeled to measure thermal conductivity by Equation 3.2 [26].

$$
k=\frac{q}{A} \frac{\Delta x}{\Delta T}[W / m \cdot K]
$$

Where:

$k=$ Thermal conductivity of the sample $(\mathrm{W} / \mathrm{m} \cdot \mathrm{K})$

$q=$ Heat Flow through Sample (W)

$A=$ Cross-sectional area of the sample, $\left(\mathrm{m}^{2}\right)$

$\Delta x=$ Sample thickness, $(\mathrm{m})$

$\Delta T=$ Temperature difference across the sample, $\left({ }^{\circ} \mathrm{C}\right)$

Printed virgin PLA material set the baseline for this analysis. Measurements allowed for identification of net percent increase of thermal conductivity as a result of the printing operation and/or addition of metallic filler materials.

Thermal conductivity of two-phase systems can be modeled using the individual phases' thermal conductivity. Relative volume percentages, as determined form prior analysis, allow the calculation of a composite thermal conductivity. In the proposed system, the spatial distribution of respective metallic particles in uncontrolled. Thus, the thermal conductivity model does not take into account morphological characteristics of the metallic fillers materials. The volume concentration dependency on bulk thermal conductivity of a two phase system, as described by Mamunya [33], follows Lichtenecker's equations. The following Equation 3.3 describes such a system where $\lambda_{\text {PLA }}$ and $\lambda_{\text {METAL }}$ correspond to the respective thermal conductivity of the PLA and metallic constituent, respectively. 


$$
\lambda=\lambda_{P L A}^{(1-\varphi)} \lambda_{\text {METAL }}^{\varphi}
$$

-equivalently-

$$
\log \lambda=\log \lambda_{P L A}+\left(\log \lambda_{M E T A L}-\log \lambda_{P L A}\right) \varphi
$$

Where:

$\lambda=$ Composite Thermal Conductivity $(\mathrm{W} / \mathrm{m} \cdot \mathrm{K})$

$\lambda_{P L A}=$ Polymer Constituent Thermal Conductivity $(\mathrm{W} / \mathrm{m} \cdot \mathrm{K})$

$\lambda_{\text {METAL }}=$ Metallic Filler Constituent Thermal Conductivity $(\mathrm{W} / \mathrm{m} \cdot \mathrm{K})$

$\phi=$ Volume Concentration of Metallic Filler (\%)

Lichtenecker's dependence does not take into account the percolation theory. Twophase modeling need not accommodate the percolation theory where thermal conductivity ratios of 1 to 103 are witnessed [33]. Thus, metallic filler particles are independent of its nearest neighbor, i.e. no continuous conductive flow paths are readily available in these analysis.

The Holmetrix TCA300 analyzed the generated sample medium with each FFF layer parallel to one another. Specifically, due to the layer-wise fashion of the manufacturing process the thermal conductivity measurements are a prediction of the series interaction of each flow through every layer. As described by Agarwala, layering effects of the printing process develop compounding un-intentional pore formation [34]. Pore phases (porosity constituents) are effectively thermal insulators. Pore thermal conductivity and pore volume fractions less than $15 \%$, of the bulk composite matrix are defined by Equation 3.4, the Maxwell-Eucken bound [35]. 


$$
\lambda_{S M I T H}=\lambda_{M E T A L} \frac{\lambda_{P L A}+2 \lambda_{M E T A L}+2 v_{P O R E}\left(\lambda_{P L A}-\lambda_{M E T A L}\right)}{\lambda_{P L A}+2 \lambda_{M E T A L}-v_{P O R E}\left(\lambda_{P L A}-\lambda_{M E T A L}\right)}
$$

Where:

$\lambda_{\text {SMITH }}=$ Smith Corrected Thermal Conductivity $(\mathrm{W} / \mathrm{m} \cdot \mathrm{K})$

$\lambda_{P L A}=$ Polymer Constituent Thermal Conductivity $(\mathrm{W} / \mathrm{m} \cdot \mathrm{K})$

$\lambda_{\text {METAL }}=$ Metallic Filler Constituent Thermal Conductivity $(\mathrm{W} / \mathrm{m} \cdot \mathrm{K})$

$V_{P O R E}=$ Volume Concentration of Air Void (\%)

Generalized models for metallic filler dependency (Equation 3.3) on thermal conductivity and degradation of that value due to porosity (Equation 3.4) are shown in Figure 3.1 and 3.2, respectively. Generated plots are shown with $\lambda_{\mathrm{PLA}}=0.1$ and $\lambda_{\text {METAL }}=10^{2}$ for comparison.

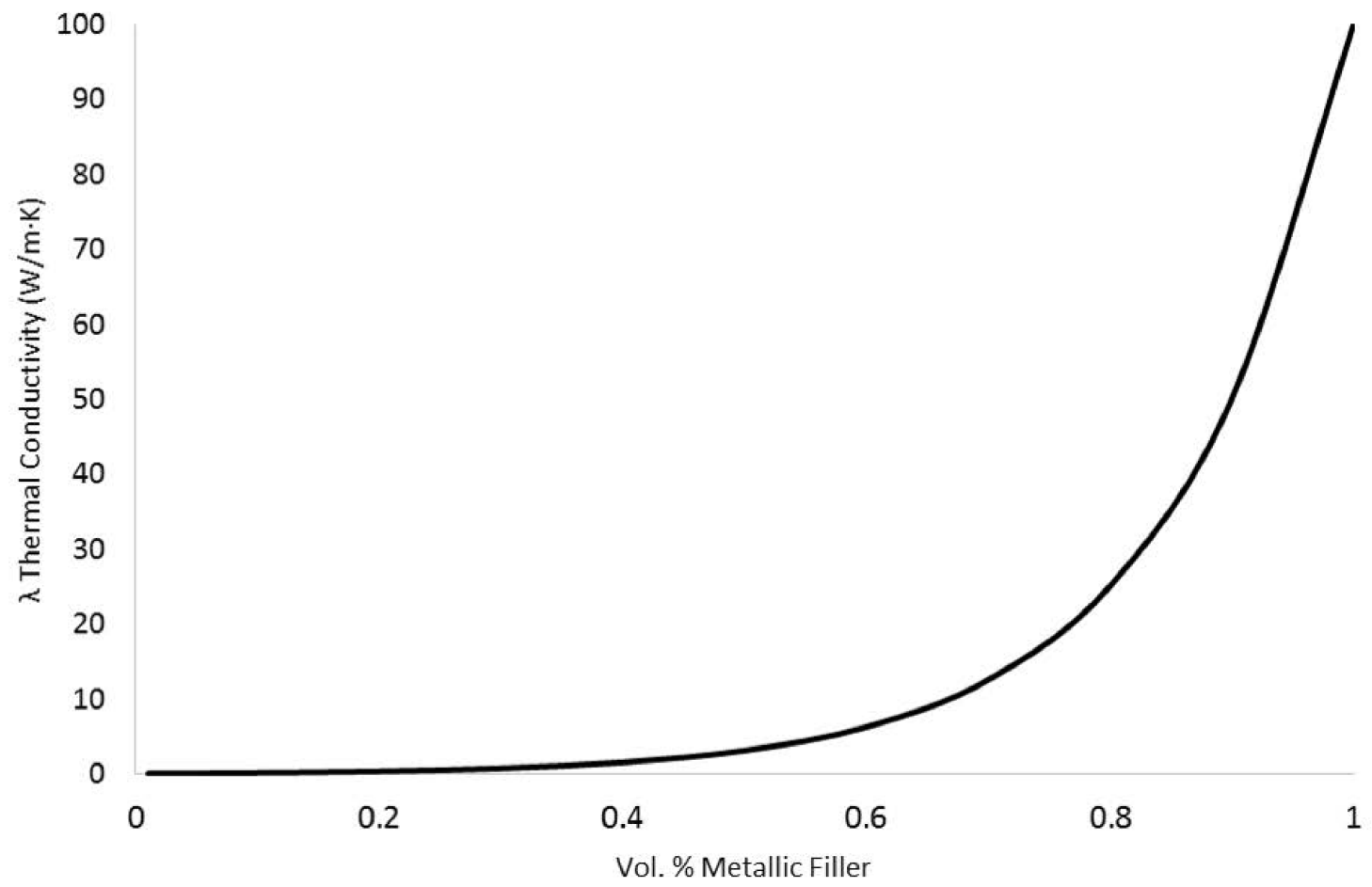

Figure 3.1. Generalized Vol. \% Metallic Filler Addition Effect on Thermal Conductivity 


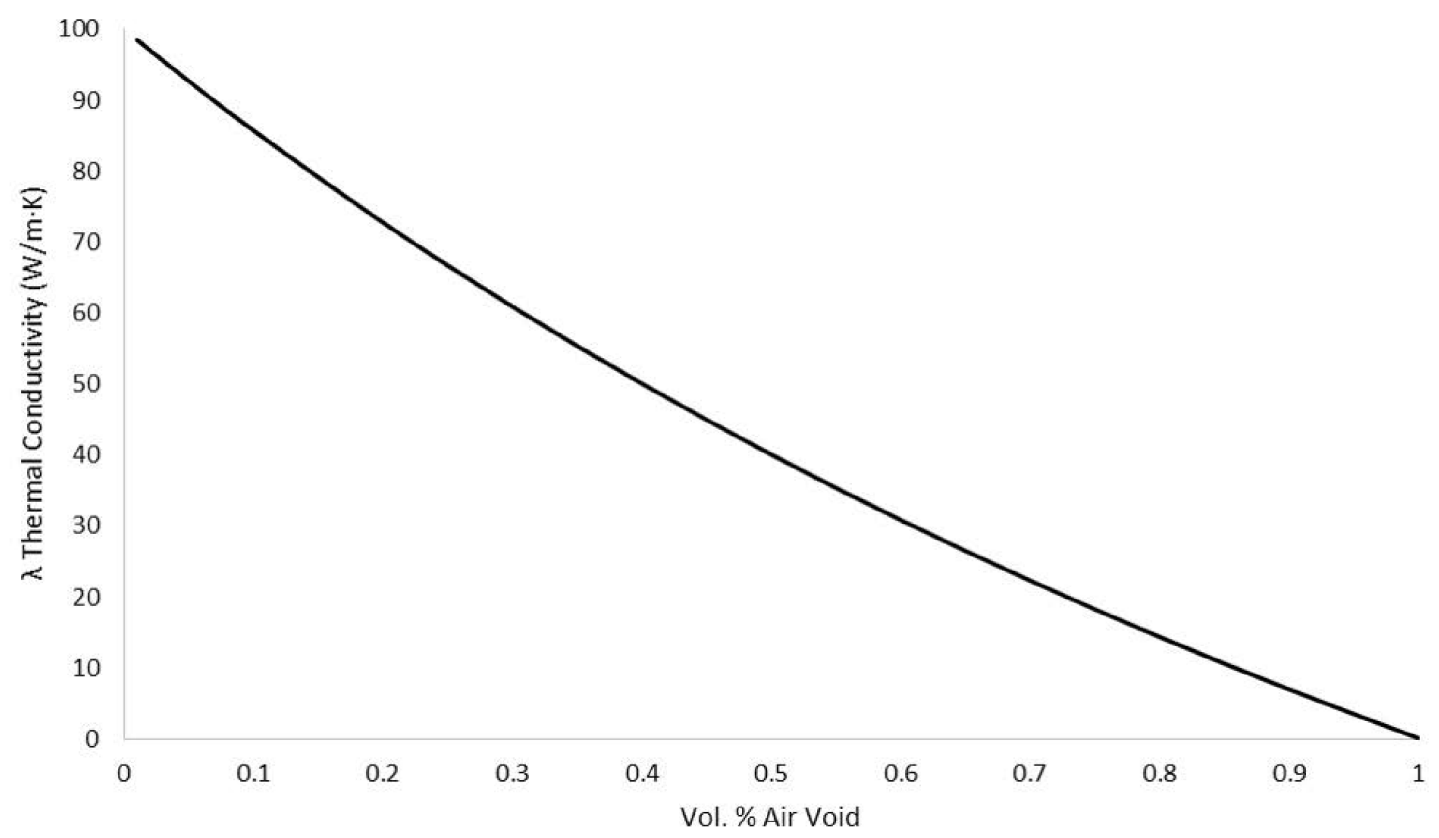

Figure 3.2. Generalized Vol. \% Air Void Effect on Thermal Conductivity

\subsection{Results}

\subsubsection{Density and Constituent Wt./Vol. Percentage Determination}

The Archimedes density analysis displayed variation in apparent densities ( $\mathrm{g} / \mathrm{cc}$ ) from part to part relative to each material. Statistical analysis including standard deviation and 95\% confidence intervals confirm valid measurements. Table 3.3 summarizes the resultant printed density, weight percent, and volume percent for each CopperFill, BronzeFill, Stainless Steel PLA, Magnetic Iron PLA, and virgin PLA sample. Calculations described in Equation 3.5 and 3.6 allow for the value determination shown in Table 3.5 [30]. Table 3.4 describes the statistical analysis of the measured values indicated. 


$$
\begin{gathered}
\text { Wt } \%_{\text {METAL }}=\frac{\left(\frac{1}{\rho_{P R I N T B O D Y}}\right)-\left(\frac{1}{\rho_{P L A}}\right)}{\left(\frac{1}{\rho_{\text {METAL }}}\right)-\left(\frac{1}{\rho_{P L A}}\right)} \\
\text { Vol. } \%_{\text {METAL }}=\frac{\frac{M_{S}\left(W t \%_{\text {METAL }}\right)}{\rho_{\text {METAL }}}}{\frac{M_{S}}{\rho_{S}}}
\end{gathered}
$$

Where:

$M_{S}=$ Dry Mass of Solid Component $(\mathrm{g})$

$\rho_{S}=$ Density of Solid Composite $(\mathrm{g} / \mathrm{ml})$

\begin{tabular}{|c|c|c|c|c|c|c|}
\hline Material & ID & $\begin{array}{c}\text { Dry } \\
\text { Mass (g) }\end{array}$ & $\begin{array}{c}\text { Wet } \\
\text { Mass (g) }\end{array}$ & $\begin{array}{c}\mathrm{\rho} \mathrm{H}_{2} \mathrm{O} \\
(\mathrm{g} / \mathrm{ml})\end{array}$ & $\begin{array}{c}\text { p of Raw } \\
\text { Filament } \\
\left(\mathrm{g} / \mathrm{cm}^{3}\right)\end{array}$ & $\begin{array}{l}\text { p of } \\
\text { Printe } \\
\text { d Body } \\
(\mathrm{g} / \mathrm{cm} \\
3 \text { ) }\end{array}$ \\
\hline \multirow[t]{4}{*}{ CopperFill } & 1 & 20.4054 & 14.0309 & 0.9978 & 3.5297 & 3.1941 \\
\hline & 2 & 21.2323 & 14.9753 & 0.9978 & 3.4390 & 3.3859 \\
\hline & 3 & 20.3595 & 14.0442 & 0.9978 & 3.4773 & 3.2167 \\
\hline & 4 & 20.5622 & 14.1454 & 0.9978 & 3.4368 & 3.1974 \\
\hline \multicolumn{7}{|l|}{ BronzeFill } \\
\hline & 1 & 23.0749 & 16.8048 & 0.9987 & 3.5996 & 3.6754 \\
\hline & 2 & 23.0788 & 16.7940 & 0.9987 & 3.6009 & 3.6674 \\
\hline & 3 & 22.9777 & 16.4980 & 0.9987 & 3.6474 & 3.5415 \\
\hline & 4 & 23.5184 & 17.2299 & 0.9987 & 3.4836 & 3.7350 \\
\hline \multicolumn{7}{|l|}{$\begin{array}{l}\text { Magnetic } \\
\text { Iron PLA }\end{array}$} \\
\hline & 1 & 12.4936 & 6.2290 & 0.9978 & 1.8689 & 1.9899 \\
\hline & 2 & 12.4908 & 6.1984 & 0.9978 & 1.8863 & 1.9807 \\
\hline & 3 & 12.5557 & 6.2534 & 0.9978 & 1.9441 & 1.9879 \\
\hline & 4 & 12.4839 & 6.2093 & 0.9978 & 1.9025 & 1.9852 \\
\hline \multicolumn{7}{|l|}{$\begin{array}{l}\text { Stainless } \\
\text { Steel PLA }\end{array}$} \\
\hline & 1 & 15.3457 & 8.8181 & 0.9978 & 2.1862 & 2.3457 \\
\hline & 2 & 15.2725 & 8.6856 & 0.9978 & 2.2037 & 2.3135 \\
\hline & 3 & 15.1862 & 8.6109 & 0.9978 & 2.2205 & 2.3045 \\
\hline & 4 & 15.2467 & 8.7468 & 0.9978 & 2.2971 & 2.3405 \\
\hline
\end{tabular}

Table 3.3. Measured Density of Filament Materials Utilizing Archimedes Method 
Table 3.4. Statistical Analysis of Measured Raw and Printed Body Density

\begin{tabular}{|c|c|c|c|c|c|c|}
\hline Material & $\begin{array}{c}\text { Avg. Raw } \\
\text { Filament } \\
p \\
\left(\mathbf{g} / \mathrm{cm}^{3}\right)\end{array}$ & $\begin{array}{l}\text { Std. } \\
\text { Error }\end{array}$ & $95 \%$ CI & $\begin{array}{c}\text { Avg. } \\
\text { Printed } \\
\text { Body } \rho \\
\left(\mathrm{g} / \mathrm{cm}^{3}\right)\end{array}$ & $\begin{array}{l}\text { Std. } \\
\text { Error }\end{array}$ & $95 \% \mathrm{CL}$ \\
\hline CopperFill & 3.47 & 0.04 & $\begin{array}{c}3.40- \\
3.53\end{array}$ & 3.23 & 0.09 & $\begin{array}{c}3.10- \\
3.40\end{array}$ \\
\hline BronzeFill & 3.58 & 0.07 & $\begin{array}{c}3.47- \\
3.69 \\
\end{array}$ & 3.65 & 0.08 & $\begin{array}{c}3.53- \\
3.78 \\
\end{array}$ \\
\hline $\begin{array}{l}\text { Magnetic } \\
\text { Iron PLA }\end{array}$ & 1.90 & 0.03 & $\begin{array}{c}1.85- \\
1.95\end{array}$ & 1.98 & 0.01 & $\begin{array}{c}1.98- \\
1.99\end{array}$ \\
\hline $\begin{array}{l}\text { Stainless } \\
\text { Steel PLA }\end{array}$ & 2.22 & 0.04 & $\begin{array}{c}2.15- \\
2.30\end{array}$ & 2.33 & 0.02 & $\begin{array}{c}2.29- \\
2.36\end{array}$ \\
\hline
\end{tabular}

CopperFill values exhibit the greatest deviation in printed density values relative to its bulk density. Approximated by Equation 3.7, an average (-) $6.61 \%$ drop in density is measured between bulk and printed samples. Conversely, BronzeFill, stainless steel PLA and magnetic iron PLA measure a net increase in density after printing; (+)1.99\%, (+)4.40\% and $(+) 4.36 \%$, respectively. Raw (i.e. virgin) printer filament was utilized as the bulk density. The measured net increase in relative density and/or mass gain within a specific volume indicates that the printing process increased the density of the composite material during the extrusion process.

$$
\% \text { Variance }=\frac{\left(\rho_{P R I N T B O D Y}\right)-\left(\rho_{B U L K}\right)}{\left(\frac{\rho_{P R I N T B O D Y}+\rho_{B U L K}}{2}\right)}(100)
$$

Scanning electron microscopy confirms and elaborates on the findings of the Archimedean analysis. Representative SEM micrographs of CopperFill, BronzeFill, magnetic iron PLA, stainless steel PLA and virgin PLA are displayed in Figures 3.33.7. Overlaid arrows indicated build direction on each respective SEM micrograph. Layer lines, resultant of multilayered printing, are abundant. Triangular shaped air voids are visible and distinguishable from the matrix as a result of their nonspherical morphology caused by oblong cross-sectional layers being deposited side by side. Combining area percent analysis to the Archimedean density shows CopperFill is the most porous of all manufactured samples. 


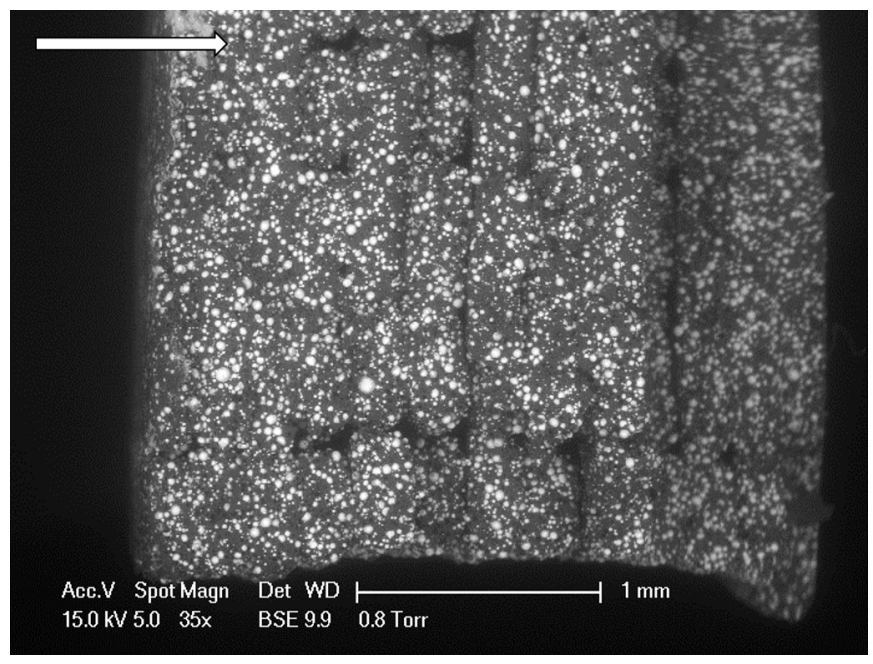

Figure 3.3. SEM-BSE Image of CopperFill Cross-Section

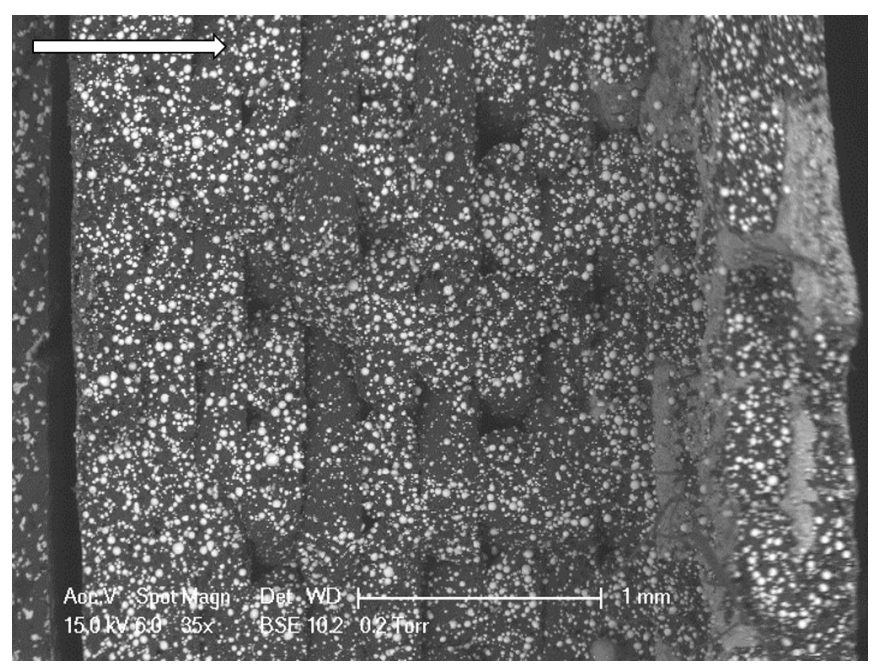

Figure 3.4. SEM-BSE Image of BronzeFill Cross-Section 


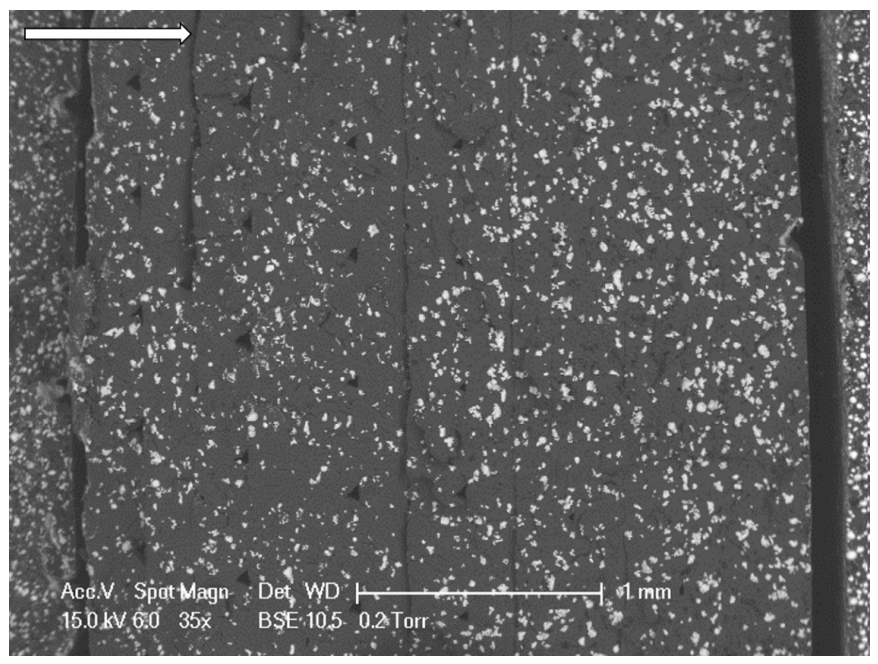

Figure 3.5. SME-BSE Image of Magnetic Iron PLA Cross-Section

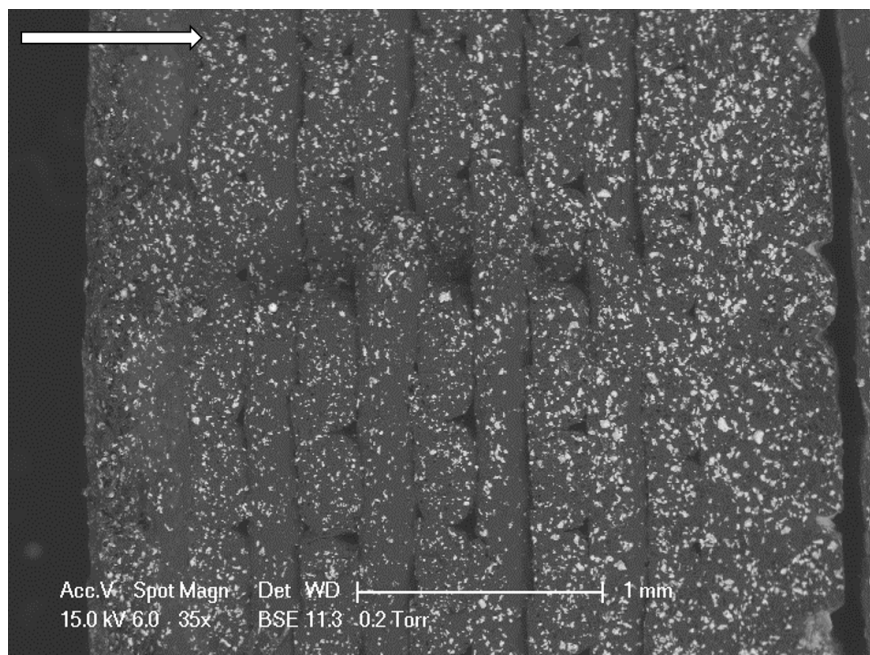

Figure 3.6. SEM-BSE Image of Stainless Steel PLA Cross-Section 


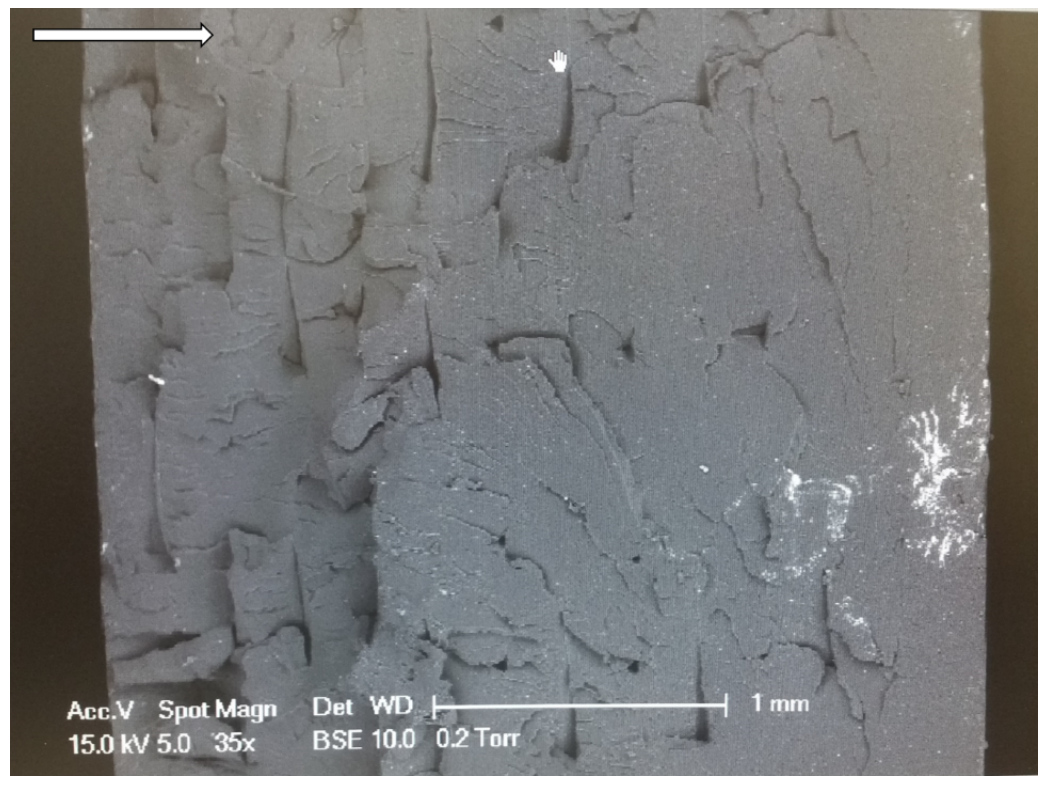

Figure 3.7. SEM-BSE Image of virgin PLA Cross-Section

Figure 3.8 shows a sample analysis from Image] for CopperFill. In this analysis, air voids correlate to the white fields displayed and represent $5.636 \%$ of the available cross section.

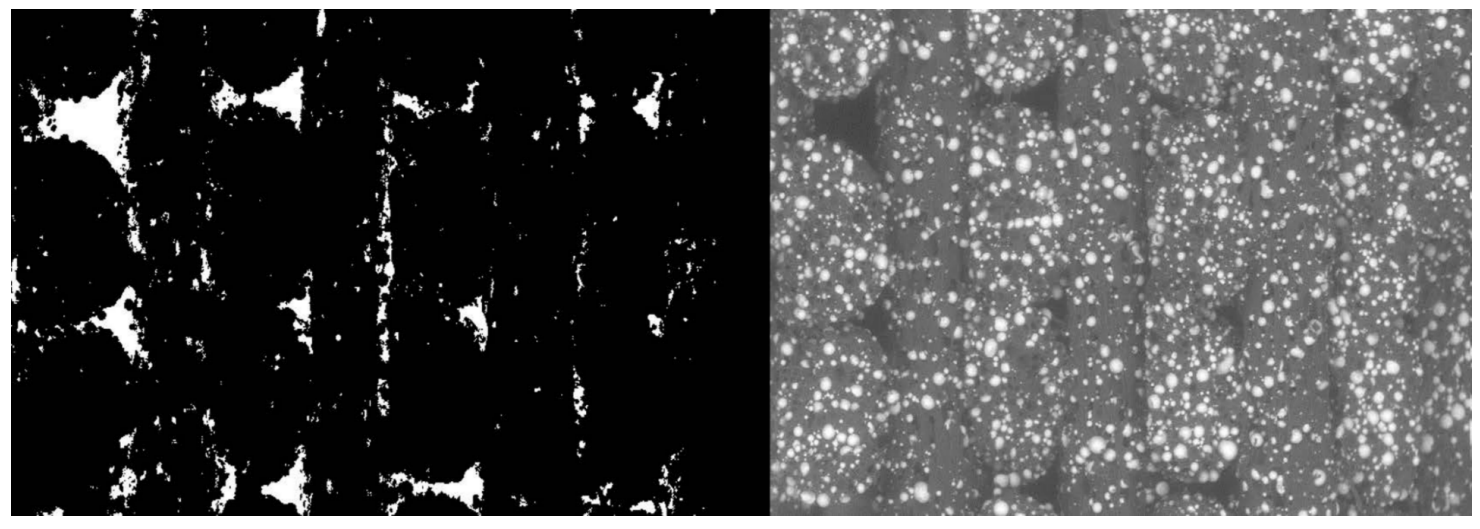

Figure 3.8. Image] 1.49 Analysis of Air Void Fraction in CopperFill. Threshold corrections have been performed thus, the representative scale base has been removed for quantitative measurement. 
Conversely, air voids are apparent within the matrix for BronzeFill, magnetic iron PLA and stainless steel PLA. These results are not in agreement with the aforementioned Archimedean density analysis, as all printed components appear to exhibit extrinsic porosity as a result of printing. These occurrences are likely due to experimental process error. There is inadequate characterization of apparent air void fraction through bulk raw filament density assumptions and raw filament buoyancy forces. Specifically, the air void fraction was determined by comparing the bulk raw filament Archimedes density to that of the composite printed sample. Archimedean density analysis was selected as an adequate method as there are no other ideal methods to determine density of an irregularly shaped object. Furthermore, the bulk raw filament density determined was assumed $100 \%$ dense during comparison. The result bulk density assumption, in addition to potential and unaccounted for significant buoyancy forces of the filament sample potentially lead to the misrepresentation of material density in the Archimedean analysis. Thus, a more accurate demonstration of the pore fraction was performed with Image] 1.49 as the weight of the sample in water (Equation 3.1) was not taken into consideration with this method. [29]. Results of this study, and their respective deviation from the Archimedes analysis are shown in Table 3.5.

Table 3.5. Average Vol. \% Determination of Polymer Metal Matrix Constituents After Printing

\begin{tabular}{|c|c|c|c|c|c|c|}
\hline & \multicolumn{3}{|c|}{ Archimedean Method } & \multicolumn{3}{c|}{ ImageJ Method } \\
\hline & $\begin{array}{c}\text { Vol. \% } \\
\text { Metallic }\end{array}$ & $\begin{array}{c}\text { Vol. \% } \\
\text { PLA }\end{array}$ & $\begin{array}{c}\text { Vol. \% } \\
\text { Air }\end{array}$ & $\begin{array}{c}\text { Vol. \% } \\
\text { Metallic }\end{array}$ & $\begin{array}{c}\text { Vol. \% } \\
\text { PLA }\end{array}$ & $\begin{array}{c}\text { Vol. \% } \\
\text { Air }\end{array}$ \\
\hline $\begin{array}{c}\text { Copper } \\
\text { Fill }\end{array}$ & 26.10 & 67.52 & 6.37 & 40.19 & 54.17 & 5.63 \\
\hline $\begin{array}{c}\text { Bronze } \\
\text { Fill }\end{array}$ & 32.38 & 67.61 & $*$ & 38.06 & 58.74 & 3.19 \\
\hline $\begin{array}{c}\text { Magnet } \\
\text { ic Iron } \\
\text { PLA }\end{array}$ & 11.32 & 88.67 & $*$ & 13.67 & 83.57 & 2.75 \\
\hline $\begin{array}{c}\text { Stainle } \\
\text { SS } \\
\text { Steel } \\
\text { PLA }\end{array}$ & 16.08 & 83.91 & $*$ & 17.25 & 80.39 & 2.34 \\
\hline
\end{tabular}

In comparison to both the Archimedean and ImageJ 1.49 results a tertiary analysis was conducted to further confirm the overall volume and weight percent(s) of the 
metallic constituents within the matrix. Geometric shape volumes $\left(V=n r^{2} h\right)$ for section filament strands were collected. Lengths and average radius(s) of each respective filament (e.g. CopperFill, BronzeFill, Magnetic Iron PLA and Stainless Steel PLA) were measured. Collected filament lengths overall mass ( $m$, grams) was measured to determine bulk/composite density $(\rho=m / V)$. Table 3.6 describes the results described.

Table 3.6. Filament geometrical shape volume, mass and density determinations for section samples of CopperFill, BronzeFill, Magnetic Iron PLA and Stainless Steel PLA. Filament strand lengths measured 50.40, 51.66, 50.24 and $49.21 \mathrm{~mm}$ for CopperFill, BronzeFill, Magnetic Iron PLA and Stainless Steel PLA, respectively. Filament strand average diameters(s) measured $2.86,2.83,2.81$ and $2.83 \mathrm{~mm}$, respectively $r=$ filament radius, $h=$ filament height/length.

\begin{tabular}{|c|c|c|c|}
\hline & $\begin{array}{c}\text { Filament Volume } \\
\left(\boldsymbol{V}=\mathbf{n r}^{\mathbf{2}} \mathbf{h} \mathbf{c m}^{\mathbf{3}}\right)\end{array}$ & $\begin{array}{c}\text { Filament Mass } \\
(\mathbf{g r a m s})\end{array}$ & $\begin{array}{c}\text { Filament Density } \\
\left(\boldsymbol{\rho}=\mathbf{m} / \mathbf{V}_{\mathbf{s}}\right. \\
\left.\boldsymbol{g r a m s} / \mathbf{c m}^{\mathbf{3}}\right)\end{array}$ \\
\hline CopperFill & 0.316 & 1.0 & 3.16 \\
\hline BronzeFill & 0.317 & 1.1 & 3.47 \\
\hline Mag Iron PLA & 0.322 & 0.6 & 1.85 \\
\hline $\begin{array}{c}\text { Stainless } \\
\text { Steel PLA }\end{array}$ & 0.324 & 0.8 & 2.46 \\
\hline
\end{tabular}

Values reported in Table 3.6 are near and/or within the 95\% confidence interval originally reported in Table 3.3 for average raw filament densities. Filament samples utilized for this analysis are curved, thus potentially leading to a standard error associated with length measurement. Under-reported length measurements will developed over-reported density $(\rho)$ values. The authors do not consider the length (h) dimension standard error discussed to be significant.

To further confirm weight and volume percentages reported in Table $3.5 \mathrm{a}$ quaternary method was formulated. A 3 Molar solution of sodium hydroxide $(\mathrm{NaOH})$ in water $\left(\mathrm{H}_{2} \mathrm{O}\right)$ was utilized to eliminate the PLA constituent of the composite matrix while retaining only the metallic constituent. The composite samples subject to this work are equivalent those discussed relative to Table 3.6. Samples were subjected to the 3 Molar $\mathrm{NaOH}$ solution for 12 hours at $30^{\circ} \mathrm{C}$ in an ultra-sonic bath. Intermittent stoppages in processing occurred due to evaporation $\mathrm{NaOH}$ solution evaporation 
during processing. Samples and solution were washed and decanted with deionized water and 200 proof ethanol. A final ethyl alcohol bath and drying cycle realized metallic constituents separated from their surrounding PLA matrix. Mass of the remaining metallic constituent was recorded and compared to the full composite mass recorded in Table 3.7 resulting in an overall metallic constituent weight percent.

Table 3.7. Volume percentage of metallic constituents evaluated with a quaternary method by dissolving PLA constituent out of the composite matrix yielding separated metallic constituent. Wt. \% to Vol. \% through Equation 3.6

\begin{tabular}{|c|c|c|}
\hline & $\begin{array}{c}\text { Resolved Mass of Metallic } \\
\text { Constituent (grams) }\end{array}$ & $\begin{array}{c}\text { Volume Percentage of } \\
\text { Metallic Constituent (\%) }\end{array}$ \\
\hline CopperFill & 0.98 & 34.8 \\
\hline BronzeFill & 0.93 & 33.7 \\
\hline Mag Iron PLA & 0.42 & 16.5 \\
\hline $\begin{array}{c}\text { Stainless Steel } \\
\text { PLA }\end{array}$ & 0.38 & 14.6 \\
\hline
\end{tabular}

Values reported in Table 3.7 are quantified without influence of air void volume fraction error and or potential flotation associated with an Archimedean method. However, quantifying the mass and/or relative volume of potentially remaining PLA constituent on the powder surface is not quantified. In comparison the volume fraction analysis presented in Table 3.5 the determined values are of similar magnitude relative to each filament.

\subsubsection{Particle Size Determination}

Back scattered electron (BSE) images can also provide a qualitative analysis of the 'microstructure'. Visible particle morphology of the metallic filler material are spherical for CopperFill and BronzeFill. Conversely, stainless steel PLA and magnetic iron PLA contain 'flake' like particles. ImageJ coupled with the BSE image allowed for the particle size determination. CopperFill and BronzeFill were assumed spherical based upon the morphology shown in Figures 3.9(a), while stainless steel and magnetic iron PLA are flake like as shown in Figure 3.9(b). 


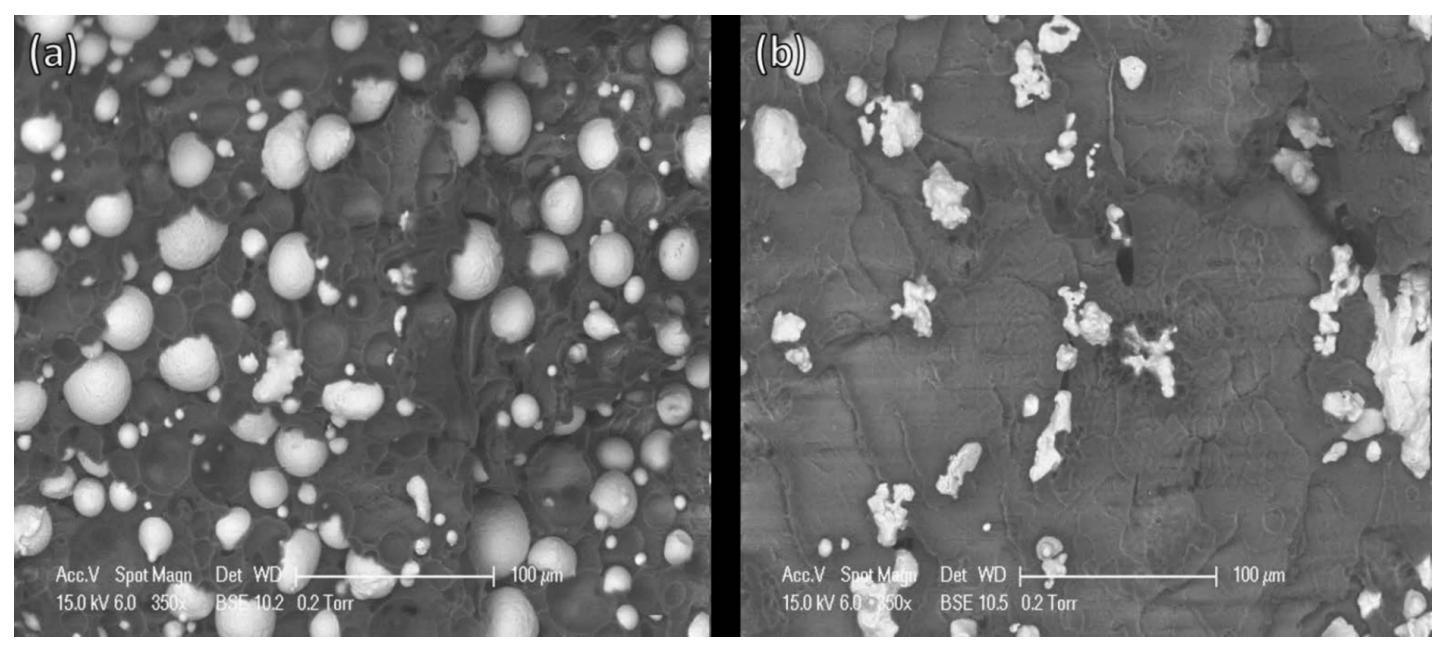

Figure 3.9. (a) Representative morphology of spherical particles (CopperFill and BronzeFill), (b) Representative morphology of flake life particles (Magnetic Iron PLA and Stainless Steel PLA)

Thus, extracted particle area measurement determination, in Image] 1.49, was converted to diameter though a common area equation calculation ( $\mathrm{rr} 2$ ). While the 'flake' like metallic particles of stainless steel PLA and magnetic iron PLA were analyzed using an average Feret diameter. The particle size distribution analysis is represented in Figures 3.10-3.13. 


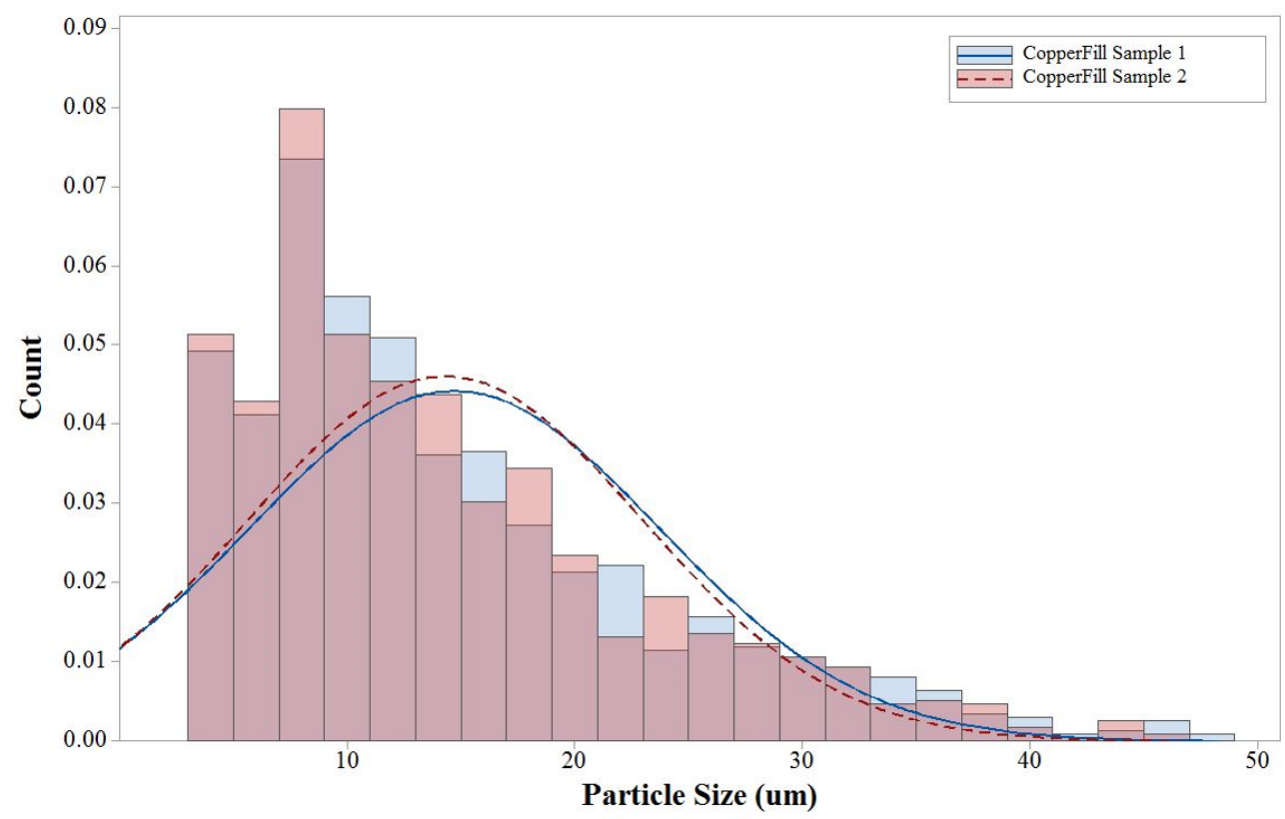

Figure 3.10. CopperFill Particle Size (um) Distribution

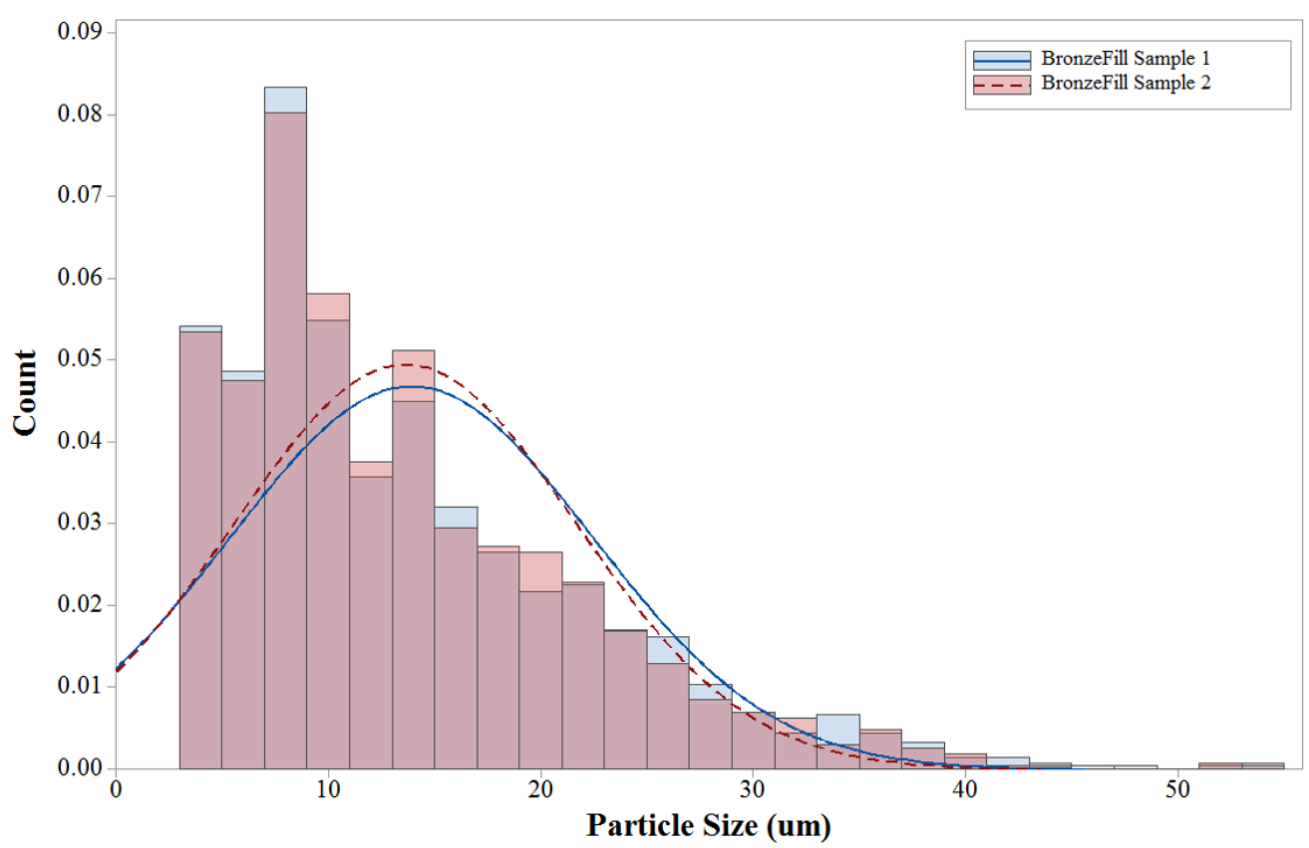

Figure 3.11. BronzeFill Particle Size (um) Distribution 


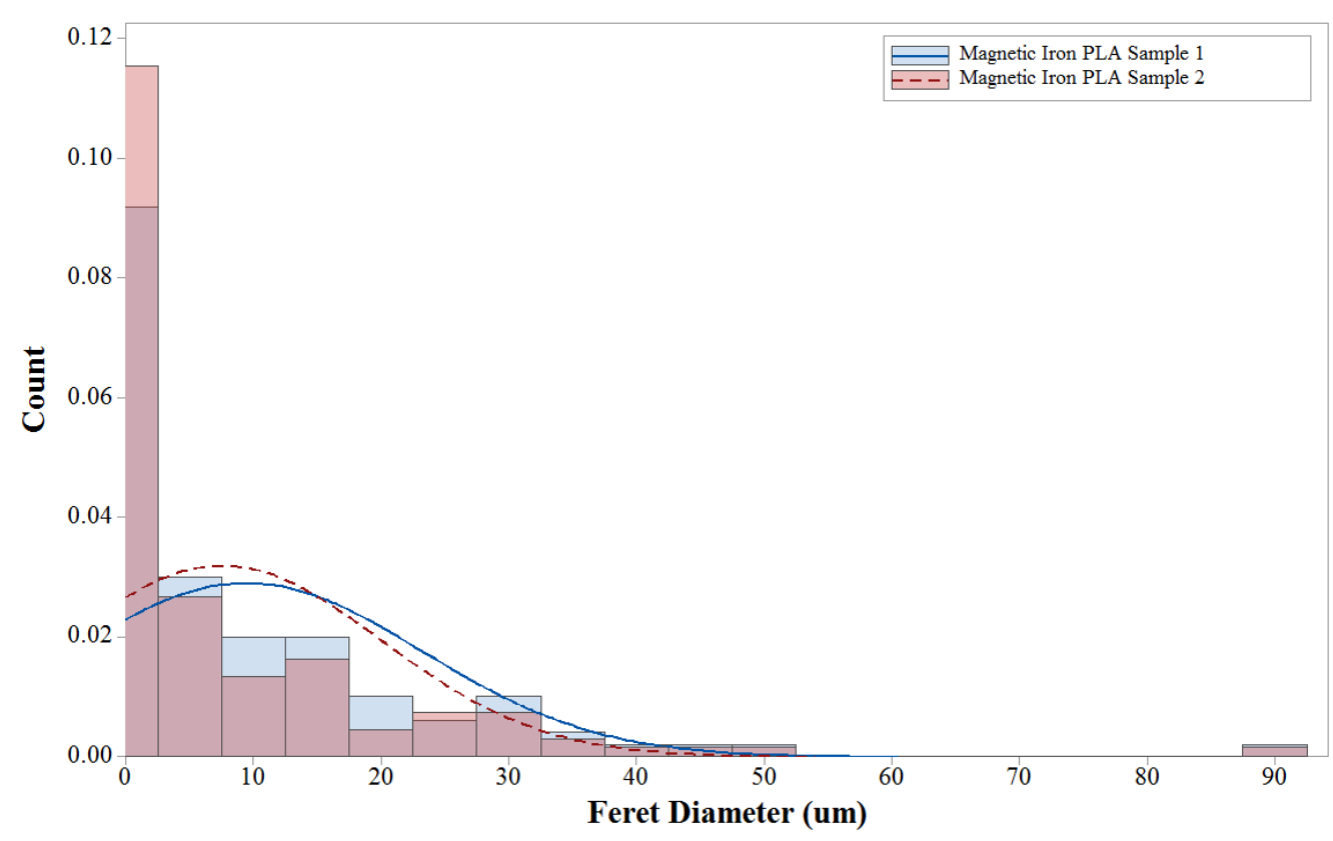

Figure 3.12. Magnetic Iron PLA Feret Diameter (um) Distribution

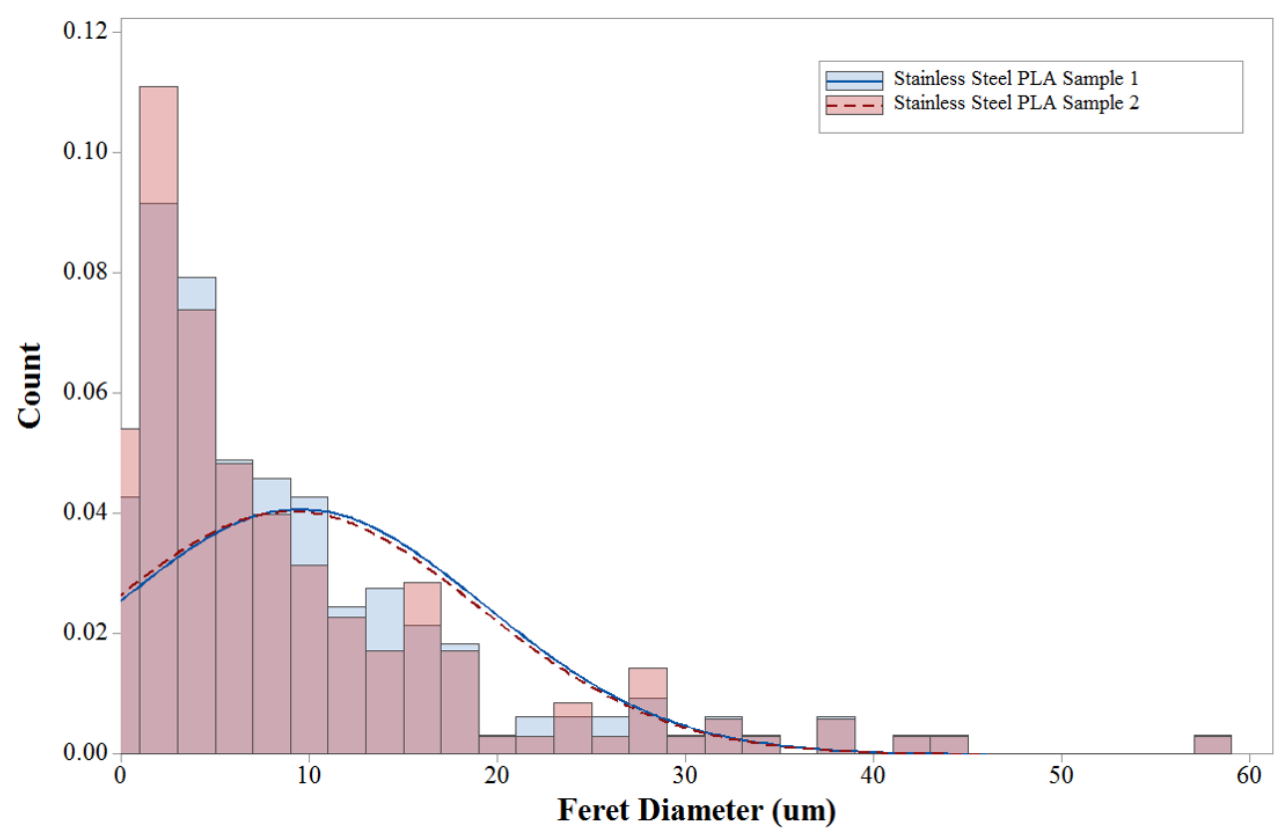

Figure 3.13. Stainless Steel PLA Feret Diameter (um) Distribution

The presented particle size analysis does not account for statistical correction methods in cross-section / microscopy particle analysis. Thus, the analysis may under-report the actual particle size. To determine the severity of this effect metallic 
constituents are evaluated independently of the PLA matrix. Separated powder, acquired from method described in Section 3.4.1, is utilized in this analysis. BSESEM micrographs of the metallic constituents for CopperFill, BronzeFill, Magnetic Iron PLA and Stainless Steel PLA are shown in Figure 3.14 below.
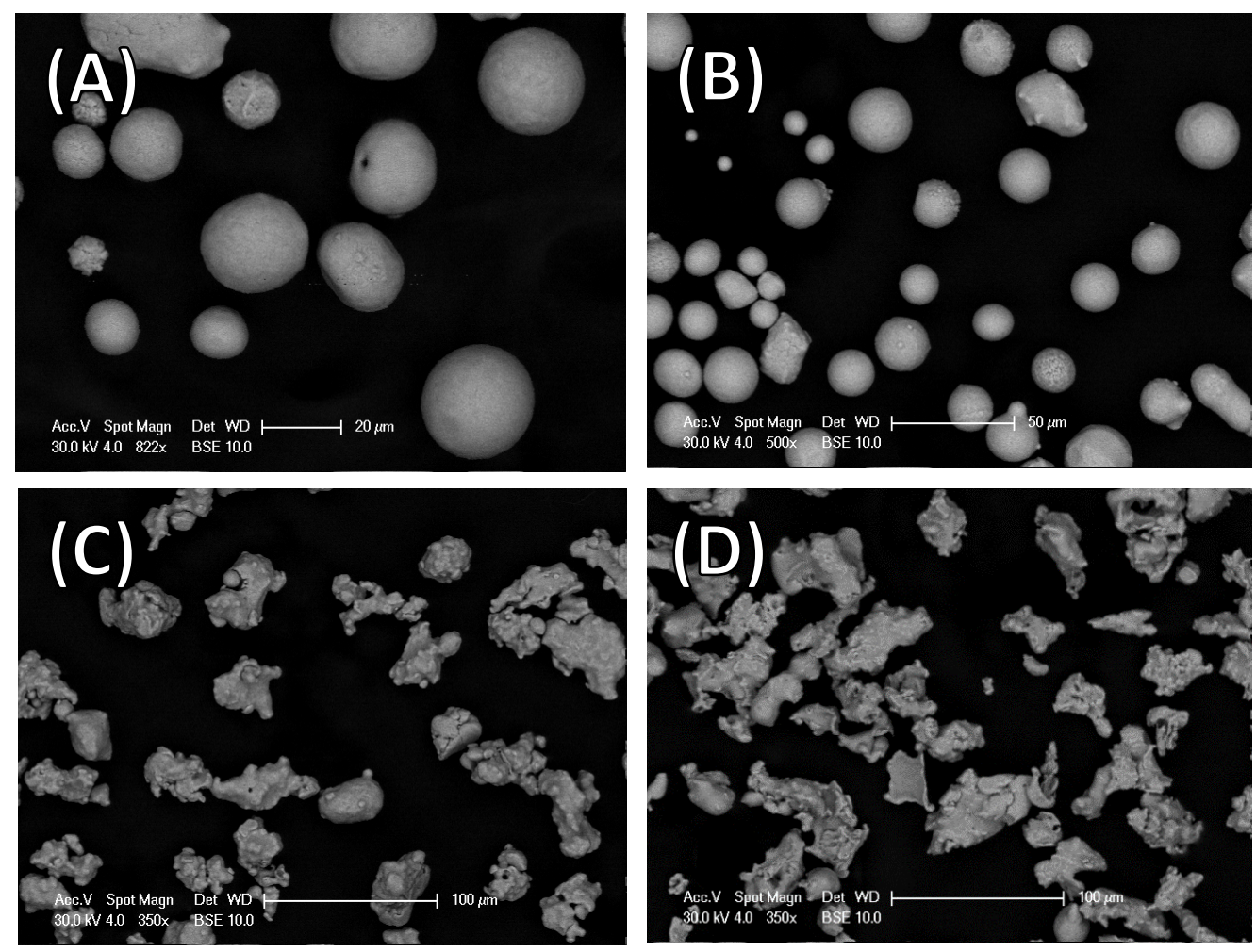

Figure 3.14. BSE-SEM micrographs of separated metal powder from: (a) CopperFill, (b) BronzeFIIl, (c) Magnetic Iron PLA, and (d) Stainless Steel PLA. Representative scale bars for images (a), (b), (c) and (d) are $20 \mu \mathrm{m}, 50 \mu \mathrm{m}, 100 \mu \mathrm{m}$ and $100 \mu \mathrm{m}$, respectively.

Application of ImageJ 1.49 allows for a particle size determination. The proposed method is identically similar to those discussed previously (Figure 3.10 - 3.13) (i.e. a spherical approximation utilized for Copper and BronzeFIll and a Feret approximation for Magnetic Iron and Stainless Steel PLA). However, in these analyses the non-cross sectioned particle is analyzed. Thus, the resultant particle size distributions are presented in Table 3.8. In total, ten BSE-SEM images were captured to provide adequate representation of the metallic constituent. Each image 
was subjected to background threshold correction in effort to prepare them for the ImageJ 1.49 analysis.

Table 3.8. Average particle size of CopperFill, BronzeFill, Magnetic Iron PLA and Stainless Steel PLA's metallic constituents. CopperFill and BronzeFill utilize a spherical approximation. Magnetic Iron and Stainless Steel PLA utilize a Feret approximation. Standard error associated with the measurement reported.

\begin{tabular}{|c|c|c|}
\hline & $\begin{array}{c}\text { Average Particle Diameter } \\
(\mu \mathrm{m})\end{array}$ & Std. Error $(\mu \mathrm{m})$ \\
\hline CopperFIII & 18.0 & 1.9 \\
\hline BronzeFill & 18.5 & 1.4 \\
\hline Mag Iron PLA & 43.9 & 10.5 \\
\hline $\begin{array}{c}\text { Stainless Steel } \\
\text { PLA }\end{array}$ & 38.0 & 5.3 \\
\hline
\end{tabular}

Resultant particle size analysis suggests that the original cross-sectional analysis underestimates the nominal particle diameter. Most severely affected are the Magnetic Iron and Stainless Steel PLA due to their particle morphology. Outside of the polymer binder the entire metallic constituent is realized, thus elongated relative to the initial analysis.

\subsubsection{Composite Thermal Conductivity $(\mathrm{W} / \mathrm{m} \cdot \mathrm{K})$ Determination}

The measured thermal conductivity for the studied open metal/PLA composites is shown in Figure 3.14. The solid lines in these figures correlate to the prescribed relationships of Equation 3.4 with $10^{3}, 10^{2}$, and $10^{1}$ constituent thermal conductivity ratios $\left(\lambda_{M E T A L} / \lambda_{P L A}\right)$. 


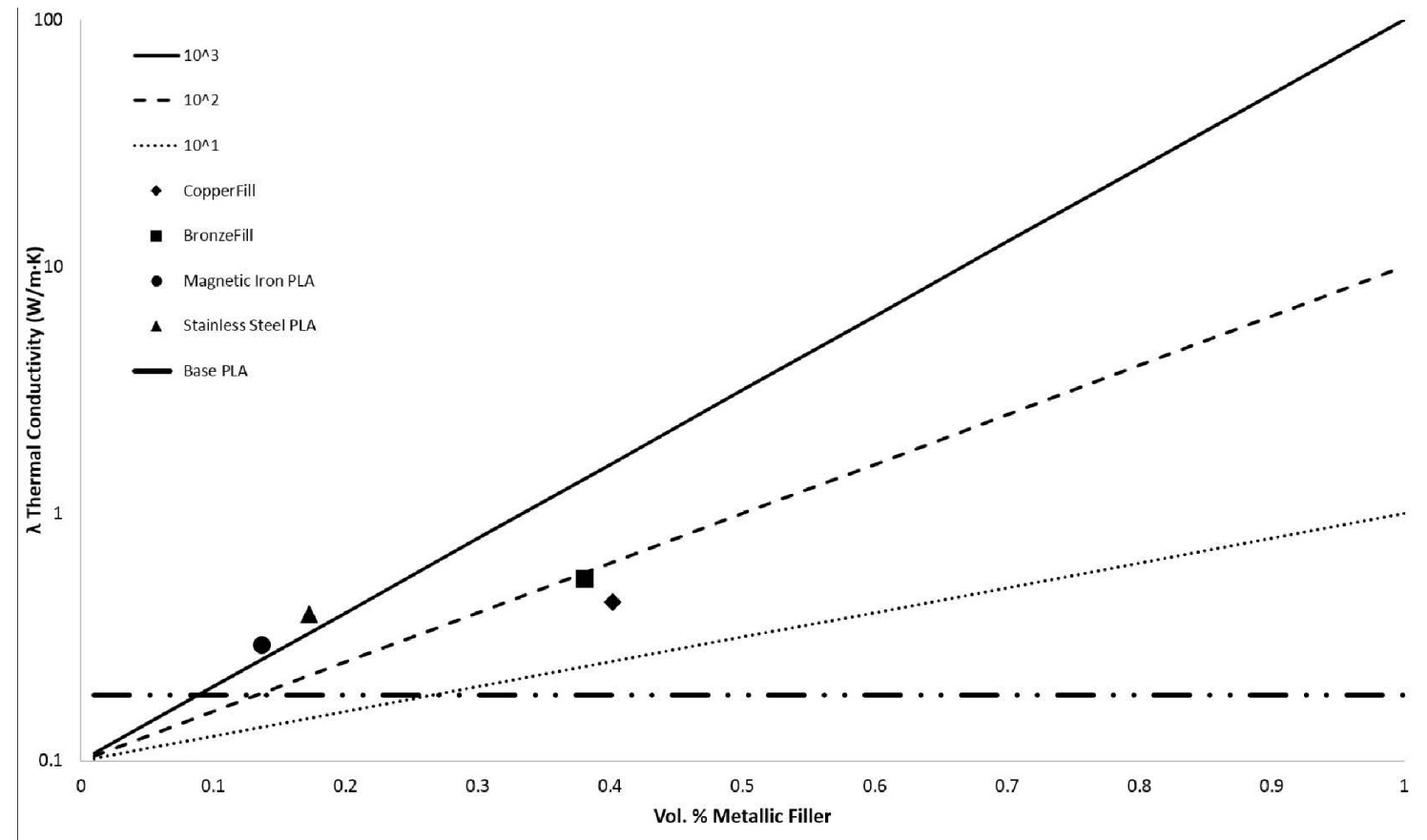

Figure 3.14. Resultant Thermal Conductivity Measurements utilizing Holometrix TCA300 Compared to Lichtenecker's Dependence (eq. 3.4)

Experimentally collected thermal conductivity values do not correlate to the prescribed models shown by Lichtenecker and Smith. Generalized modeled and quantitative thermal conductivity presented prior (Figure 3.14) are further developed in Table 3.9. Selected metallic constituent thermal conductivity values, shown in Table 3.9, represent corresponding magnitudes of the metallic filler component. Thus, the values presented are to be considered reference and may vary depending upon chemistry (i.e. purity and alloy of the respective constituent). 
Table 3.9. Measured thermal conductivity of CopperFill, BronzeFill, Magnetic Iron PLA and Stainless Steel PLA compared to Lichtenecker Model, Smith Air Void Correction and Base PLA

\begin{tabular}{|c|c|c|c|c|c|c|}
\hline $\begin{array}{c}\text { Sample } \\
\text { Materi } \\
\text { al }\end{array}$ & $\begin{array}{c}\text { Average } \\
\text { Holometr } \\
\text { ix TCA } \\
300 \lambda_{s} \\
(W / \mathrm{m} \cdot \mathrm{K})\end{array}$ & $\begin{array}{c}\text { Lichteneck } \\
\text { er } \\
\text { Prediction } \\
(\text { EQ. 4) } \\
\lambda_{\text {Lichtenecker }} \\
(\mathbf{W} / \mathbf{m} \cdot \mathbf{K})\end{array}$ & $\begin{array}{c}\text { Lichteneck } \\
\text { er } \\
\text { Deviation } \\
\% \text { from } \\
\text { Measured } \\
\lambda_{s} \\
\end{array}$ & $\begin{array}{c}\text { Smith } \\
\text { Air Void } \\
\text { Correcti } \\
\text { on (EQ. } \\
5) \lambda_{\text {Smith }} \\
(W / m \cdot K \\
)\end{array}$ & $\begin{array}{l}\text { Smith } \\
\text { Deviati } \\
\text { on } \% \\
\text { from } \\
\text { Measur } \\
\text { ed } \lambda_{s} \\
\end{array}$ & $\begin{array}{c}\text { Base } \\
\lambda_{\mathrm{pLA}} \\
\text { Deviati } \\
\text { on } \% \\
\text { from } \\
\text { Measur } \\
\text { ed } \boldsymbol{\lambda} s \\
\end{array}$ \\
\hline $\begin{array}{c}\text { CopperF } \\
\text { ill }\end{array}$ & \multirow[b]{2}{*}{0.4381} & \multirow[b]{2}{*}{3.9904} & \multirow[b]{2}{*}{$(+) 160.42$} & \multirow[b]{2}{*}{3.6657} & \multirow[b]{2}{*}{$\begin{array}{c}(+) \\
157.29\end{array}$} & \multirow[b]{2}{*}{$\begin{array}{c}(+) \\
81.28\end{array}$} \\
\hline $\begin{array}{c}* \lambda_{\text {Copper }} \\
=380 \\
(\mathrm{~W} / \mathrm{m} \cdot \mathrm{K} \\
)\end{array}$ & & & & & & \\
\hline \multirow{2}{*}{$\begin{array}{c}\begin{array}{c}\text { BronzeF } \\
\text { ill }\end{array} \\
{ }^{*} \lambda_{\text {Bronze }} \\
=50 \\
(\mathrm{~W} / \mathrm{m} \cdot \mathrm{K} \\
) \\
\text { Maaneti }\end{array}$} & \multirow[b]{2}{*}{0.5460} & \multirow[b]{2}{*}{1.5677} & \multirow[b]{2}{*}{$(+) 96.67$} & \multirow[b]{2}{*}{1.4957} & \multirow[b]{2}{*}{$\begin{array}{c}(+) \\
93.03\end{array}$} & \multirow[b]{2}{*}{$\begin{array}{c}(+) \\
98.81\end{array}$} \\
\hline & & & & & & \\
\hline $\begin{array}{c}\text { Magneti } \\
\text { c Iron } \\
\text { PLA }\end{array}$ & \multirow[b]{2}{*}{0.2943} & \multirow[b]{2}{*}{0.4271} & \multirow[b]{2}{*}{ (+) 36.82} & \multirow[b]{2}{*}{0.4114} & \multirow[b]{2}{*}{$\begin{array}{c}(+) \\
33.18\end{array}$} & \multirow[b]{2}{*}{$\begin{array}{c}(+) \\
45.66\end{array}$} \\
\hline $\begin{array}{c}{ }^{*} \lambda_{\text {Magnetic }} \\
= \\
\text { Iron } \\
79.5 \\
(\mathrm{~W} / \mathrm{m} \cdot \mathrm{K} \\
) \\
\end{array}$ & & & & & & \\
\hline $\begin{array}{c}\text { Stainles } \\
\text { s Steel } \\
\text { PLA }\end{array}$ & \multirow[b]{2}{*}{0.3907} & \multirow[b]{2}{*}{0.4106} & \multirow[b]{2}{*}{$(+) 4.98$} & \multirow[b]{2}{*}{0.4074} & \multirow[b]{2}{*}{$(+) 4.17$} & \multirow[b]{2}{*}{$\begin{array}{c}(+) \\
71.51\end{array}$} \\
\hline $\begin{array}{c}{ }^{*} \lambda_{\text {Stainless }} \\
\text { Steel } \\
18 \\
(\mathrm{~W} / \mathrm{m} \cdot \mathrm{K} \\
)\end{array}$ & & & & & & \\
\hline $\begin{array}{l}\text { Base } \\
\text { PLA }\end{array}$ & .1849 & - & - & - & - & - \\
\hline
\end{tabular}


Significant deviation is notable from the analysis with exception to stainless steel PLA. The calculated $\lambda_{\text {SMITH }}$ value for CopperFill, BronzeFill and magnetic iron PLA vary, relative to the measured thermal conductivity by Holometrix TCA 300 by $(+) 157.29$, $(+) 93.03$ and $(+) 33.18 \%$, respectively. Conversely, measured values for stainless steel PLA deviate by $4.17 \%$. The largest variance presents in metal/polymer composites where the metallic constituent thermal conductivity is $10^{3}$ times greater than the polymer constituent. Comparing base PLA, $0.1849 \mathrm{~W} / \mathrm{m} \cdot \mathrm{K}$, to measured values implies that there is greater dependence on apparent print density than thermal conductivity of each respective constituent. Specifically, BronzeFill outperforms CopperFill by $21.92 \%$ even though the metal thermal conductivities are 50 and $380 \mathrm{~W} / \mathrm{m} \cdot \mathrm{K}$, respectively. Conversely, Magnetic Iron PLA outperforms Stainless Steel PLA where the metal thermal conductivities are $79.5 \mathrm{vs} .18 \mathrm{~W} / \mathrm{m} \cdot \mathrm{K}$, and metallic filler volume percentages are 13.37 and $17.25 \%$, respectively.

Developed models for porosity considerations assume cylindrical obstacles (pores) dispersed uniformly within the metal/polymer matrix. Other methods, described by Smith, include open porosity considerations more readily suited to fit the developed samples [35]. The realized cross-sectional geometry, described in Figures 3.3-3.7 indicate the presence of non-equiaxed open pores which are more readily suited by Landauer's relation to percolation theory. Landauer's theory assumes pore zones to be equally dispersed throughout the matrix with respect to the input heat [36]. These concepts apply to the developed samples due to printer type and layer base manufacturing methods. In effect, an assumption can be made that each build layer contains equivalently randomly orientated air pore structures. Application of the modeled, described in Equation 3.8 yields the following results displayed in Table 3.10 . 


$$
\lambda_{\text {Landauer }}=\frac{1}{4}\left\{\left(3 v_{c}-1\right) \lambda_{C}+\left(3 v_{A}-1\right) \lambda_{A}+\left(\left(3 v_{C}-1\right) \lambda_{C}+\left(3 v_{A}-1\right) \lambda_{A}\right)^{2}+8 \lambda_{C} \lambda_{A}{ }^{1 / 2}\right\} \text { (eq. 3.8) }
$$

Where:

$\lambda_{\text {Landauer }}=$ Landauer Corrected Thermal Conductivity

$v_{C}=$ Vol. \% Composite (CopperFill, BronzeFill, Magnetic Iron PLA, Stainless

Steel PLA

$v_{A}=$ Vol. \% Air Void

$\lambda_{C}=$ Measured Thermal Conductivity of Composite $(\mathrm{W} / \mathrm{m} \cdot \mathrm{K})$

$\lambda_{A}=$ Standard Value for the Thermal Conductivity of Air $(\mathrm{W} / \mathrm{m} \cdot \mathrm{K})$

Table 3.10. Smith Air Void Correction vs. Landauer Air Void Correction

\begin{tabular}{|c|c|c|c|c|}
\hline $\begin{array}{l}\text { Sample } \\
\text { Material }\end{array}$ & $\begin{array}{c}\text { Average } \\
\text { Holometrix } \\
\text { TCA } 300 \lambda_{s} \\
(\mathrm{~W} / \mathrm{m} \cdot \mathrm{K}) \\
{[\text { Table 6] }}\end{array}$ & $\begin{array}{l}\text { Smith Air } \\
\text { Void } \\
\text { Correction } \\
(E Q .5) \lambda_{\text {smith }} \\
(\mathbf{W} / \mathbf{m} \cdot \mathbf{K})\end{array}$ & $\begin{array}{c}\text { Landauer Air } \\
\text { Void } \\
\text { Correction } \\
(\text { EQ. 8) } \\
\lambda_{\text {Landauer }} \\
(\mathbf{W} / \mathbf{m} \cdot \mathbf{K})\end{array}$ & $\begin{array}{c}\text { Percent } \\
\text { Variance } \\
\text { Smith } \\
\text { Method (EQ. } \\
\text { 5) vs. } \\
\text { Landauer } \\
\text { Method (EQ. } \\
\text { 8) }\end{array}$ \\
\hline CopperFill & 0.4381 & 3.6657 & 3.6565 & $(-) 0.25$ \\
\hline BronzeFill & 0.5460 & 1.4957 & 1.4945 & (-) 0.08 \\
\hline $\begin{array}{c}\text { Magnetic Iron } \\
P L A\end{array}$ & 0.2943 & 0.4114 & 0.4112 & $(-) 0.05$ \\
\hline $\begin{array}{l}\text { Stainless } \\
\text { Steel PLA }\end{array}$ & 0.3907 & 0.4074 & 0.3976 & $(-) 2.43$ \\
\hline
\end{tabular}

It is clear that the existing models are deficient in fitting the experimental data.

\subsection{Discussion}

More rigorous quantitative exercises are required to determine true percent porosity in order to accurately model the effect of air pore volume fraction on thermal conductivity. In effect, low pore volume fraction $(<6 \%)$ does not model the system accurately.

Specifically, Smith and Landauer models are expected to model the system appropriate assuming appropriate volume fraction determination. Tsotsas et al. 
compiled multiple analytical approach methods for thermal conductivity determination of gas-filled packed beds [37]. Moreover, the layer based manufacturing methods induce porosity formation layer-by-layer and by each subsequent pass of the hot end compounds the development of air voids. The models utilized may not adequately represent the geometry of the air void fraction. Thus, the assumption of non-equiaxed pores is insufficient at modeling printed components. More likely, however, is the presence of micron size "layers" of air void fraction between each printed metal/polymer composite layer. Optimized printing parameters, specifically extrusion temperature $\left({ }^{\circ} \mathrm{C}\right)$ and speed $(\mathrm{mm} / \mathrm{s})$, could alleviate this issue To investigate the proposed theory, secondary calculation utilizing the prescribed through plane and non-continuous heat flow path assumptions, thermal conductivity values are equated. Table 3.11 represents these determinations abiding Equation 3.3a (Lichtenecker dependence) has been applied to determine the perpendicular (relative to the printed layer) thermal conductivity of the composite. The determined composite(s) thermal conductivity (Table 3.9.) are re-utilized as an input into Equation 3.3a to determine the perpendicular thermal conductivity assuming that the air void fraction is a layer oriented perpendicular to the heat flow. Air void volume fraction percentages are utilized as shown in Table 3.5.

Table 3.11. Lichtenecker Through Plane Air Thermal Conductivity Determination

\begin{tabular}{|c|c|c|c|}
\hline Filament & $\begin{array}{c}\text { Lichtenecker } \\
\text { Prediction }(E Q \cdot 3 a) \\
\lambda_{\text {Lichtenecker }}(\mathrm{W} / \mathrm{m} \cdot \mathrm{K})\end{array}$ & $\begin{array}{c}\text { Air Void } \\
\text { Volume } \\
\text { Fraction \% }\end{array}$ & $\begin{array}{c}\text { Lichtenecker } \\
\text { Through Plane Air } \\
\text { Layer Thermal } \\
\text { Conductivity } \boldsymbol{\lambda}_{\text {LAYER }} \\
(\mathrm{W} / \mathrm{m} \cdot \mathrm{K})\end{array}$ \\
\hline CopperFill & 3.9904 & 5.63 & 3.02 \\
\hline BronzeFill & 1.5677 & 3.19 & 1.37 \\
\hline $\begin{array}{c}\text { Magnetic Iron } \\
\text { PLA }\end{array}$ & 0.4271 & 2.75 & 0.39 \\
\hline $\begin{array}{c}\text { Stainless Steel } \\
\text { PLA }\end{array}$ & 0.4106 & 2.34 & 0.38 \\
\hline
\end{tabular}

The variance between $\lambda_{\text {LAYER }}, \lambda_{\text {Lichtenecker, }} \lambda_{\text {Smith }}$ is most substantial in composites with $10^{3}$ or $10^{2}$ metallic thermal conductivity $(\mathrm{W} / \mathrm{m} \bullet \mathrm{K})$. To obtain the measured Holometrix TCA 300 composite thermal conductivity of CopperFill, BronzeFill, Magnetic Iron PLA and Stainless Steel PLA air void fraction percentages of $44.70 \%$, $26.31 \%, 13.75 \%$ and $1.86 \%$, respectively, would be required. The performed 
Archimedes analysis suggest that these values are not representative of the composite matrix.

Single sample cross sectional analysis is inadequate at quantifying the air void volume content. In effect, single sample microscopy of FFF developed samples do not represent the porosity of the entire matrix. Further analysis should aim for rigorous sample procedures to analyze all appropriate component locations and orientations. Methods utilized in these analysis analyzed the ZX plane for quantitative microscopy. A proposed method would utilize, at minimum, 3 distinct sample planes that highlight critical features of the $X Y, Z X$ and $Z Y$ three-dimensional coordinate planes. Figure 3.15 elaborates on this proposal.

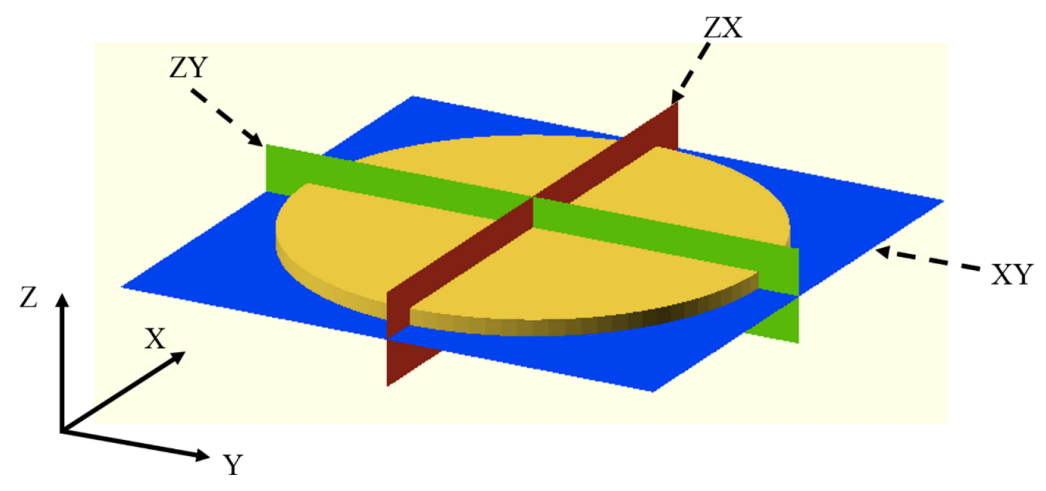

Figure 3.15. Proposed cross-section analysis methods to properly quantify apparent air void fraction of FFF printed components

Although all of the materials did not have high thermal conductivities expected of high weight percentage metal materials, there are several high-value applications of such 3-D printed materials that look metallic, but have low thermal conductivity. For example, these composites can be used in the fabrication of muntins for energy efficient windows with complex geometries. A muntin (also referred to as muntin bar, glazing bar or sash bar) is generally a strip of metal separating and holding panes of glass in a window. Today, window manufacturers are basically locked into extruded shapes for muntins resulting in options of straight bars of slightly varying widths. 3D printing composite materials such as those investigated here with high air void density would enable better heat retention in the building while enabling more 
artistic latitude and organic designs in windows. Future work is needed to test the UV stability of such composites, and high-temperature thermopolymers should also be investigated.

Limiting the printed component porosity by secondary processing methods needs to be investigated. Several processes are readily available and can potentially increase the printed density of the material. Specifically, isostatic pressing can be utilized post printing to increase layer to layer adhesion and remove residual air pockets as result of poor print vector overlap. Cold isostatic pressing (CIP) is readily applicable for this application. While immersed in a liquid, typically water based, isostatic pressure is applied to the specimen at an ambient temperature resulting in part densification. Initial investigations indicate a $5.0 \%$ increase in printed density after a CIP operation. Samples subjected to experimentation had a similar geometry to the thermal conductivity samples. Components were subjected to vessel pressures of 30,000 psi and held for 5 minutes, thus completing an entire test cycle. Significant dimensional variation (i.e. warp) resulted from the CIP processing. Conversely, hot isostatic pressing (HIP) utilizes the increase driving force of an elevated temperature to plastically deform internal cavities and promote diffusion bonding [38]. The melting temperature of PLA is greater than $155^{\circ} \mathrm{C}[39]$, while the typical HIP operating temperature range is $\sim 500-2000^{\circ} \mathrm{C}$ [38]. Thus, CopperFill, BronzeFill, Magnetic Iron PLA and Stainless Steel PLA are not readily suited for this secondary process.

Considering the relative deviation from the filament raw bulk analysis, the printing operation significantly impacts the resultant component density. Baseline parameters sufficed for these analyses, however, future work should continue to develop the printing parameters for acquiring $100 \%$ density as printed. Elimination of required secondary processes, such as CIP, accelerates manufacturing time at reduced cost. As such, novel printing processes and procedures require development to optimize the current available systems. Obstacles to overcome, specific to complex build geometries, include both interior and exterior accommodations. External errors include: staircase/rastering effects, cure approximation errors, top/bottom skins and start-stop errors [34]. Internal errors, more directly effecting thru-thickness thermal conductivity measurements, include: proper alignment of contour and internal vector 
path overlap resulting in air voids, inadequate material flow during material deposition processes [34].

Numerous quantitative exercises have been enacted to in effort to quantify these polymer-metal composites. However, various approximations and estimations were utilized for account unknown values. Specifically, the purity and/or specific alloy of each metallic is not quantified. Thus, base metallic constituent thermal conductivity (e.g. $\left.\lambda_{\text {Copper, }} \lambda_{\text {Bronze, }} \lambda_{\text {Magnetic, }} \lambda_{\text {Stainless }}\right)$ approximations could be incorrect. For example, austenitic vs. ferritic stainless steel may have vastly difference thermal conductivities. Furthermore, oxide layers present on the surfaces of the metallic constituents would hinder the ability to transfer thermal energy effectively. SEM imaging coupled with electron dispersive spectroscopy (EDS) enabled the ability to quantify the presence of oxide formation. An Oxford INCA PentaFETx3 EDS detector coupled with the previously discussed ESEM allowed for this analysis. Representative particle morphology of an analyzed metallic particle cross section is shown in Figure 3.16. Represented in Figure 3.16. is a CopperFill metallic powder sample.

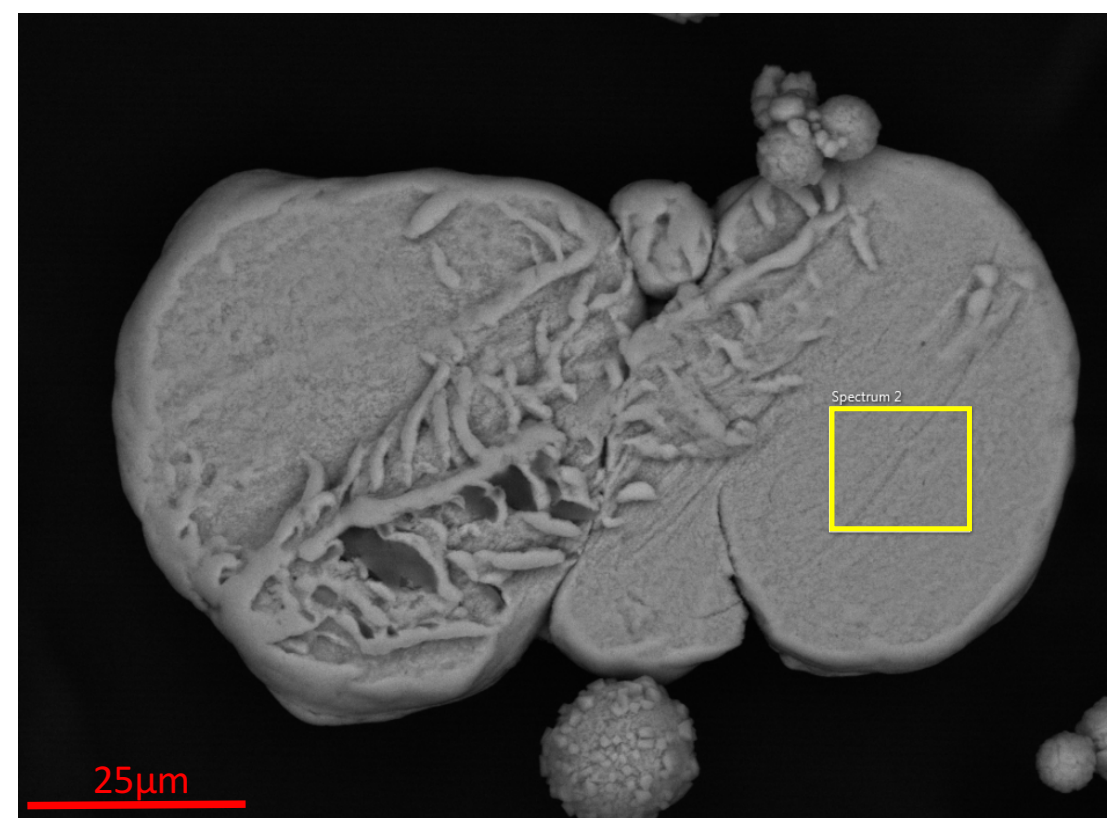

Figure 3.16. Representative CopperFill metallic particle constituent utilized for EDS chemical analysis. Drawn box presents EDS scanning region on the particulate. 
Un-normalized qualitative spectra results are shown in Table 3.12 - 3.15 for each metallic constituent analyzed. In each circumstance, primary alloying additions are realized. Moreover, the presence of surface oxide is not abundantly shown.

CopperFill metallic constituents, at a maximum, shown critical k series peak for oxygen quantified at 2.8 weight percent.

Table 3.12. Qualitative EDS spectra on CopperFill metallic constituent. Displayed results are not normalized

\begin{tabular}{|c|c|c|}
\hline Element & K Ratio & Wt. \% \\
\hline $\mathrm{O}$ & 0.007 & 2.8 \\
\hline $\mathrm{P}$ & 0.001 & 0.32 \\
\hline $\mathrm{Cu}$ & 0.986 & 99.32 \\
\hline TOTAL & - & $\mathbf{1 0 2 . 4 4}$ \\
\hline
\end{tabular}

Table 3.13. Qualitative EDS spectra on BronzeFIll metallic constituent. Displayed results are not normalized

\begin{tabular}{|c|c|c|}
\hline Element & K Ratio & Wt. \% \\
\hline $\mathrm{Cu}$ & 0.878 & 88.41 \\
\hline $\mathrm{Sn}$ & 0.062 & 7.45 \\
\hline TOTAL & - & $\mathbf{9 5 . 8 7}$ \\
\hline
\end{tabular}

Table 3.14. Qualitative EDS spectra on Magnetic Iron PLA metallic constituent. Displayed results are not normalized

\begin{tabular}{|c|c|c|}
\hline Element & K Ratio & Wt. \% \\
\hline Fe & 0.985 & 95.83 \\
\hline TOTAL & - & $\mathbf{9 5 . 5 3}$ \\
\hline
\end{tabular}

Table 3.15. Qualitative EDS spectra on Stainless Steel PLA metallic constituent. Displayed results are not normalized

\begin{tabular}{|c|c|c|}
\hline Element & K Ratio & Wt. \% \\
\hline $\mathrm{Al}$ & 0.001 & 0.54 \\
\hline $\mathrm{Si}$ & 0.002 & 0.7 \\
\hline $\mathrm{Cr}$ & 0.181 & 16.2 \\
\hline $\mathrm{Fe}$ & 0.604 & 63.76 \\
\hline $\mathrm{Ni}$ & 0.115 & 14.31 \\
\hline $\mathrm{Mo}$ & 0.016 & 2.54 \\
\hline TOTAL & - & $\mathbf{9 8 . 0 4}$ \\
\hline
\end{tabular}


Metal polymer filament composites, as described in these analysis, have a limited supply on the open market. Few manufactures readily develop composite filament materials for thermal applications. Numerous investigations have developed understandings of electrically conductive polymers suited for FFF [40, 41]. However, thermal applications specific to thermal conductivity are limited at this time. Custom manufactured filaments utilizing semi-automated recyclebot technology [42] can be investigated, which can use post-consumer thermoplastics [43]. Design of the recylebot technology is feasible to suggest the potential application to the material development of composite materials. A proof of concept, in this realm, could yield vast advancements in polymer and powdered metal recycling capabilities. Specific to the industrial 3-D printing/additive manufacturing sphere, powdered metal is readily available as a waste product. Generally, the nominal particle size of the metallic powder deviation and the smooth sphere morphology is distorted as result of continual re-use [44]. The deviated particle will begin to degrade the mechanical performance of the printed components. Large particles sizes typically result in porosity and edge contour gaps relative to the internal microstructure. Thus, unuseable powdered materials could be combined with recycled plastic filament to yield recycled metal polymer composites for $3-D$ printing.

\subsection{Conclusions}

Porosity coupled with lack of sufficient metal constituent cross section resulted in degraded thermal conductivity performance. Current manufacturing and secondary processing techniques have shown to increase the thermal conductivity of the matrix of CopperFill, BronzeFill, magnetic iron PLA and stainless steel PLA by $81.28 \%$, $98.81 \%, 45.66 \%$ and $71.51 \%$, respectively. While non-ideal results have surmounted after rigorous analysis, a proof of concept has been proposed. However, further work is required to maximize the metallic filler volume percent and thus increase available sites for thermal transfer. Using recyclable metal powder materials, recylebot technologies aim to develop custom composite materials with various metallic filler volume percentages. Also, quantitative volume fraction determination requires further advancement, including appropriate model fittings. The utilized thermodynamic models do not properly model an FFF printed sample polylactic acid - metal composite in their current state. Future work is needed to 
properly represent the irregular air void fraction shape, layer to layer interface mechanisms, and percolation site probability / random dispersion of metallic powder. Secondary processing mechanisms, specifically CIP, have been shown to be capable of decreasing printed matrix porosity. Further CIP development needs to occur to reduce the geometric shift (i.e. warp during the process).

\subsection{Acknowledgements}

The authors would like to acknowledge technical assistance from $G$. Anzalone and P. Fraley and support from Aleph Objects, Inc. and the ARPA-E ARID program.

\subsection{References}

[1] Sells, E., Smith, Z., Bailard, S., Bowyer, A., \& Olliver, V. (2010). RepRap: the replicating rapid prototyper: maximizing customizability by breeding the means of production. Handbook of Research in Mass Customization and Personalization, Forthcoming.

[2] Jones, R., Haufe, P., Sells, E., Iravani, P., Olliver, V., Palmer, C., \& Bowyer, A. (2011). RepRap-the replicating rapid prototyper. Robotica, 29(01), 177-191. doi: $10.1017 / \mathrm{S} 026357471000069 \mathrm{X}$

[3] Bowyer, A. (2014). 3D Printing and Humanity's First Imperfect Replicator. 3D printing and additive manufacturing, 1(1), 4-5. doi: 10.1089/3dp.2013.0003

[4] Rundle, G. (2014). A Revolution in the Making. Simon and Schuster.

[5] Moilanen, J., \& Vadén, T. (2012). Manufacturing in motion: first survey on 3D printing community. Statistical Studies of Peer Production, 1, 6.

[6] Irwin, J. L., Oppliger, D. E., Pearce, J. M.,Anzalone, G. (2015) Evaluation of RepRap 3D Printer Workshops in K-12 STEM. 122nd ASEE 122nd ASEE Conf. Proceedings. Paper ID\#12036, 2015.

[7] Gebler, M., Uiterkamp, A. J. S., \& Visser, C. (2014). A global sustainability perspective on 3D printing technologies. Energy Policy, 74, 158-167. doi: 10.1016/j.enpol.2014.08.033

[8] Pearce, J. M., Blair, C. M., Laciak, K. J., Andrews, R., Nosrat, A., \& ZelenikaZovko, I. (2010). 3-D printing of open source appropriate technologies for 
self-directed sustainable development. Journal of Sustainable Development, $3(4), 17$.

[9] Lipson, H., \& Kurman, M. (2013). Fabricated: The new world of 3D printing. John Wiley \& Sons.

[10] Berman, B. (2012). 3-D printing: The new industrial revolution. Business horizons, 55(2), 155-162. doi: 10.1016/j.bushor.2011.11.003

[11] Laplume, A., Anzalone, G. C., \& Pearce, J. M. (2015). Open-source, selfreplicating 3-D printer factory for small-business manufacturing. The International Journal of Advanced Manufacturing Technology, 1-10. doi: $10.1007 / \mathrm{s} 00170-015-7970-9$

[12] Masood, S. H., \& Song, W.Q. (2004) . Development of new metal/polymer materials for rapid tooling using fused deposition modeling..Materials \& Design, no.7, 587-694. doi: 10.1016/j.matdes.2004.02.009

[13] Hopkinson, N., \& Dicknes, P. (2003). Analysis of rapid manufacturing-using layer manufacturing processes for production. Proceedings of the Institution of Mechanical Engineers, Part C: Journal of Mechanical Engineering Science, 217(1), 31-39. doi: 10.1243/095440603762554596

[14] Wittbrodt, B. T., Glover, A. G., Laureto, J., Anzalone, G. C., Oppliger, D., Irwin, J. L., \& Pearce, J. M. (2013). Life-cycle economic analysis of distributed manufacturing with open-source 3-D printers. Mechatronics, 23(6), 713-726. doi: 10.1016/j.mechatronics.2013.06.002

[15] Kreiger, M., \& Pearce, J. M. (2013). Environmental life cycle analysis of distributed three-dimensional printing and conventional manufacturing of polymer products. ACS Sustainable Chemistry \& Engineering, 1(12), 15111519. doi: $10.1021 / \mathrm{sc} 400093 \mathrm{k}$

[16] Sa'ude, N., Masood, S.H., Nikzad, M., Ibrahim, M., \& Ibrahim, M.H.I. (2013) Dynamic mechanical properties of copper-ABS- composite for FDM feedstock. International Journal of Engineering Research and Application, 3(3), 257-126. (see also:

http://citeseerx.ist.psu.edu/viewdoc/download?doi=10.1.1.418.8269\&rep=re p1\&type $=p d f$ )

[17] Wu, G., Langrana, N. A., Sadanji, R., \& Danforth, S. (2002). Solid freeform fabrication of metals components using fused deposition of metals. Materials and design, 23(1), 97-105. doi: 10.1016/S0261-3069(01)00079-6 
[18] Lee, G. W., Park, M., Kim, J., Lee, J. I., \& Yoon, H. G. (2006). Enhanced thermal conductivity of polymer composites filled with hybrid filler. Composites Part A: Applied Science and Manufacturing, 37(5), 727-734. (see also: http://dx.doi.org/10.1016/j.compositesa.2005.07.006 ).

[19] Wilson, J. L., P. Poddar, N. A. Frey, H. Srikanth, K. Mohomed, J. P. Harmon, S. Kotha, \& J. Wachsmuth. (2004). Synthesis and magnetic properties of polymer nanocomposites with embedded iron nanoparticles. Journal of Applied Physics, 95(3), 1439-1443. doi: 10.1063/1.1637705

[20] Hoque, M. J., Chakraborty, S., Mahbub, M., \& Gafur, M. A. (2013). Thermal Conductivity of Polypropylene Based Composite Materials Filled with Graphite and Carbon Black. International Journal of Composite Materials, 3, 5. doi: 10.5923/j.cmaterials.20130305.04

[21] Tekce, H. S., Kumlutas, D., \& Tavman, I. H. (2007). Effect of particle shape on thermal conductivity of copper reinforced polymer composites. Journal of Reinforced Plastics and Composites, 26(1), 113-121. doi:

$10.1177 / 0731684407072522$

[22] Technical Datasheet copperFill (Eng)-ColorFabb. (Accessed January 24th, 2016) Available from: http://www.colorfabb.com/files/TDS-copperFill-en.pdf

[23] Technical Datasheet bronzeFill-ColorFabb. (Accessed January 24th, 2016) Available from: http://www.colorfabb.com/files/TDS-bronzeFill-en-.pdf

[24] Proto-pasta. "Stainless Steel PLA" (Accessed January 24th, 2016) Available from: http://www.proto-pasta.com/pages/stainless-steel-pla

[25] Proto-pasta. "Magnetic Iron PLA" (Accessed January 24th, 2016) Available from: http://www.proto-pasta.com/pages/magnetic-iron-pla

[26] "Evaluating Thermal Conductivity of Gasket Materials," ASTM Test Method F43302 (Reapproved 2014)

[27] Tymrak, B. M., Kreiger, M., \& Pearce, J. M. (2014). Mechanical properties of components fabricated with open-source 3-D printers under realistic environmental conditions. Materials \& Design, 58, 242-246. doi: 10.1016/j.matdes.2014.02.038

[28] Wittbrodt, B., \& Pearce, J. M. (2015). The effects of PLA color on material properties of 3-D printed components. Additive Manufacturing, 8, 110-116. doi: 10.1016/j.addma.2015.09.006 
[29] Rasband, W.S., Image], U.S. National Institutes of Health, Bethesda, Maryland, USA, http://imagej.nih.gov/ij/, 1997-2015.

[30] Operating Instructions. "Mettler Toledo 33360+210260 Density determination kit". (Accessed Janurary 24th, 2016).

[31] Product Information. "Dow Corning $® 340$ Heat Sink Compound TDS" (Accessed May 9th, 2015) Available from: http://www.dowcorning.com/DataFiles/090276fe801904dc.pdf

[32] King, J. A., Johnson, B. A., Via, M. D., \& Ciarkowski, C. J. (2010). Effects of carbon fillers in thermally conductive polypropylene based resins. Polymer Composites, 31(3), 497-506. doi: 10.1002/pc.20830

[33] Mamunya, Y. P., Davydenko, V. V., Pissis, P., \& Lebedev, E. V. (2002). Electrical and thermal conductivity of polymers filled with metal powders. European polymer journal, 38(9), 1887-1897. doi: 10.1016/S0014-3057(02)00064-2

[34] Agarwala, M. K., Jamalabad, V. R., Langrana, N. A., Safari, A., Whalen, P. J., \& Danforth, S. C. (1996). Structural quality of parts processed by fused deposition. Rapid Prototyping Journal, 2(4), 4-19. doi: $10.1108 / 13552549610732034$

[35] Smith, D. S., Alzina, A., Bourret, J., Nait-Ali, B., Pennec, F., Tessier-Doyen, N., Otsu, K., Matsubara, H., Pierre, E., Gozenbach, U. T. (2013) Thermal conductivity of porous materials. Journal of Materials Research, 28(17), 22602272. doi: $10.1557 / j m r .2013 .179$

[36] Landauer, R. (1952). The electrical resistance of binary metallic mixtures. Journal of Applied Physics, 23(7), 779-784.

[37] Tsotsas, E., \& Martin, H. (1987). Thermal conductivity of packed beds: a review. Chemical Engineering and Processing: Process Intensification, 22(1), 19-37. doi: 10.1016/0255-2701(87)80025-9

[38] Atkinson, H. V., \& Davies, S. (2000). Fundamental aspects of hot isostatic pressing: an overview. Metallurgical and Materials Transactions A, 31(12), 2981-3000. doi: 10.1007/s11661-000-0078-2

[39] Technical data sheet Bio-Flex-ColorFabb. (Accessed January 24th, 2016) Available from: http://www.colorfabb.com/files/FKUR/TD_BIOFLEX_V_135001_en.pdf

[40] Czyżewski, J., Burzyński, P., Gaweł, K., \& Meisner, J. (2009). Rapid prototyping of electrically conductive components using 3D printing technology. Journal of 
Materials Processing Technology, 209(12), 5281-5285. doi:

10.1016/j.jmatprotec.2009.03.015

[41] Leigh, S. J., Bradley, R. J., Purssell, C. P., Billson, D. R., \& Hutchins, D. A. (2012). A simple, low-cost conductive composite material for 3D printing of electronic sensors. PloS one, 7(11), e49365. doi:

$10.1371 /$ journal.pone.0049365

[42] Baechler, C., DeVuono, M., \& Pearce, J. M. (2013). Distributed recycling of waste polymer into RepRap feedstock. Rapid Prototyping Journal, 19(2), 118125. doi: $10.1108 / 13552541311302978$

[43] Hunt, E. J., Zhang, C., Anzalone, N., \& Pearce, J. M. (2015). Polymer recycling codes for distributed manufacturing with 3-D printers. Resources, Conservation and Recycling, 97, 24-30. doi: 10.1016/j.resconrec.2015.02.004

[44] Tang, H. P., Qian, M., Liu, N., Zhang, X. Z., Yang, G. Y., \& Wang, J. (2015). Effect of powder reuse times on additive manufacturing of Ti-6Al-4V by selective electron beam melting. Jom, 67(3), 555-563. doi: 10.1007/s11837015-1300-4 


\section{4 - Open Source Multi-head 3-D Printer for Polymer-Metal Composite Component Manufacturing ${ }^{5}$}

\subsection{Abstract}

As low-cost desktop 3-D printing is now dominated by free and open source selfreplicating rapid prototype (RepRap) derivatives there is an intense interest in extending the scope of potential applications to manufacturing. This study describes a manufacturing technology that enables a constrained set of polymer-metal composite components. This paper provides 1 ) free and open source hardware and 2) software for printing systems that achieves metal wire embedment into a polymer matrix 3-D printed part via a novel weaving and wrapping method using 3) OpenSCAD and parametric coding for customized gcode commands. Composite parts are evaluated from a technical viability of manufacturing and quality. The results show that utilizing a multi-polymer head system for multi component manufacturing reduces manufacturing time and reduces the embodied energy of manufacturing. Finally, it is concluded that an open source software and hardware tool chain can provide low-cost industrial manufacturing of complex metal-polymer compositebased products.

\subsection{Introduction}

The increased utilization [1,2] of self-replicating rapid prototypers (RepRap) 3-D printers $[3,4]$ using fused filament fabrication (FFF) (material extrusions by ASTM F2792-12a: Standard Terminology for Additive Manufacturing Technologies) [5], has increased the engineering applications of polymer extrusion materials. Printable polymer material characterization has increased the knowledge available to engineers for common PLA and ABS materials [6-9] along with an increasing list of

\footnotetext{
${ }^{5}$ The material contained in this chapter is currently in review for publication with Technologies
} 
thermoplastics $[10,11]$, polymer metal composite materials [12-14], and polymer ceramic composite materials [15-18] for a number of novel applications including medical and health-related components [19-23]. Subsequently, advancements in material understanding has led to the development of more sophisticated RepRap machines. Currently, multi-head printers (typically two hot ends) are readily available from re:3D, Aleph Objects, Prusa Research and other open source 3-D printer manufacturers and distributed designs are downloadable with creative commons and GPL licenses from the RepRap wiki and internet repositories of 3-D designs Multi-head printers allow for multi-color printing to achieve aesthetic requirements and/or multi-material manufacturing of the same work piece [24]. Commonly sacrificial material (e.g. polyvinyl alcohol) is utilized as a supporting material to be easily removed during post-processing [25]. Recently, Ma et al. developed processing techniques to manufacture heterogeneous structures / composites using thin wall mold cavities and reusable multipart molds by combining shape deposition manufacturing (SDM), FFF and casting [26]. Furthermore, while still in early stages of development, metal printing RepRap's provide a partial step towards full adoption of additive manufacturing techniques [27] and multi-material selection in 3-D manufacturing [28-32] to accommodate future requirements of material quality, design for manufacturing, processing monitor and achievement of near net shape [33]. Further expanding the RepRap machine customization is the advent of Franklin [34], an open-source 3D printing control software. Franklin's application to a variety of RepRap applications has been shown including: laser welding of HDPE polymer sheet [35], multi-material additive and subtractive fabrication [36], printed components for small organic farms [37] and voltage monitoring of GMAW (gas metal arc welding) metal-based RepRap Delta printer [38]. Multi-material 3-D printers including those able to fabricate with composite materials such as, fibre reinforced polymer materials have been academically researched by Quan et al. [39]. Furthermore, similar to the application to be described, are numerous applications of metal wire embedment into a primarily polymer matrix [40]. Recent investigative research has provided insight to copper wire encapsulation of copper for electronic sensing [41], tool path planning for wire embedment on FFF printed curved surfaces [42], metal fiber encapsulation for electromechanical robotic components [43], flexible printed circuit boards (PCB) for structural electronic 
devices [44], and open-source 3-D printing CAD/CAM software for quality function deployment (QFD) and theory of inventive problem solving (TRIZ) optimization [45]

To further the scope of potential applications of RepRap manufacturing, this paper aims to describe a manufacturing technology that accomplishes a partial step forward to true multi-material selection. This paper provides free and open source hardware and software for printing systems that achieves metal wire embedment into a polymer matrix 3-D printed part via weaving and wrapping procedures. In addition, a method utilizing OpenSCAD and parametric coding, is provided that enables customized gcode commands to be developed for a given component design and material selection. Then upon fixture placement, this method enables weaving and wrapping procedures by gcode line entries after each successive polymer layer deposition to create metal matrix composites. These composite parts are then evaluated from a technical viability of manufacturing and quality. Specifically, to identify the advantages of utilizing a multi-polymer head system for multi component manufacturing time studies are to be conducted and compared to traditional singlehead per material manufacture of the same part. In addition, the metal/polymer interface bond strength is quantified with a burst pressure measurement. The results are presented and discussed in the context of low-cost distributed manufacturing of complex metal-polymer composites.

\subsection{Materials and Methods}

\subsubsection{Fabrication of the Gigabot for Multihead Metal-Polymer Composite Printing}

A re:3D Gigabot 3.0 3-D printer [46] was modified for the development of the metal polymer matrix apparatus. The printing system utilizes a gantry system to accommodate five extruder nozzles and $x$-axis directional commands. A single NEMA 17 stepper motor with 20 tooth GT2 pulleys control the movement of the $x$-axis. The $y$-axis commands are controlled by two NEMA 17s, one at each end of the gantry length. Similar to the $y$-axis, the z-axis movement is controlled by two NEMA $17 \mathrm{~s}$ at opposite sides of the $60 \times 60 \mathrm{~cm}(\mathrm{XY})$ build platform. Both $z$-axis and $y$-axis commands are sent to a NEMA 17 and replicated by the 'follower' second motor 
based upon the provided g-code. The printer is constructed with 80-20 extruded aluminum with bolts, nuts, fittings, threaded rods and brackets where required following re:3D standard design. Figure 4.1 pictorially describes the printing apparatus to be discussed. Described are the relative locations of extruder/directional motors along with hot end locations on the $\mathrm{X}$-axis gantry and electrical control board mounting locations.

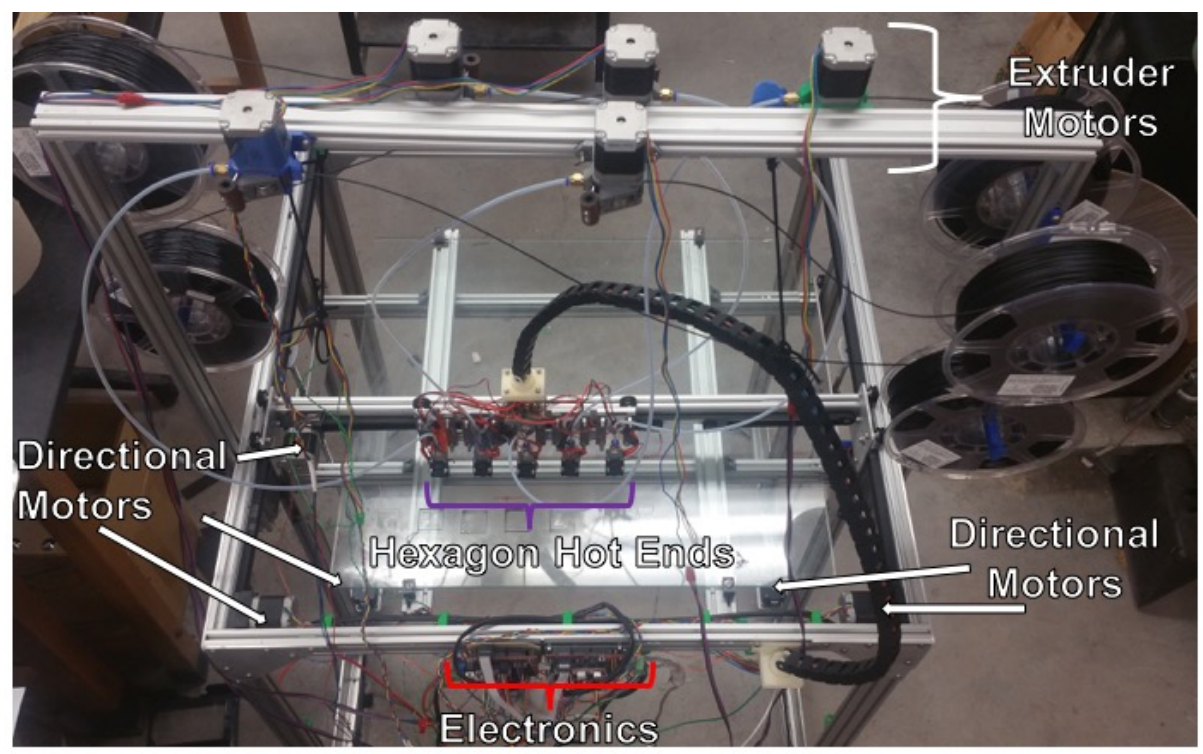

Figure 4.1. Complete manufactured metal-polymer composite Gigabot. Primary electromechanical components and their respective mounting locations are identified

Plastic 3-D printed components needed for the assembly are shown in Table 4.1. They were obtained through, Thingiverse, a collaborative online maker space with downloadable component files (indicated by thing number in Table 4.1) or custom designed in OpenSCAD [47], a parameter modeling computer aided design (CAD) software. Designed or downloaded part files were printed with polylatic acid (PLA) on either a MOST delta RepRap or a Lulzbot 5.0. Component design, coding and printing parameters allowed for easy modification, development, decreased print time and economical use of filament material. All part files (.scad/.stl), Table 4.1, designed by MOST in OpenSCAD are available for download [49] under the GNU GPLv3 [50]. Secondly, the complete bill of materials including metric type accessory components and electrical components are displayed in Table 4.2 and 4.3, respectively. Operational and installation instructions are available online at Appropedia [51]. 
Table 4.1. Metal-Polymer Composite Gigabot Printed / Structural Components

\begin{tabular}{|c|c|c|c|c|c|}
\hline Part Name & Count & $\begin{array}{c}\text { Rendered } \\
\text { Image }\end{array}$ & Part Name & Count & $\begin{array}{c}\text { Rendered } \\
\text { Image }\end{array}$ \\
\hline $\begin{array}{c}\text { Extruder } \\
\text { Mount Bracket }\end{array}$ & 5 & & $\begin{array}{c}\text { Z-Height End } \\
\text { Stop } \\
\text { Solenoid } \\
\text { Mount }\end{array}$ & 2 & \\
\hline $\begin{array}{l}\text { Z-Height Bed } \\
\text { Leveling } \\
\text { Adjustment }\end{array}$ & 5 & & $\begin{array}{c}\text { 80/20 Wire } \\
\text { Guides }\end{array}$ & 10 & \\
\hline $\begin{array}{c}\text { Z-Height Bed } \\
\text { Leveling } \\
\text { Dovetail } \\
\text { Mounts }\end{array}$ & 5 & & $\begin{array}{c}\text { Gantry Cable } \\
\text { Supports }\end{array}$ & 3 & \\
\hline $\begin{array}{c}\text { Filament } \\
\text { Spool Holders } \\
\text { thing: } 1269563\end{array}$ & 6 & & $\begin{array}{l}\text { Build Plate } \\
\text { Fixturing } \\
\text { Brackets }\end{array}$ & 4 & \\
\hline $\begin{array}{c}\text { 80-20 M4 T- } \\
\text { Slot Mount } \\
\text { thing: } 1061769\end{array}$ & 2 & & $\begin{array}{c}\text { Hexagon Hot } \\
\text { end Fan } \\
\text { Mount }\end{array}$ & 5 & \\
\hline $\begin{array}{l}\text { Z-Height Z1 } \\
\text { and Z0 } \\
\text { Leveling } \\
\text { Screw Knob }\end{array}$ & 2 & & $\begin{array}{l}\text { MOST } \\
\text { Bowden } \\
\text { Extruder } \\
\text { Drive }\end{array}$ & 5 & \\
\hline $\begin{array}{l}\text { Gantry Mount } \\
\text { Cable Carrier } \\
\text { Connection }\end{array}$ & 1 & & $\begin{array}{l}\text { Arduino } \\
\text { Mega } 250 \\
\text { Mount } \\
\text { Bracket }\end{array}$ & 1 & \\
\hline
\end{tabular}




Customized
I/O Board
Mount Bracket

Table 4.2. Metal-Polymer Composite Gigabot mechanical bill of materials

\begin{tabular}{|c|c|c|c|}
\hline Part Description & Count & Source & $\begin{array}{c}\text { Serial / Pat } \\
\text { Number }\end{array}$ \\
\hline $\begin{array}{c}\text { GT2 } 3 \text { MR 9mm } \\
\text { Wide }\end{array}$ & $1(15 \mathrm{ft})$ & Gates & - \\
\hline GT2 Timing Pulley & 3 & Gates & - \\
\hline $\begin{array}{c}9 \mathrm{~mm} \text { Idler Pulley } \\
\text { with } 625-2 \mathrm{RS} \\
\text { bearings }\end{array}$ & 3 & re:3D & - \\
\hline $\begin{array}{c}\text { M5x8 Button } \\
\text { Head Cap Screws } \\
\text { Hexagon Full }\end{array}$ & 100 & BoltDepot.com & - \\
\hline $\begin{array}{c}\text { Metal Hot-End } \\
1.75 \mathrm{~mm}, 12 \mathrm{~V} \\
\text { Cyclemore }\end{array}$ & 5 & IC3D - Hexagon & XOOOSVOTON \\
\hline $\begin{array}{c}1.0 \mathrm{~mm} \text { Brass } \\
\text { Nozzle }\end{array}$ & 5 & Cyclemore & X000WJAXH5 \\
\hline $\begin{array}{l}\text { PC4-M6 Push-In } \\
\text { Fitting }\end{array}$ & 10 & Cyclemore & $\begin{array}{c}\text { 30-60007-016- } \\
\text { FBA }\end{array}$ \\
\hline $\begin{array}{c}53 \text { Link Cable } \\
\text { Carrier }\end{array}$ & 1 & $\operatorname{Re}: 3 D$ & - \\
\hline
\end{tabular}


Teflon (PTFE)

Bowden Tube

$1.75 \mathrm{~mm}(2.0 \mathrm{~mm}$ -

ID / 4.0mm OD)

3/8" - 8 ACME

Threaded Rods

V-Grove Roller

Bearings

$67 \times 60 \mathrm{~mm}$

Annealed Glass

Build Plate

80-20 Series 20

T-Slot Nuts

Threaded Rod Z-

Nut Cup

2

re:3D

20

$\operatorname{Re}: 3 D$

1

Locally sourced

MXL 18 Tooth

Motor Pulley

100

re:3D

MXL 36 Tooth

Motor Pulley

(Threaded Rod)

Z-Axis MXL Belt

Aluminum Side

Plate

re:3D

2

re:3D

2

re:3D

2

re:3D

4

re:3D

Aluminum Corner

$$
\text { Plate }
$$

re:3D

Rectangular

Brackets for

Extruder Motor

Gantry

$3 \times 9 \mathrm{~mm}$ Stainless

18-8 Washer

100

DIY: Gigabot

Parts Kit

M2 Hex Nut

1

100

Eccentric Wheel

Spacer

Z-Motor Shelf

Truck Plates (L/R)

Thermal Tape

A4988 Pololu

Heat Sink

4

2

2

10

10
BoltDepot.com

7319

re:3D

re:3D

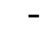

BoltDepot.com

re:3D

re:3D

re:3D

adafruit

1468 
Table 4.3. Metal-polymer Composite Gigabot electrical components

\begin{tabular}{ccc}
\hline Part Description & Count & Source \\
\hline NEMA 17 Stepper & 10 & - \\
Motor & 2 & - \\
RAMPS 1.4 & 10 & - \\
A4988 Pololu Driver & 1 & - \\
Arduino 250 Mega & 1 & - \\
Custom I/O Board & 1 & - \\
12V Power Supply & 1 & - \\
36V Power Supply & 5 & re:3D \\
End Stop Solenoid & & \\
Limit Switches &
\end{tabular}

The $x$-axis gantry is installed with five full metal $1.75 \mathrm{~mm}$ Hexagon hot ends [52] spaced $55 \mathrm{~mm}$ apart. Spacing of the hot-end is controlled by two manufactured aluminum plate measuring $3.175 \mathrm{~mm} \times 25.400 \mathrm{~mm} \times 295.75 \mathrm{~mm}$. The $55 \mathrm{~mm}$ spacing is driven by the placement of the z- leveling dovetail mounting points. The aluminum plates and z-leveling dovetails are fixture by the application of M5 bolts and roller bearings. The printed hexagon mounting fixture is a tongue and groove design allowing for independent z-axis leveling with adjustment of an M3 set screw i.e. each extruder nozzles is individually leveled to the build platform. This allows for replicate parts to be simultaneously printed assuming gcode commands do no exceed the $55 \mathrm{~mm}$ spacing machine constraint. Figure 4.2 displays the $\mathrm{x}$-gantry mounting system. 


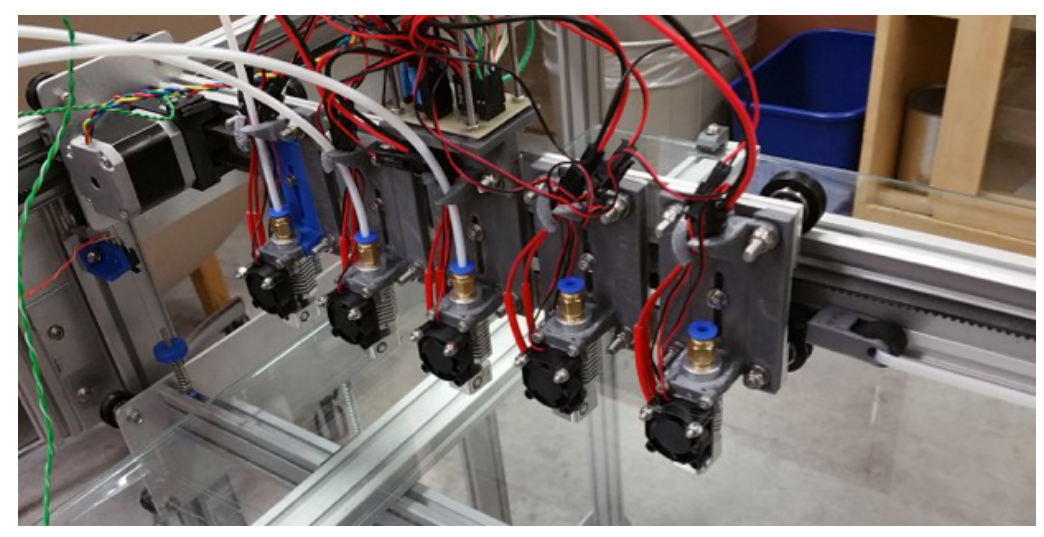

Figure 4.2. X-axis gantry assembly. 5x Hexagon Full-Metal $12 \mathrm{~V}$ hot ends are shown fixture to their respective 'Z-Height Bed Leveling Adjustment' part file. As shown, dovetail leveling mechanisms are attached to the machined aluminum plate $(3.175 \mathrm{x}$

$25.4 \times 295.75 \mathrm{~mm}$ ) with Hexagon nozzle diameter cylindrical axis spaced $55 \mathrm{~mm}$

The five hexagon hot ends are provided filament through Bowden sheaths constructed from $4 \mathrm{~mm}$ OD ( $2 \mathrm{~mm}$ ID) pressure fitting compatible polytetrafluoroethylene (PTFE) flexible tubing. The Bowden extruder system decreases the weight on the $x$-axis gantry thus allowing for faster and more accurate prints. Decreased weight on the x-axis gantry is also advantageous as it will decrease the likely hood of the single $x$-axis NEMA 17 skipping leading to a loss of positioning. The Bowden extruder bodies, NEMA 17s and assembly structures are mounted to the secondary elevated gantry. M5 and t-slot nuts allow proper fixture to the secondary 80-20 aluminum gantry. Figure 4.3 provides further details of the five extruder motors installed on the gantry along with a close up image of the extruder motor assembly. Furthermore, the feed filament is spooled adjacent to its respective extruder motor. 

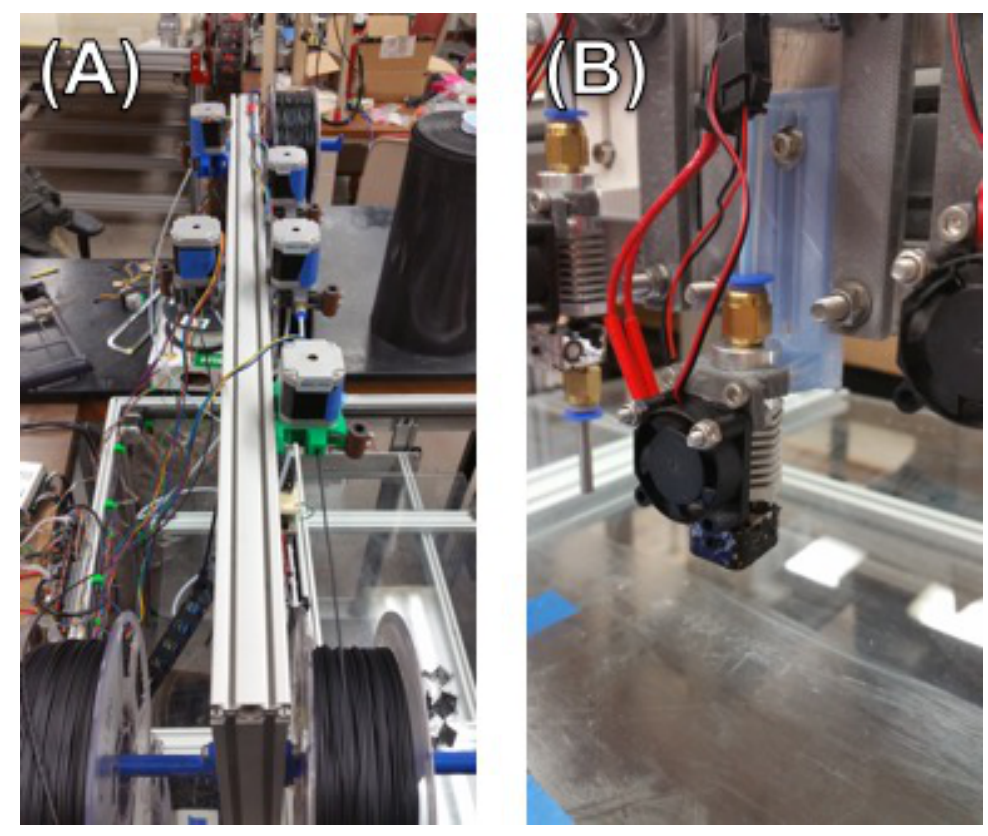

Figure 4.3. а.) Top printer gantry with fixture $x 5$ NEAM 17 exturder drive motors and respective 'MOST Bowden Extruder Drive' printed components, b.) Hexagon Hotend assembly detail with 'Z-Height Bed Leveling Adjustment' dovetails

Additionally, due to the large build platform two z-axis zeroing locations are utilized. Two M5 screws with fitted ergonomic adjustment knobs and tension springs allow for z-axis leveling independently. Upon proper adjustment, the x-axis gantry extruders can be leveled to the build platform. Figure 4.4 displays the leveling system. 

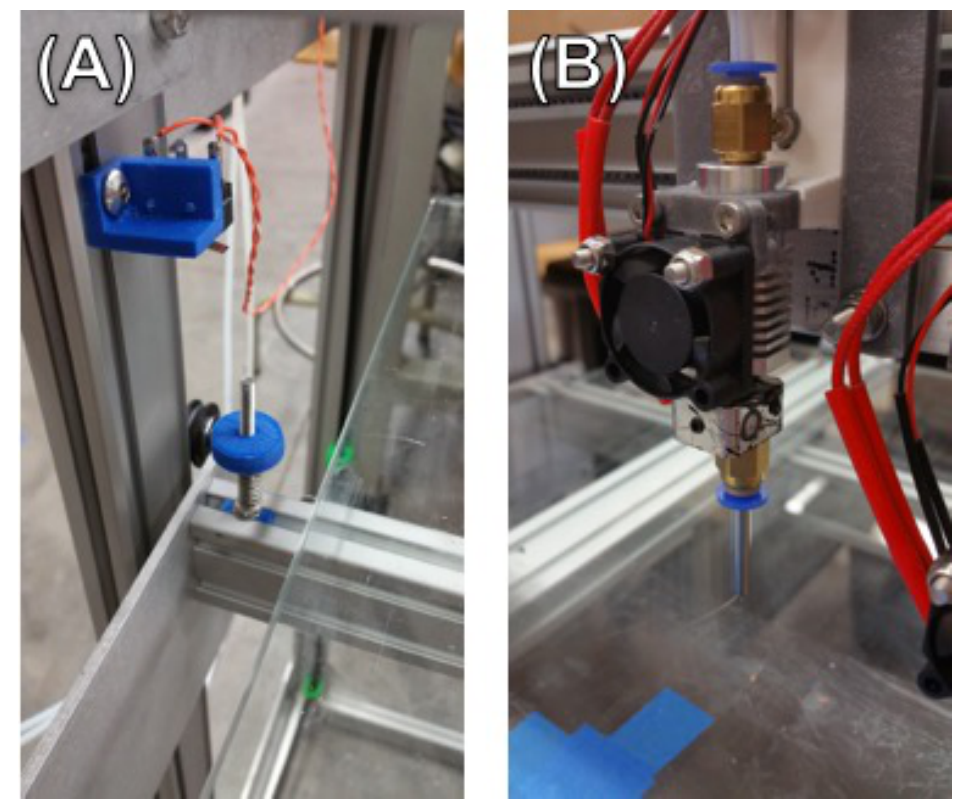

Figure 4.4. a.) Bed platform Z-height leveling. Shown are 'Z-Height End Stop Solenoid Mount', 80-20 M4 T-Slot Mount thing:1061769' and 'Z-Height Z1 and Z0

Leveling Screw Knob' fixture to 80-20 aluminum rails with M5 nuts, b) Height adjustment assembly shown at the maximum height adjustment in contrast to Figure 4.2(a)

\subsubsection{Circuit Assembly and Printer Control}

To accommodate the quantity of NEMA 17 stepper motors, solenoid end stops, thermistors a custom circuit board enabling application of two RAMPS (RepRap Arduino Mega Polulo Shield) 1.4 [53]. Application of this circuit, as described in Figure 4.5 and Figure 4.6, provides two functional RAMPS 1.4 and subsequent A4988 stepper motor driver carriers [54] from one Arduino Mega 2560 [55]. The KiCadPcbNew 4.0.3 designed I/O board communicates with the secondary RAMPS 1.4 board allowing for the further allocation of pins on the Arduino microcontroller [56]. Pin assignments, as presented in the Franklin printer profile, are shown in Table 4.4 and 5 . The A4988 potentiometers are adjusted to provide $0.6-1.2 \mathrm{mV}$ of potential measured between ground. Each potentiometer is fitted with an aluminum heatsink fixture with thermal tape to aid in temperature control. 

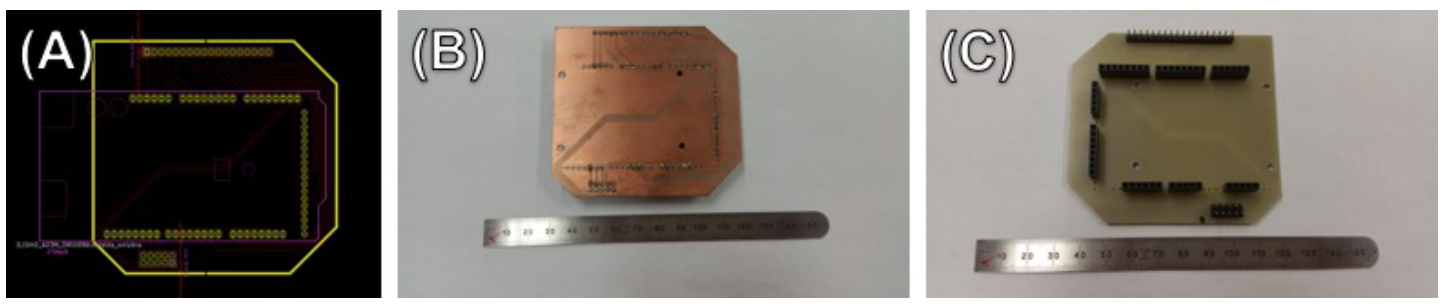

Figure 4.5. a.) Electrical diagram / schematic developed in KiCAD-PcbNew, b.) Milled PCB surface for representation, C.) PCB pin side for representation

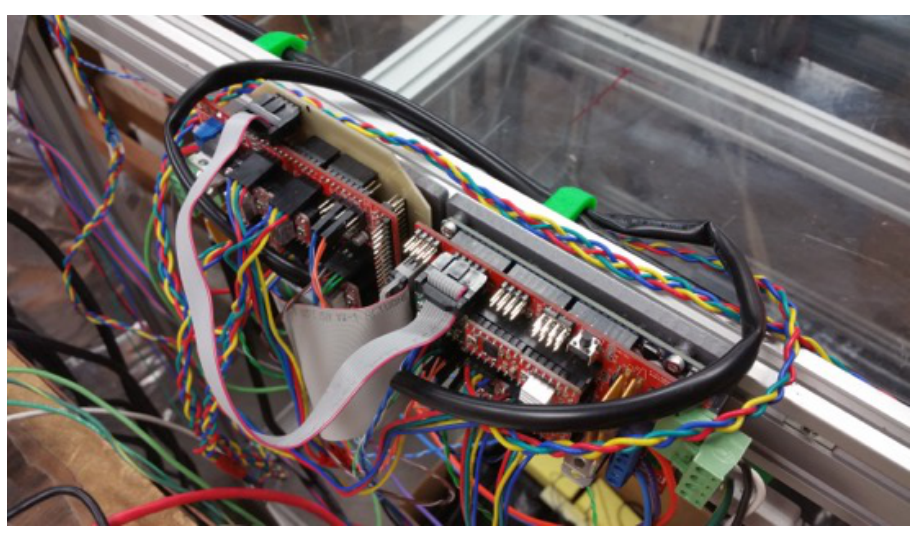

Figure 4.6. Assembled $2 x$ RAMPS 1.4 with Custom I/O PCB per KiCAD-PcbNew specification

Table 4.4. Stepper Motor Pin Assignments ${ }^{6}$

\begin{tabular}{|c|c|c|c|c|c|c|c|c|c|c|}
\hline Pin Type & $X_{D}$ & $\mathbf{Y O}_{\mathrm{D}}$ & $\mathbf{Y} \mathbf{1}_{\mathrm{D}}$ & $\mathbf{Z O}_{\mathrm{D}}$ & $\mathbf{Z} 1_{D}$ & $\mathrm{ExO}_{\mathrm{E}}$ & $\operatorname{Ex1}_{\mathrm{E}}$ & Ex2 $2_{E}$ & $E_{E} 3_{E}$ & $\mathbf{A}_{\mathrm{E}}$ \\
\hline Step & D32 & D60 & D43 & D46 & D37 & D29 & D36 & D26 & D54 & D35 \\
\hline Direction & D47 & D61 & D41 & D48 & D39 & D31 & D34 & D28 & D55 & D33 \\
\hline Enable & D45 & D56 & D45 & D62 & D45 & D45 & D30 & D24 & D38 & D45 \\
\hline $\begin{array}{l}\text { Min } \\
\text { Limit }\end{array}$ & D3 & D14 & D23 & D18 & D0 & DO & DO & DO & Do & DO \\
\hline $\begin{array}{c}\text { Max } \\
\text { Limit }\end{array}$ & D2 & D15 & D25 & D19 & D0 & DO & DO & DO & DO & DO \\
\hline
\end{tabular}

${ }^{6}$ Pin assignments are relative to the A4988 and stepper motors physical location on the RAMPS 1.4. Refer to Figure 5 for specific location details. 
Table 4.5. Hexagon Hot End Arduino Pin Assignments

\begin{tabular}{cccccc}
\hline Pin Type & Ex0 $_{\mathbf{E}}$ & Ex1 $_{\mathbf{E}}$ & Ex2 $_{\mathbf{E}}$ & Ex3 $_{\mathbf{E}}$ & $\mathbf{A}_{\mathbf{E}}$ \\
\hline Heater & $\mathrm{D} 9$ & $\mathrm{D} 10$ & $\mathrm{D} 42$ & $\mathrm{D} 64(\mathrm{~A} 11)$ & $\mathrm{D} 8$ \\
Fan & $\mathrm{D} 0$ & $\mathrm{D} 0$ & $\mathrm{D} 0$ & $\mathrm{D} 0$ & $\mathrm{D} 0$ \\
Thermistor & $\mathrm{A} 14(\mathrm{D} 68)$ & $\mathrm{A} 15(\mathrm{D} 69)$ & $\mathrm{A} 10(\mathrm{D} 64)$ & $\mathrm{A} 12(\mathrm{D} 66)$ & $\mathrm{A} 13(\mathrm{D} 67)$ \\
\hline
\end{tabular}

As indicated in Table 4.5, 24V heater cartridges, cooling fans and thermistors are connected to their respective RAMPS 1.4 positions through a secondary custom I/O board. The I/O board acts as a central hub for all communication to the components on the X-axis gantry. Figure 4.7 identifies the location of this board and the connection points of each component while Figure 4.8 describes the PCB in greater detail.

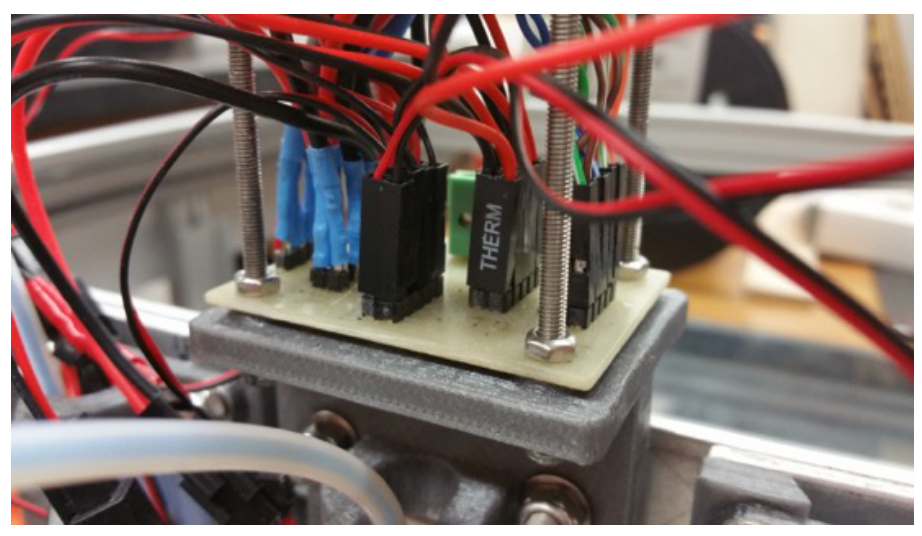

Figure 4.7. Assembled secondary I/O PCB for X-axis gantry components 


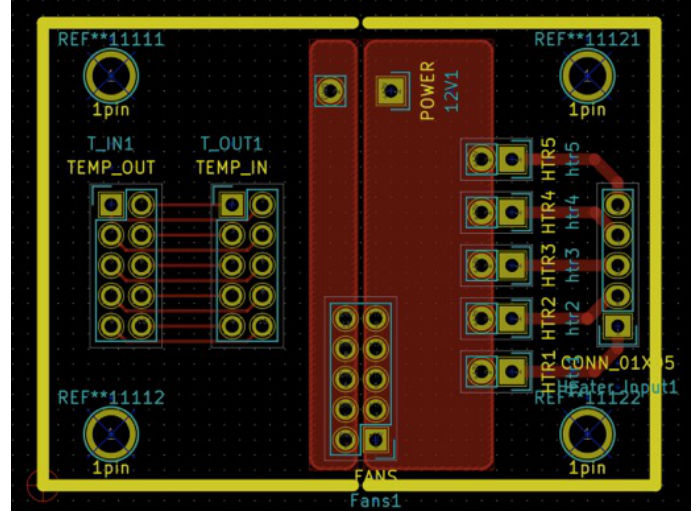

Figure 4.8. Secondary I/O PCB schematic developed in KiCAD-PcbNew. Connection zones are indicated in this image are further described in Figure 4.7 described previously

The Metal-Polymer Composite Gigabot requires two power supplies to meet full operational requirements. As designed, an Input: 110/220V Output: 12V 20A power supply is utilized for thermistor operation. Input: $110 / 220 \mathrm{~V}$ Output: $36 \mathrm{~V} 10 \mathrm{~A}$ power supply enables the operation of both RAMPS 1.4 boards and the secondary custom I/O board. Thus, location, position and extruder motor(s) operate on a separate power supply as compared to the thermistors and heater cartridges.

In total, ten NEMA 17 motors need to be controlled for proper functionality of the printer assembly. Specifically, there is a NEMA 17 assigned to each movement axis as listed; X, Y0, Y1, Z0, Z1, E0, E1, E2, E3 and A. Further functional description of each motor is shown in Table 4.6 along with a qualitative electromechanical process map, shown in Figure 9, indicating primary connection mechanisms hot ends, thermistors, heater cartridges, end stops, extruder motors and directional motors. 
Table 4.6. NEMA 17 Motor Settings and Physical Description

\begin{tabular}{|c|c|c|c|}
\hline $\begin{array}{c}\text { Motor } \\
\left(x_{D}=\text { direction, }\right. \\
\left.x_{\mathrm{e}}=\text { extruder }\right)\end{array}$ & $\begin{array}{c}\text { Coupling } \\
(\text { steps } / \mathbf{m m})\end{array}$ & $\begin{array}{c}\text { Limit } \\
\text { Velocity } \\
(\mathrm{mm} / \mathrm{s}) \\
\end{array}$ & $\begin{array}{l}\text { Limit Acceleration } \\
\qquad\left(\mathrm{mm}^{2} / \mathrm{s}\right)\end{array}$ \\
\hline $\mathbf{X}_{\mathrm{D}}$ & 59.292 & 150 & 250 \\
\hline$Y_{D}$ & 59.292 & 150 & 250 \\
\hline $\mathbf{Y 1}_{\mathbf{D}}$ & 59.292 & 150 & 250 \\
\hline $\mathbf{Z O}_{\mathrm{D}}$ & 2133.333 & 4 & 250 \\
\hline $\mathbf{Z 1}_{\mathrm{D}}$ & 2133.333 & 4 & 250 \\
\hline $\mathrm{ExO}_{\mathrm{E}}$ & 100 & 200 & 1000 \\
\hline$E x 1_{E}$ & 100 & 200 & 1000 \\
\hline $\operatorname{Ex} 2_{E}$ & 100 & 200 & 1000 \\
\hline$E \times 3_{E}$ & 100 & 200 & 1000 \\
\hline $\mathbf{A}_{E}$ & 100 & 200 & 1000 \\
\hline
\end{tabular}

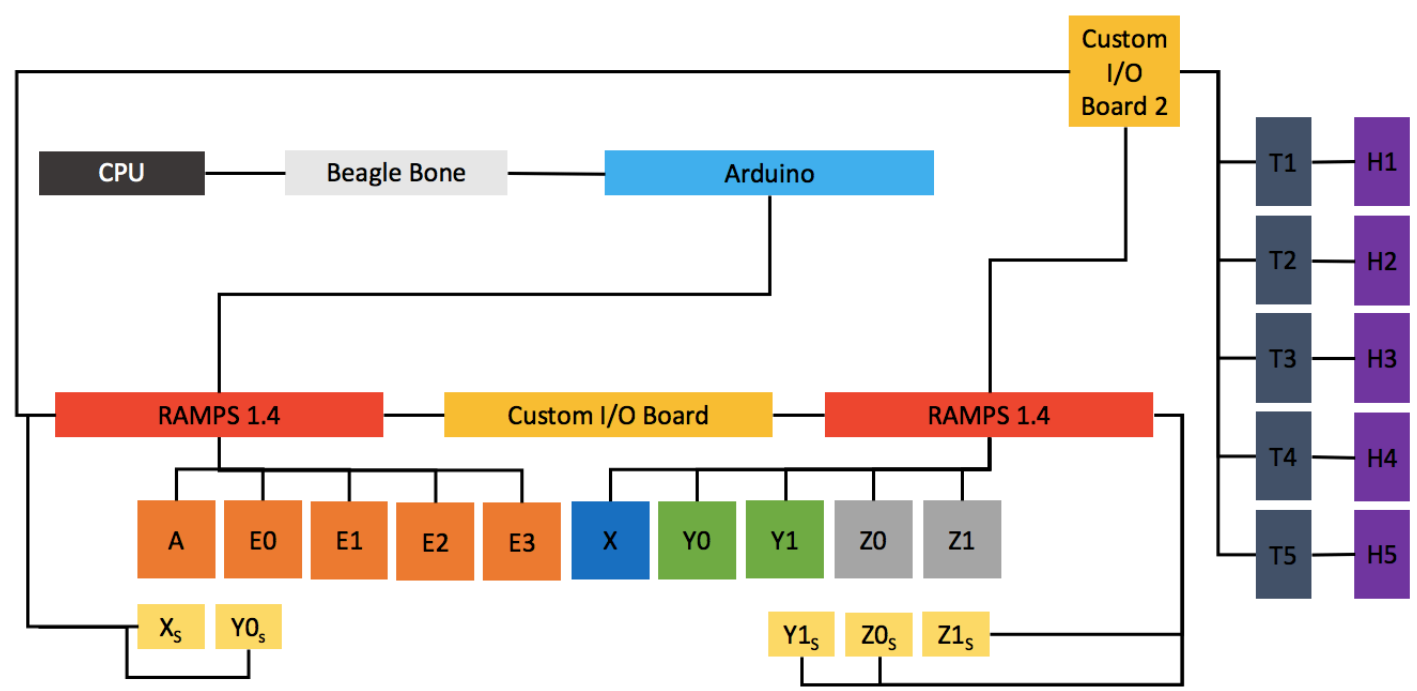

Figure 4.9. Electromechanical process map of the metal-polymer composite Gigabot. This diagram represents a qualitative understanding of the primary connection points between operational mechanisms and electronic controllers. Extruder motors: A, E0, E1, E2, E3. Directional motors: X, Y0, Y1, Z0, Z1. Solenoid end stops: $\mathrm{X}_{\mathrm{S}}, \mathrm{YO}_{\mathrm{S}}, \mathrm{Y} 1_{\mathrm{S}}, \mathrm{Z0_{S }}, \mathrm{Z} 1_{\mathrm{S}}$. Thermistors: T1, T2, T3, T4, T5. Heater cartridges: $\mathrm{H} 1, \mathrm{H} 2, \mathrm{H} 3, \mathrm{H} 4, \mathrm{H} 5$. 
The open-source firmware (Franklin) controls the motion of the printer assembly. The graphic user interface (GUI) of Franklin provides the user with an interface in which to upload G-code and customize printer settings and parameters. G-code and printer settings are communicated to the printer through the host computer into to the controller. Respective g-code is formulated upon the generation of a stereolithography file (e.g. STL file). Print layer g-code was developed with Sli3r 1.2.9 [57]. The resultant g-code is typical such that the application into any RepRap printer should be easily achieved. Uniquely, however, is the Metal-Polymer Composite Gigabot's multiple motors per axis (e.g. Y0/Y1, Z0/Z1 and Ex0/Ex1/Ex2/Ex3). In the current state, Slic3r in unable to individually command multiple extruders and axis motors simultaneously. Subsequently, Franklin allows for motors to be controlled via a "leader and follower" principle. For example, in a printer controlled by Franklin a g-code command of "G1 Y213 Z55" will signal movement of $Y 0 / Y 1$ and $Z 0 / Z 1$ to a relative position of $213 \mathrm{~mm}$ and $55 \mathrm{~mm}$, respectively. In effect, the g-code command pulsed through the controller to the stepper motor is initially recognized by the "leader" (i.e. YO or ZO and henceforth followed and/or replicated by $\mathrm{Y} 1$ or $\mathrm{Z1}$ ). The resultant interaction is duplicate movements by the affected stepper motors. The "leader and follower" principle are also used for the $E x 0_{E}-E x 3_{E}$ extruder motors (i.e. four of the five hotends will extruder the same portion of filament based upon a standard g-code command). In this circumstance, $E x 0_{E}$ is the leader extruder followed by $E x 1_{E}, E x 2_{E}$, and $E x 3_{E}$. Unique to the Metal-Polymer Composite Gigabot machine is extruder AE. Functionally, $A E$, is a directional movement axis which has been modified to be used as an extruder. The proper coupling, limit velocity and acceleration settings in Franklin allow for this change. Separation of AE from ExOE - Ex3E allows for individualized commands within the g-code. Other than " $E$ " commands, Slic3r cannot currently generate extruder commands for different extruders. To introduce " $A$ " commands visual basic applications were utilized to reformat the text of the outputted gcode. Table 4.7 describes a sample operation of this process. 
Table 4.7. Visual Basic G-Code Modifier (Spreadsheet Reference Cell\#)

\begin{tabular}{|c|c|c|}
\hline & Initial G-Code Command Line & $\begin{array}{c}\text { G1 F900 } \\
\text { X143.487 } \\
\text { Y114.988 } \\
\text { E0.51434(A27) } \\
\end{array}$ \\
\hline $\begin{array}{c}\text { Operation } \\
1\end{array}$ & $\begin{array}{l}=\operatorname{IF}(\text { ISNUMBER(SEARCH("G1",A27)), RIGHT( } \\
\text { A27,LEN(A27)-SEARCH("E",A27,1)+1),"NA") }\end{array}$ & E0.51434 \\
\hline $\begin{array}{l}\text { Operation } \\
2\end{array}$ & $\begin{array}{c}=\operatorname{IF}(\text { ISNUMBER(SEARCH("G1",A27)), RIGHT( } \\
\text { A27,LEN(A27)-SEARCH("E",A27,1))," ") }\end{array}$ & $0.51434(E 27)$ \\
\hline $\begin{array}{l}\text { Operation } \\
3\end{array}$ & =IF(ISNUMBER(SEARCH(" ",E27))," ", "A") & $A(F 27)$ \\
\hline $\begin{array}{c}\text { Operation } \\
4\end{array}$ & $=$ CONCATENATE $(F 27, E 27)$ & $A 0.51434(G 27)$ \\
\hline $\begin{array}{l}\text { Operation } \\
5\end{array}$ & $\begin{array}{c}=\text { IFERROR(IF(ISNUMBER(SEARCH(" } \\
\text { ",G27)),A27,CONCATENATE(A27\&" } \\
\text { " \&G27)),A27) }\end{array}$ & $\begin{array}{c}\text { G1 F900 } \\
\text { X143.487 } \\
\text { Y114.988 E.51434 } \\
\text { A0.51434 }\end{array}$ \\
\hline
\end{tabular}

The process described in Table 4.7 is for utilization of all five hot ends for replicate polymer component printing. However, there are applications in which $A E$, may be use independent relative to $\mathrm{EXO}_{\mathrm{E}}-\mathrm{Ex} 3_{\mathrm{E}}$. In these unique circumstances $\mathrm{g}$-code for $A E$ is made separately and then superimposed upon the g-code for $E \times 0_{E}-E \times 3_{E}$ resulting in a composite code.

\subsubsection{Modification of Extruder $A_{E}$ for Wire-Feeding}

A modified Bowden extruder design (thing:275593) was utilized for a wire feeding / guide apparatus. The print assembly and miscellaneous hardware were assembled in a standard manner, however, the MK7 drive gear was inverted. Inversion of the MK7 drive gears allows for a smooth, non-galled, surface to contact the metal wire.

Electrical tape surface coatings were applied to both the $608 \mathrm{zz}$ idler bearing and the smooth end of the MK7 drive gear for grip of a wire. The feed wire spool is mounted near the wire extruder such that top dead center is tangent to the primary axis of the Bowden feed pathway. Figure 4.10 displays the assembled metal wire feeder. Utilizing the same Bowden sheath as would a polymer filament, an 1100 series aluminum wire with a diameter of $0.508 \mathrm{~mm} \pm 0.012 \mathrm{~mm}$ is directed down through a 
Hexagon hot end. In a modified application such as this, the hexagon hot end nozzle has been removed while the main assembly is present to help guide the wire. A M5 pressure fitting, similar to those in the Bowden sheath assembly, are mounted to the hot end in replacement of the $1.0 \mathrm{~mm}$ nozzle. The utilized pressuring fitting allows for installation of a 304 stainless tube with an outer-diameter (OD) of $1.422 \mathrm{~mm}-0.050$ $\mathrm{mm}$ to $+0.101 \mathrm{~mm}$ and inner-diameter (ID) of $2.184 \mathrm{~mm}$. The outer diameter is equivalent to a standard $4 \mathrm{~mm}(\mathrm{OD})$ and secures properly into a $\mathrm{M} 5$ pressure fitting. The ID is substantial enough to allow for passage of the $0.508 \mathrm{~mm}$ diameter wire while also providing room for a PTFE fitting to decrease wire friction while the wire exits the tube. The wire feed guide tube and remaining extruders $\left(E x 0_{E}-E x 3_{E}\right)$ are run simultaneously. Thus, the 304 tubing prior to installation in the pressure fitting is cut to a length of $\sim 46 \mathrm{~mm}$. Thus, all extruder nozzles and wire guide tube can be leveled to the build platform at a similar height. Figure 4.11 displays the assembly of the structure.

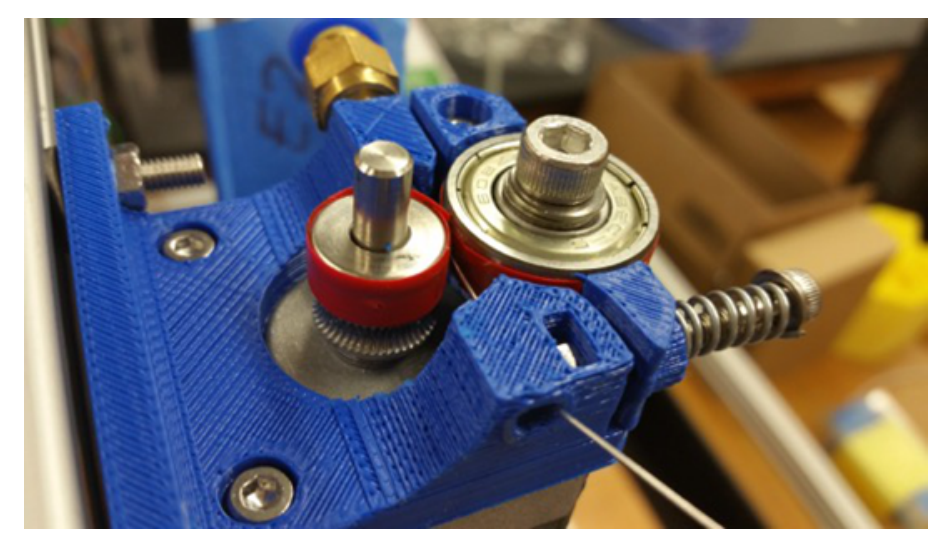

Figure 4.10. Wire feed Bowden assembly assembled with supplementary hardware and 'Compact Bowden Extruder thing:275593'. Note that a common 1.75mm (MK7) extruder drive tooth gear has been inverted and coupled with electrical tape to provide frictional rolling resistance to aid in guiding the 1100 series aluminum wire 


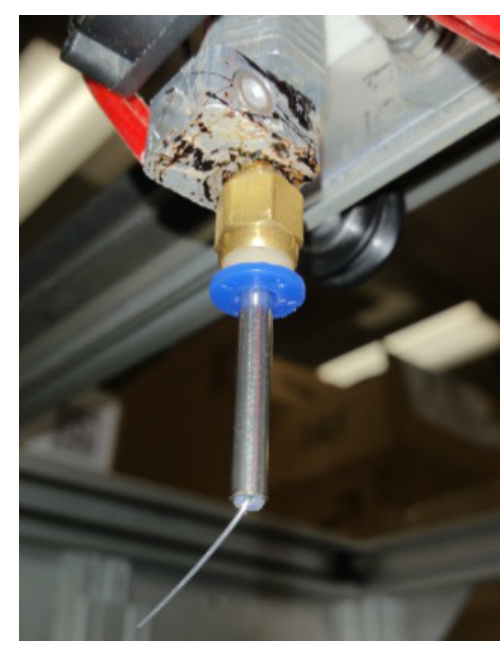

Figure 4.11. Wire feed guide tube. As shown a standard M6 4.0mm press fitting accommodates the standard threading in the hot-zone of a standard Hexagon $12 \mathrm{~V}$ hot end. 304 Stainless tubing press fits similar to a 4.0 PTFE tubing. Scrap PTFE tubing is fixture to the exit zone of the 304 stainless tubing to reduce the friction associated with wire wrapping processes

The wire feed Bowden assembly enables the ability for small increments (e.g. 1-10 $\mathrm{mm}$ ) of wire feeding based upon an AE gcode command. However, the drive mechanism is not primarily responsible for the displacement of aluminum wire. In practice, an initial length of wire is fed through the wire guide. The excess length is fixed to a pin located on the Metal-Polymer Composite Gigabot's build platform. Controlled movement of the wire feed cross head allows for accurate positioning of the aluminum wire. As shown in Figure 4.9, placement of multiple secondary pins will allow for wrapping of the aluminum wire. Positioning of the fixture on the build plate is critical to success of the wrapping procedure. Secondary fixtures are independent of the Metal-Polymer Composite Gigabot's motor controllers thus offsets, in Slic3r, are to be programmed into resultant gcode. The offsets are readily determinable by manually progressing the wire-feed hot end to a known location on the secondary fixture and recording the positional coordinates provided by Franklin's GUI. The deviation in positional coordinates between the known location on the secondary fixture and Franklin's GUI output correspond to the offsets required. In this application, positioning is only critical and programmable in the two-dimensional (XY) 
realm as z-axis, as mentioned earlier, is adjusted mechanically by the operator. The primary gcode, responsible for the wire rapping operations, can be produced from a digital parametric model. In this method, the model is set up to accommodate the fixture as shown in Figure 4.12. For proper generation of both the fixture and parametric "wrapping" model must be modeled in the same relative positioning. In these analysis, OpenSCAD modeling was used to model the entire print preproduction. Figure 4.13 displays a rendering of the OpenSCAD modeling.

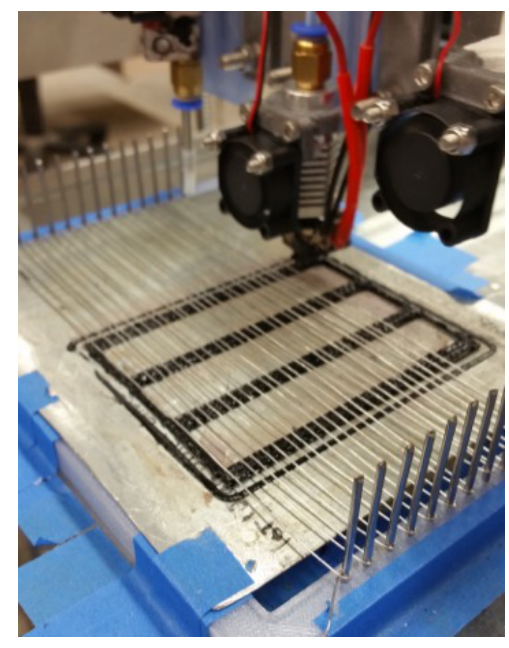

Figure 4.12. In-situ process photo of Franklin controlled wire wrapping. 


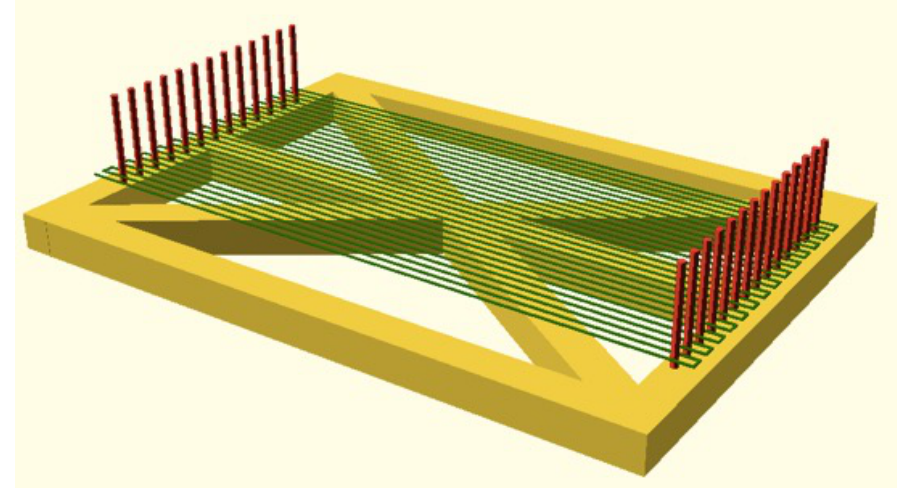

Figure 4.13. Rendering of parametric OpenSCAD model (Yellow: fixture, Red: pins, Green: Wire). In-situ process of the designed OpenSCAD model displayed in Figure 4.12

Gcode generated for the wire weaving is obtained by individually exporting the (green) wire portion as a STL. The exported model can be placed into Slic3r and sliced into a single layer forgoing any Z-components. The fixture, pins and wire modeling in OpenSCAD all share an equivalent "zero" position. Thus, assuming that a specific location on the fixture can be located the required offsets to realign the digital wire model to the physical fixture can be obtained. Typically, modifications to the generated wire wrapping gcode are required as the models shown in Figure 4.11 are designed to a nominal dimension. Thus, no tolerance is designed for accommodating manufacturing / assembly of fixture positioning issues. The total realized errors, due to assembly accuracy, are not realized until initial test prints begin.

\subsubsection{Composite Printing - Utilizing Wire-Feed Guide and Standard Brass $1.0 \mathrm{~mm}$ Extruder Nozzle}

Slic3r 1.2.9 allows for placement of custom gcode before and/or after a layer has been completed. Application of this software utility allows for customized wire weaving operations to occur during a standard print operation. Thus, composite structures containing 1100 series aluminum wire along with polymer FFF materials are realized. Developed processing parameters, metal-polymer composite printer modifications are all in effort to accommodate a pre-prescribed model relative to the 
funding agency project scope. Further secondary operations during printing are required. For example, the aluminum wires need to be heated to an elevated temperature such that the localized polymer material, at each intersection, is melted. Currently, a heater is utilized to elevate the local temperature of the metal / polymer interface. The localized heating enables the 1100 series aluminum wire and polymer material to bond sufficiently and provide significant z-height clearance for the subsequent layers of polymer material.

\subsubsection{Polymer Filament Materials Selection and Printing Parameter Development}

Readily available polymer materials polyethylene terephthalate glycol modified (PETG) and polypropylene (PP) were selected for analysis. PETG was sourced from Shenzhen Esun Industries Co., Ltd. (eSUN) and the PP from Gizmo Dorks. Materials were procured in $1 \mathrm{~kg}$ filament spools with a nominal diameter $1.75 \mathrm{~mm} \pm 0.05 \mathrm{~mm}$ where roundness tolerances were not considered. Relevant intrinsic materials properties, as described by the respective materials technical data sheets, are displayed in Table $4.8[58,59]$.

Table 4.8. Material properties of PETG and $\mathrm{PP}^{7}$

\begin{tabular}{cccc}
\hline \multicolumn{2}{c}{ eSUN PETG } & \multicolumn{2}{c}{ Gizmo Dorks PP } \\
\hline $\begin{array}{c}\text { Print Temperature } \\
\left({ }^{\circ} \mathrm{C}\right)\end{array}$ & $230-250$ & Print Temperature $\left({ }^{\circ} \mathrm{C}\right)$ & $230-260$ \\
$\begin{array}{c}\text { Build Plate } \\
\begin{array}{c}\text { Temperature }\left({ }^{\circ} \mathrm{C}\right) \\
\text { Feeding Speed } \\
(\mathrm{mm} / \mathrm{s})\end{array}\end{array}$ & 80 or none & $\begin{array}{c}\text { Build Plate Temperature } \\
\left({ }^{\circ} \mathrm{C}\right)\end{array}$ & 60 \\
\hline
\end{tabular}

A variety of experimental trial prints and manufacturing runs were conducted to optimize the printing parameters. The primary metrics considered include: print speed $(\mathrm{mm} / \mathrm{s})$, extrusion/hot-end temperature $\left({ }^{\circ} \mathrm{C}\right)$, layer height $(\mathrm{mm})$, nozzle diameter $(\mathrm{mm})$, shell thickness $(\mathrm{mm})$ and bottom/top layer thickness $(\mathrm{mm})$. An optimized parameter set yields a quality component upon visual inspection and can

\footnotetext{
${ }^{7}$ Gizmo Dorks and eSUN present further and more detailed parameter settings beyond those presented here.
} 
be quantified with interface adhesion. Developed parameter sets are discussed and further evaluated below.

\subsubsection{Composite Printing Test for Metal-Polymer Composite Gigabot}

Test coupons were generated using OpenSCAD to dimensions of 1 in $x 1$ in $x 1$ in (25.4 $\mathrm{mm} \times 25.4 \mathrm{~mm} \times 25.4 \mathrm{~mm}$ ). The coupon geometry was selected to provide a simplistic volumetric model for which to compare print quality and to provide power consumption data. Print quality was determined by metrics quantifiable by visual inspection and digital caliper measurements $( \pm 0.01 \mathrm{~mm})$ (e.g. surface smoothness, dimensional accuracy, and apparent layer adhesion). Dimensional adherence to the as designed nominal dimension of the test coupon are deeply dependent upon the sliced parameters set. The intent of the dimensional analysis is to quantify the part dimensional stability per extruder, not to determine the optimum parameter set to produce nominal and/or accurate components (i.e. $\sim \pm 0.005$ in or $\pm 0.127 \mathrm{~mm}$ ). Energy consumption measurements were performed with a multi-meter for cumulative kWh monitor ( $\pm 0.01 \mathrm{kWh}$ ) and instantaneous power draw (Watts).

\subsection{Results}

\subsubsection{Resultant print quality and power consumption measurements}

An example of the resultant polymer-metal composite structure is shown in Figure 4.14 . 


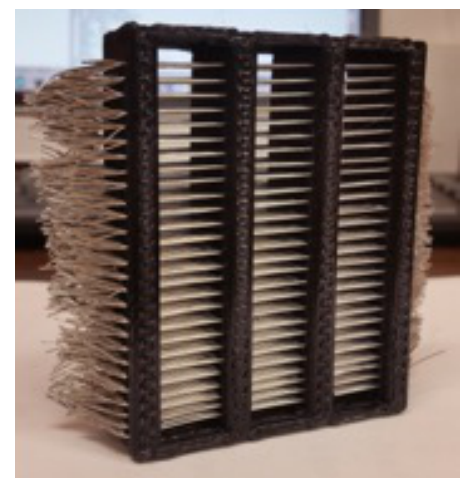

Figure 4.14. Metal polymer composite generation dimensionally accurate to prescribed models. Cross flow media is 1100 series aluminum wire, encased in a polymeric matrix of PETG

Resultant print quality is shown in Figure 4.15. A layer height of $0.5 \mathrm{~mm}$ was utilized in conjunction with a $1.0 \mathrm{~mm}$ brass nozzle. Evidence of the relatively large layer height and nozzle are shown on the component surfaces. Wave patterns apparent on the exterior perimeters of the test coupon(s) are result of the twenty-five percent infill percentage parameter. Wave "peaks" are adjacent to vector pathways of the infill section lines on the interior surface of the perimeter. Dimensional measurements identifying deviation from nominal are shown in Table 4.9. Width, length and height correspond to primarily $\mathrm{X}, \mathrm{Y}$ and $\mathrm{Z}$ coordinates, respectively. 


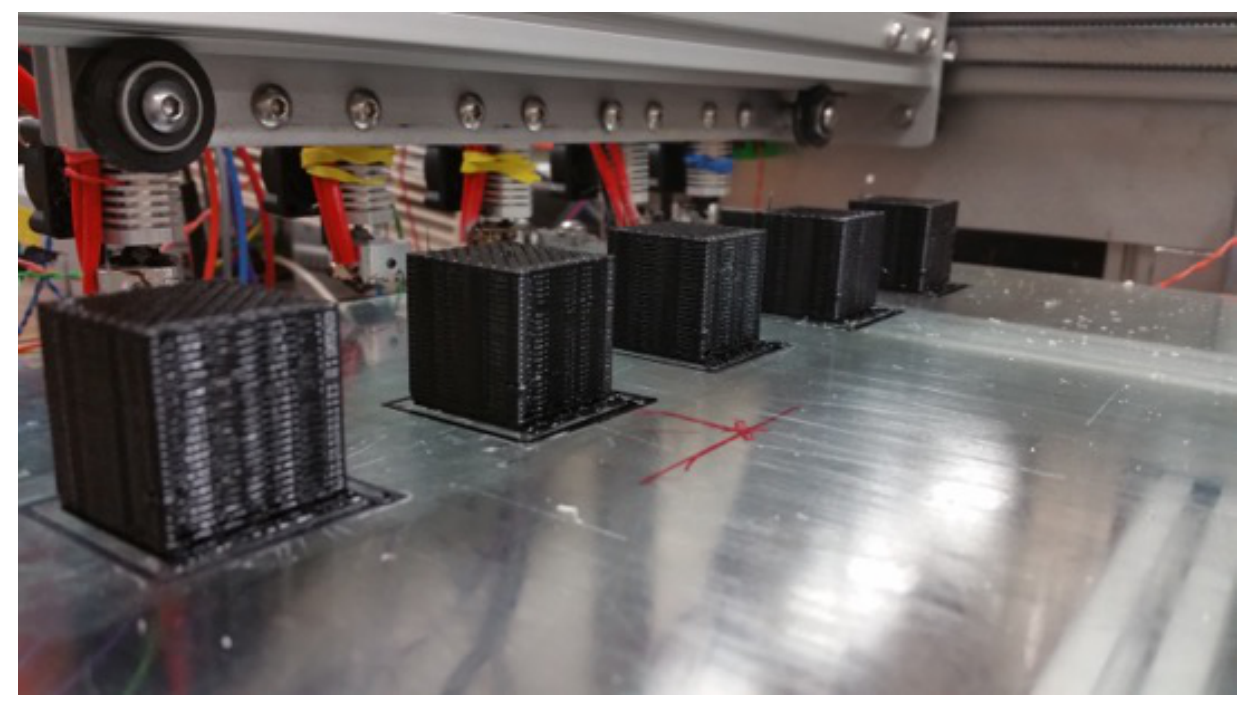

Figure 4.15. Printed component part quality (visual inspection) prior to removal from substrate to be measured for dimensional precision. As indicated in Table 4.9, dimensional variation between hot ends is determined to be a critical metric in contrast to print parameters adjustable deviation form nominal dimensional values (i.e. $25.4 \mathrm{~mm}$ )

Table 4.9. Printed component average dimensions relative to nominal dimension

$$
( \pm \mathrm{mm})^{8}
$$

\begin{tabular}{ccccccccccc}
\hline Dim. & $\left(\mathbf{A}_{\mathrm{E}}\right)$ & $\mathbf{\pm \sigma}$ & ${\mathbf{( E 0 _ { E }}}_{\mathbf{n}}$ & $\mathbf{\pm \sigma}$ & $\mathbf{( E 1 _ { E } )}$ & $\mathbf{\pm \sigma}$ & $\left.\mathbf{( E 2}_{\mathrm{E}}\right)$ & $\mathbf{\pm \sigma}$ & $\left.\mathbf{( E 3}_{\mathrm{E}}\right)$ & $\mathbf{\pm \sigma}$ \\
\hline $\mathrm{X}$ & 25.82 & 0.08 & 25.86 & 0.08 & 25.93 & 0.06 & 25.94 & 0.06 & 25.93 & 0.18 \\
$\mathrm{Y}$ & 25.77 & 0.06 & 25.80 & 0.04 & 25.79 & 0.06 & 25.88 & 0.01 & 25.70 & 0.04 \\
$\mathrm{Z}$ & 26.42 & 0.09 & 26.66 & 0.05 & 26.39 & 0.06 & 26.45 & 0.04 & 26.25 & 0.03 \\
\hline
\end{tabular}

Electrical power draw (Watts) for a variety of operating conditions are shown in Table 10. Conditions were selected to identify the power requirements for each component of the metal-polymer composite Gigabot, including thermistors, heater cartridges, stepper motors (extruder and position).

\footnotetext{
${ }^{8}$ Nominal designed dimensions of $25.4 \mathrm{~mm}$. Averages determined from a sample size of three measurements.
} 
Table 4.10. Power consumption for various metal-polymer composite Gigabot operating conditions (Watts) ${ }^{9}$

\begin{tabular}{cc}
\hline Operating Condition & Power Draw (Watts) $^{1}$ \\
\hline 36V 10A Stand Alone & $5.9-6.9$ \\
12V 20A Stand Alone & $13.2-14.0$ \\
12V 20A with Heaters On & $117-118$ \\
12V 20A and 36V 10A with Heaters On & $138-144$ \\
12V 20A and 36V 10A Temp Limit $\left(220^{\circ} \mathrm{C}\right)$ & $138-144$ \\
12V 20A and 36V 10A with Motors Enabled & $45.9-46.7$ \\
12V 20A and 36V 10A with no Heaters or \\
Motors \\
12V 20A and 26V 10A Motors on Heaters on \\
and Printing
\end{tabular}

Cumulative kWh, per print cycle, measurements are displayed in Table 4.11. Four parameter sets were utilized for this analysis utilizing the same test coupon geometry to quantify visual part quality. The four conditions were set-up as follows: twenty-five percent infill $x 5$ extruders, one-hundred percent infill $x 5$ extruders, twenty-five percent infill $x 1$ extruder and 100 percent infill $x 1$ extruder. Single extruder studies used the AE stepper motors and respective heater elements to print five test coupons. Conversely, multi extruders utilized five extruders replication the actions of AE. The metal polymer composite Gigabot was allowed four minutes of heat up from $100^{\circ} \mathrm{C}$ to $220^{\circ} \mathrm{C}$ for each condition. All print cycles resulted in five printed components.

\footnotetext{
${ }^{9}$ Measurements are recorded in an enabled state but idle condition (i.e. not performing a build sequence.
} 
Table 4.11. Energy consumption (kWh) measurements for various print cycles ${ }^{10}$

\begin{tabular}{|c|c|c|c|c|}
\hline Conditions & Metrics & Heat Up & Build & Total kWh \\
\hline \multicolumn{5}{|l|}{$\begin{array}{c}25 \% \text { In-Fill } \\
\text { and } 5 x\end{array}$} \\
\hline \multirow[t]{2}{*}{ Extruders } & Time (min) & 4 & 9 & \multirow[t]{2}{*}{0.03} \\
\hline & 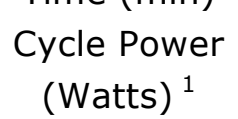 & $140-144$ & $138-144$ & \\
\hline \multicolumn{5}{|l|}{$\begin{array}{l}100 \% \text { In- } \\
\text { Fill and } 5 x\end{array}$} \\
\hline \multirow[t]{2}{*}{ Extruders } & Time (min) & 4 & 20 & \multirow[t]{2}{*}{0.06} \\
\hline & 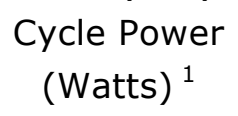 & $140-144$ & $138-144$ & \\
\hline \multicolumn{5}{|l|}{$\begin{array}{c}25 \% \text { In-Fill } \\
\text { and } 1 x\end{array}$} \\
\hline Extruders & Time (min) & 4 & 10 & \multirow[t]{2}{*}{0.01} \\
\hline & 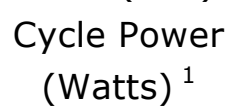 & $68-69$ & $62-65$ & \\
\hline \multicolumn{5}{|l|}{$\begin{array}{l}100 \% \text { In- } \\
\text { Fill and } 1 x\end{array}$} \\
\hline Extruders & Time (min) & 4 & 21 & \multirow[t]{2}{*}{0.03} \\
\hline & 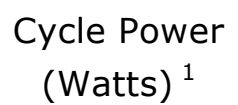 & $68-69$ & $62-65$ & \\
\hline
\end{tabular}

\subsubsection{Printing parameter and material development}

Slic3r 1.2.9 was selected as the primary slicing tool for gcode generation. As compared to Cura 15.04.6, Slic3r allowed for custom gcode, including: start gcode, end gcode, before layer change gcode and after layer change gcode [60]. Without the implementation of this interface combining metal wire wrapping processes with the polymer printing would not be possible.

${ }^{10}$ Cycle power (Watts) are measured and noted in Table 4.10 as well. 
PETG was selected as the primary polymer material for the metal/polymer composite over PP. In virgin filament form PETG is rigid in comparison to PP. During manufacturing trials PP would consistently twist and bend within the Bowden sheath, thus, causing filament jams. Developing processing techniques to ensure consistent material flow throughout the hot end was troublesome. Secondly, PP requires like to like material for proper build plate adhesion. Specifically, a PP build plates are required to reduce delamination part warping after deposition. Conversely, PETG is readily suited to adequately bond to a glass build plate with application of a thin adhesive layer from a glue stick. Due to the relative ease of manufacturing and build preparation set-up the advantages of PETG over PP are clear from a manufacturing standpoint.

Selected build parameters are displayed in Table 4.12. Determined build parameters are relative to a $1 \mathrm{~mm}$ hot-end nozzle and should be modified as such in the case of any significant machine design change. Critical metrics are identified in Table 4.12 However, more elaborate and complete ".ini" files are included in the supplementary documentation.

Table 4.12. Manufacturing parameters for PETG on a Metal-Polymer Composite Gigabot

\begin{tabular}{cc}
\hline Retraction Parameters Type & Corresponding Slic3r Setting \\
\hline Print Temperature $\left({ }^{\circ} \mathrm{C}\right)$ & 220 \\
Print Speed (mm/s) & 40 \\
Layer Height (mm/s) & 0.5 \\
Horizontal Shells (Top) & 2 \\
Horizontal Shells (Bottom) & 3 \\
First Layer Extrusion Width (\%) & 200 \\
Extrusion Multiplier & $\mathrm{X} 2$ \\
\hline
\end{tabular}

Without sufficient accommodation PETG was noted to string during vector movements and stick to the nozzle. These phenomena caused concern in regards to dimensional stability, printed part accuracy and visual appearance of the printed component. Proper calibration of retention setting and seam locations was required. Table 4.13 identified the required print parameter settings to ensure adequate 
retraction of PETG filament after a vector pass such that no undesired filament was deposited onto the printed part.

Table 4.13. Manufacturing parameters for PETG on a Metal-Polymer Composite Gigabot

\begin{tabular}{cc}
\hline Parameters Type & Corresponding Slic3r Setting \\
\hline Length $(\mathrm{mm})$ & 10 \\
Lift Z $(\mathrm{mm})$ & 0.5 \\
Speed $(\mathrm{mm} / \mathrm{s})$ & 100 \\
Extra length on restart $(\mathrm{mm})$ & 8 \\
Minimum travel after retraction & 0.1 \\
$(\mathrm{~mm})$ & Yes \\
Retract on layer change & Yes \\
Wipe while retracting & Nearest \\
Seam Position &
\end{tabular}

\subsection{Discussion}

\subsubsection{Practical application of the metal-polymer composite Gigabot}

Attachment of x5 extruder nozzles to a gantry allows for significant energy/part savings. The developed system contains nearly identical embodied energy and energy consumption when compared to other Cartesian type printer systems on the market (e.g. Lulzbot) [61]. Specifically, comparable systems use an near equivalent amount of NEMA 17 motors one X-motor, one-two Y-motor(s) and two Z-motors. However, the metal-polymer composite Gigabot allows operators to utilize the embodied energy in the manufacture of multiple components in regards to all $\mathrm{X}, \mathrm{Y}$ and $Z$ travel movements in all $\times 5$ nozzles simultaneously. Furthermore, the timed based analysis presented in Section 3.1 displays significant manufacturing time variances between the parameter sets. Most notably are the advantages of utilizing the metal-polymer Gigabot for the manufacture of $x 5$ components. At $25 \%$ in-fill operators print single components (i.e. one hot end) at a time 70 minutes are required for complete manufacture while $100 \%$ requires 125 minutes for 
manufacturing. Comparatively, utilizing the full capacity of the metal-polymer Gigabot reduce manufacturing time to $13 \mathrm{~min}$ and $24 \mathrm{~min}$ for $25 \%$ and $100 \%$ in-fill, respectively. On a percentage basis this is a variance of $\sim 438 \%$ and $\sim 420 \%$ for $25 \%$ in-fill and $100 \%$ in-fill, respectively. This improved product manufacturing time is an advantage for small lots as could be used in a 3-D print shop or part to order factory for small business manufacturing [62]. In addition, this improved embodied energy of manufacturing $[63,64]$ if dispersed would provide an advantage over conventional manufacturing and home-based manufacturing $[61,65,66]$. At the same time this methodology points the way to potential 3-D printing-based mass production [67] by ganging many print heads to manufacture identical bespoke products simultaneously [68-71]. This would in theory allow scaling up to the limits of the mechanical strength of the gantry materials to add additional nozzles and the stepper motors to move the assembly of hot ends. This would provide an advantage over smaller producers if the lot sized is matched with the number of heads of the 3-D printer, while enabling rates approaching more traditional mass manufacturing. However, practically as the lot sized increases and the geographic market for a particular product expands the embodied energy of transportation reduces the benefits of reduced embodied energy of manufacturing. Future work is need in environmental life cycle analysis (LCA) to optimize the digital manufacturing mode for energy efficiency and emissions.

\subsubsection{Areas of Improvement and comparison to other technologies}

Extruders nozzles mounted on the Y0/Y1 controlled gantry (e.g. the primary crosshead gantry) are fixed upon the $\mathrm{X}$-axis providing limit mobility relative to one another. Specifically, all five extruders are controlled by the same $X_{D}, Y 0_{D}$, and $Y 1_{D}$ commands, thus, equivalent movements are required of head hot end/nozzle. Multi head FFF systems utilizing Autodesk Project Escher technology [72], for instance Titan Robotics Cronus 3D Printer [73], allow for hot-end individualized positional movements on $X, Y$ and $Z$ for each respective hot end. Current metal-polymer composites designs required a limiting maximum distance of $55 \mathrm{~mm}$ in the $X-$ direction. As a result this limits the maximum part volume printable on the metalpolymer composite Gigabot. To increase the printable part volume, the extents of the printer would have to be enlarged to accommodate hot end linear spacing greater 
than $55 \mathrm{~mm}$. Extension of the machine mechanical limits would also enable the operator practical utilization of the XD directional motor at increased hot end spacing. However, build volume optimization processes (i.e. component orientation and 2-D build plate layout) can aid operators in design of manufacturing process parameters within the machine limits. Specifically, the metal-polymer Gigabot retains the ability to print components with their primary (maximum) linear dimension to be oriented perpendicular to the $X$-direction on the print bed. Effectively, this requires an increased utilization of YOD and Y1D for printing as opposed to XD. Baumers developed an algorithmic methodology promoting densification of available build plate volume [74]. The methodology employs a selection criterion to promote agglomeration of parts in a build volume [74]. The criterion includes part rotation / orientation, part $X / Y$ positioning coordinates, collision checking and total surface area of part. In practice, the algorithm selects components to be printed and places them in the proper geometrical coordinates such that their centers of mass are near as possible to their nearest neighbor [74]. Chernov, et al. has developed practical packing algorithm for classical cutting and packing (C\&P) problems. The realized application promotes the minimization of scrap loss during fabrication techniques such as garment manufacturing, sheet metal cutting and furniture manufacturing. The heuristic algorithms are also applicable to 3-D packaging efficiency simulations (i.e. cargo shipments and granular media packaging). In the prescribed models most are commonly used to analyze simplified polygons fixed in a specific orientation denoted phi-objects [75]. Similar phi-object models are presented in $[76,77]$. In FFF printing processes the operator commonly selects the build orientation based upon metrics related to print quality, dimensional stability and mechanical properties. Thus, the slicing software (i.e. Slic3r) is responsible for $X / Y$ orientation of components to an engineered build plate "density" based upon the software algorithms. Thus, while currently developed for non-additive manufacturing processes, Chernov et al.'s methodologies and driving equations could be applied to any metal-polymer composite Gigabot manufacturing system in an effort to optimize build platform part layout under machine constraints. Furthermore, while these methodologies are to be applied to optimize manufacturing processes due to mechanical constraints, in context of the metal-polymer Gigabot, there are also significant advantages to be discovered from an embodied energy and total capacity utilization (Table 11 ) standpoint in regards to multihead (x5) printing. 
Bowden sheaths are utilized to provide feed stock material to the five Hexagon hot ends. Bowden sheaths reduce the amount of weight on the extruder gantry. A reduction in gantry weight, on any printing system, is generally considered to increase the part quality and positional accuracy as there is less momentum shift between various vector paths. This phenomena is most apparent at faster print speeds. Other composite printers readily available in the marketplace (e.g. Mark Forged) use a direct drive system [78]. At the expense of gantry weight direct drive printers allow for flexible materials to be extruded. Direct drive accomplishes this by locating a extruder drive motor near the extruder hot end thus provide sufficient pressure and not allowing a flexible material strands (e.g. carbon fiber, fiberglass, HSHT fiberglass and Kevlar) to bend and/or flex [78]. The developed metal-polymer composite Gigabot is able to utilize a Bowden system for the feeding of aluminum wire by requiring a pre-engineer tool path and proper fixturing to pull and weave wire through the guide pin into a specified layer geometry. However, the manufactured fixturing bracket for the five hot ends increases the gantry mass greatly, relatively to delta style Bowden system [79]. Subsequently, maximum print speeds are not fully realized as the excess mass causes the XD positioning motor to slip and lose calibration during fast vector changes.

\subsubsection{Future Work}

The layer based manufacturing methodology described is adaptable to other material systems beyond metal / polymer composites. For example, designed reinforcement schemes utilizing carbon fibre and/or fibre glass strands potentially increase the printed composites mechanical properties. A Metal-Polymer Composite Gigabot allows for site specific placement of reinforcement material for localized strengthening mechanisms. The performance effects of carbon fibre and/or fibre glass embedding require further investigation. Specifically, bonding mechanisms and mechanical property verification (e.g. tensile, yield, elongation and stiffness) is required prior to any implementation into engineering applications. 


\subsection{Conclusions}

This study described an open source manufacturing technology that enables the manufacturing of polymer-metal composite components by providing free and open source hardware and software. The developed printing systems achieves metal wire embedment into a polymer matrix 3-D printed part via a novel weaving and wrapping method using OpenSCAD and parametric coding for customized gcode commands. The results indicate that utilizing a multi-polymer head system for multi component manufacturing reduces manufacturing time by $\sim 420-438 \%$ and provides dimensionally uniform components throughout all hot ends / extruders. Maximum dimensional deviation occurs in the $X$ dimension with a value of $0.18 \mathrm{~mm}$ on extruder E3. Thus, multi-component manufacturing can produce dimensionally accurate parts for practical engineering applications.

\subsection{Acknowledgements}

The authors would like to thank helpful discussion and technical assistance from $\mathrm{S}$. Snabes, M. Fiedler, B. Wijnen, M. Ohadi and G.C. Anzalone. Financial support was provided by the US Department of Energy ARPA-E /University of Maryland Subaward No. 30353-Z7214003. The views and opinions of authors herein do not necessarily state or reflect those of the United States Government or any agency thereof. Additionally, the authors wish to thank Dr. James Klausner and Mr. Geoffrey Short (both of ARPA-E) for their technical insight and discussions that favorably affected the design of our modules and the general approach to the problem.

\subsection{References}

[1] Bowyer, A. 3D printing and humanity's first imperfect replicator. 3D Print. Addit. Manuf. 2014, 1, 4-5.

[2] Rundle, G.A. Revolution in the Making: 3D Printing, Robots and the Future; Affirm Press: South Melbourne, Australia, 2014.

[3] Jones, R.; Haufe, P.; Sells, E. Reprap-The replicating rapid prototype. Robotica 2011, 29, 177-191. 
[4] Sells, E.; Bailard, S.; Smith, Z.; Bowyer, A.; Olliver, V. RepRap: The replicating rapid prototyper-maximizing customizability by breeding the means of production. In Handbook of Research in Mass Customization and Personalization, Volume 1: Strategies and Concepts; Pillar, F.T., Tseng, M.M., Eds.; World Scientific: Hackensack, NJ, USA, 2009; pp. 568-580.

[5] ASTM International. Standard Terminology for Additive Manufacturing Technologies; ASTM F2792-12a; ASTM: West Conshohocken, PA, USA, 2001.

[6] Wittbrodt, B.; Pearce, J. M. The effects of PLA color on material properties of 3-D printed components. Additive Manufacturing 2015, 8, 110-116 DOI: 10.1016/j.addma.2015.09.006.

[7] Tymrak, B. M.; Kreiger, M.; Pearce, J. M. Mechanical properties of components fabricated with open-source 3-D printers under realistic environmental conditions. Materials \& Design 2014, 58, 242-246 DOI:

10.1016/j.matdes.2014.02.038.

[8] Lanzotti, A.; Grasso, M.; Staiano, G.; Martorelli, M. The impact of process parameters on mechanical properties of parts fabricated in PLA with an opensource 3-D printer. Rapid Prototyping Journal 2015, 21(5), pp.604-617.

[9] Afrose, M.F.; Masood, S.H.; Iovenitti, P.; Nikzad, M.; Sbarski, I. Effects of part build orientations on fatigue behaviour of FDM-processed PLA material. Progress in Additive Manufacturing, 2015 pp.1-8.

[10] Nagendra G. Tanikella, Ben Wittbrodt and Joshua M. Pearce. Tensile Strength of Commercial Polymer Materials for Fused Filament Fabrication 3-D Printing. (to be published).

[11] Kasture, P.V., Deole, P.; Irwin, J.L. Case Study Using Open Source Additive Manufacturing (AM) Technology for Improved Part Function. In ASME 2015 International Mechanical Engineering Congress and Exposition. American Society of Mechanical Engineers. 2015, (pp. V02AT02A002-V02AT02A002).

[12] Laureto, John J.; Tomasi, Julie; King, Julia A.; Pearce, Joshua M. Thermal Properties of 3-D Printed Polylactic Acid - Metal Composites. Progress in Additive Manufacturing (2017, in press).

[13] Sugavaneswaran, M.; Arumaikkannu, G. Analytical and experimental investigation on elastic modulus of reinforced additive manufactured structure. Materials \& Design. 2015,66, pp.29-36. 
[14] Le Duigou, A., Castro, M., Bevan, R.; Martin, N. 3D printing of wood fibre biocomposites: From mechanical to actuation functionality. Materials \& Design. 2016, 96, pp.106-114.

[15] Taboas, J. .; Maddox, R. .; Krebsbach, P. .; Hollister, S. . Indirect solid free form fabrication of local and global porous, biomimetic and composite 3D polymer-ceramic scaffolds. Biomaterials. 2003, 24 (1), 181-194 DOI: 10.1016/S0142-9612(02)00276-4.

[16] Seitz, H.; Rieder, W.; Irsen, S.; Leukers, B.; Tille, C. Three-dimensional printing of porous ceramic scaffolds for bone tissue engineering. Journal of Biomedical Materials Research Part B: Applied Biomaterials. 2005, 74B (2), 782-788 DOI: $10.1002 / \mathrm{jbm} \cdot$ b. 30291.

[17] Habraken, W. J. E. M.; Wolke, J. G. C.; Jansen, J. A. Ceramic composites as matrices and scaffolds for drug delivery in tissue engineering. Advanced Drug Delivery Reviews. 2007, 59 (4-5), 234-248 DOI:

10.1016/j.addr.2007.03.011.

[18] Liu, X.; Ma, P. X. Polymeric Scaffolds for Bone Tissue Engineering. Annals of Biomedical Engineering. 2004, 32 (3), 477-486 DOI:

10.1023/B:ABME.0000017544.36001.8e.

[19] da Silva, J.R.C., da Fonsêca, G.F.G. and de Andrade, M.M. Mechanical tests in thermoplastic elastomers used in 3D printers for the construction of hand prosthesis. In Health Care Exchanges (PAHCE) Pan American. 2014, (pp. 1$6)$.

[20] Trachtenberg, J.E., Mountziaris, P.M., Miller, J.S., Wettergreen, M., Kasper, F.K.; Mikos, A.G.,. Open-source three-dimensional printing of biodegradable polymer scaffolds for tissue engineering. Journal of Biomedical Materials Research Part A. 2014, 102(12), pp.4326-4335.

[21] Wong, J.Y.; Pfahnl, A.C. 3D printing of surgical instruments for long-duration space missions. Aviation, space, and environmental medicine. 2014, 85(7), pp.758-763.

[22] Dimas, L.S.; Graham H.B; Ido E.; Markus J.B. "Tough composites inspired by mineralized natural materials: computation, 3D printing, and testing." Advanced Functional Materials. 2013, 23(36): 4629-4638.

[23] Chia, H. N.; Wu, B. M. Recent advances in 3D printing of biomaterials. Journal of Biological Engineering 2015, 9 (1) DOI: 10.1186/s13036-015-0001-4. 
[24] Espalin, D., Muse, D. W., MacDonald, E., Wicker, R. B. 3D Printing multifunctionality: structures with electronics. The International Journal of Advanced Manufacturing Technology. 2014, 72 (5-8), 963-978 DOI: 10.1007/s00170-014-5717-7.

[25] Serra, T.; Planell, J. A.; Navarro, M. High-resolution PLA-based composite scaffolds via 3-D printing technology. Acta Biomaterialia. 2013, 9 (3), 55215530 DOI: $10.1016 /$ j.actbio.2012.10.041.

[26] Ma, R.R., Belter, J.T. and Dollar, A.M. Deposition Manufacturing: Design strategies for multimaterial mechanisms via Three-Dimensional printing and material deposition. Journal of Mechanisms and Robotics. 2015, 7(2), p.021002.

[27] Frazier, William E. "Metal additive manufacturing: a review." Journal of Materials Engineering and Performance 23. 2014, no. 6, 1917-1928.

[28] Ready, Steve, Gregory Whiting, and Tse Nga Ng. "Multi-material 3D printing." In NIP \& Digital Fabrication Conference Society for Imaging Science and Technology. 2014, no. 1, pp. 120-123.

[29] Anzalone, G.C.; Zhang, C; Wijnen, B; Sanders, P.G.; Pearce, J.M. A low-cost open-source metal 3-D printer. IEEE Access. 2013, 1, 803-810.

[30] Haselhuhn, A.S.; Wijnen, B.; Anzalone, G.C.; Sanders, P.G.; Pearce, J.M., In Situ Formation of Substrate Release Mechanisms for Gas Metal Arc Weld Metal 3-D Printing. Journal of Materials Processing Technology. 2015, 226, pp. 50-5

[31] Haselhuhn, A.S.; Gooding, E.J.; Glover, A.G.; Anzalone, G.C.; Wijnen, B. ; Sanders, P.G.; Pearce, J.M. Substrate release mechanisms for gas metal arc weld 3D aluminum metal printing. 3D Printing and Additive Manufacturing. 2014, no. 4, 204-209.

[32] Haselhuhn, A.S.; Buhr, W.M.; Wijnen, B.; Sanders, P.G.; Pearce, J.M.. "Structure-property relationships of common aluminum weld alloys utilized as feedstock for GMAW-based 3-D metal printing." Materials Science and Engineering. 2016, 673, 511-523.

[33] Ding, Donghong, Zengxi Pan, Dominic Cuiuri, and Huijun Li. Wire-feed additive manufacturing of metal components: technologies, developments and future interests. The International Journal of Advanced Manufacturing Technology. 2015, no. $1-4,465-481$. 
[34] Wijnen, B.; Anzalone, G.C.; Haselhuhn, A.S.; Sanders, P.G.; Pearce, J.M. Free and open-source control software for 3-D motion and processing. Journal of Open Research Software. 2015, 4, no. 1.DOI: http://doi.org/10.5334/jors.78

[35] Laureto, J.J.; Dessiatoun, S.V.; Ohadi, M.M.; Pearce, J.M. Open Source Laser Polymer Welding System: Design and Characterization of Linear Low-Density Polyethylene Multilayer Welds. Machines 2016, 4, 14.

[36] Anzalone, G. C.; Wijnen, B.; Pearce, J.M. Multi-material additive and subtractive prosumer digital fabrication with a free and open-source convertible delta RepRap 3-D printer. Rapid Prototyping Journal 2015, no. 5, 506-519

[37] Pearce, J.M. "Applications of open source 3-D printing on small farms." Organic Farming 2015, no. 1, 19-35.

[38] Nilsiam, Y.; Haselhuhn, A.S.; Wijnen,B.; Sanders, P.G.; Pearce, J.M. Integrated Voltage-Current Monitoring and Control of Gas Metal Arc Weld Magnetic BallJointed Open Source 3-D Printer. Machines 2015, no. 4,339-351.

[39] Quan, Zhenzhen, Amanda Wu, Michael Keefe, Xiaohong Qin, Jianyong Yu, Jonghwan Suhr, Joon-Hyung Byun, Byung-Sun Kim, and Tsu-Wei Chou. "Additive manufacturing of multi-directional preforms for composites: opportunities and challenges." Materials Today 2015, no. 9, 503-512.

[40] Bayless, Jacob, Mo Chen, and Bing Dai. Wire embedding 3D printer. Engineering Physics Department, University of British Columbia 2010.

[41] Shemelya, C.; Cedillos, F.; Aguilera, E.; Espalin, D.; Muse, D.; Wicker, R.; MacDonald, E. Encapsulated Copper Wire and Copper Mesh Capacitive Sensing for 3-D Printing Applications. IEEE Sensors Journal 2015, 15 (2), 1280-1286 DOI: 10.1109/JSEN.2014.2356973.

[42] Kim, C.; Espalin, D.; Cuaron, A.; Perez, M. A.; Lee, M.; MacDonald, E.; Wicker, R. B. Cooperative Tool Path Planning for Wire Embedding on Additively Manufactured Curved Surfaces Using Robot Kinematics. Journal of Mechanisms and Robotics 2015, 7 (2), 021003 DOI: 10.1115/1.4029473.

[43] Saari, M.; Cox, B.; Richer, E.; Krueger, P. S.; Cohen, A. L. Fiber Encapsulation Additive Manufacturing: An Enabling Technology for 3D Printing of Electromechanical Devices and Robotic Components. 3D Printing and Additive Manufacturing 2015, 2 (1), 32-39 DOI: 10.1089/3dp.2015.0003. 
[44] Macdonald, E.; Salas, R.; Espalin, D.; Perez, M.; Aguilera, E.; Muse, D.; Wicker, R. B. 3D Printing for the Rapid Prototyping of Structural Electronics. IEEE Access 2014, 2, 234-242 DOI: 10.1109/ACCESS.2014.2311810.

[45] Francia, D.; Caligiana, G.; Liverani, A. ; Frizziero, L.; Donnici, G. PrinterCAD: a QFD and TRIZ integrated design solution for large size open moulding manufacturing. International Journal on Interactive Design and Manufacturing (IJIDeM) 2017 DOI: 10.1007/s12008-017-0375-2.

[46] Re:3D. Available online: http://shop.re3d.org/ (accessed 19 Jan 2017)

[47] OpenSCAD. Available online: http://www.openscad.org/ (accessed on 21 April 2016).

[48] Franklin Firmware on Gigabot. Available online: http://www.appropedia.org/Franklin_Firmware_on_GigabotHX:MOST (accessed on 19 Jan 2017)

[49] Open Science Framework. Available online: https://osf.io/jvhqt/ (accessed on 1 March 2017).

[50] GNU General Public License. Available online: http://www.gnu.org/licenses/gpl3.0.en.html (accessed on 12 Jan 2017).

[51] MOST Gigabot. Available online: http://www.appropedia.org/Franklin_Firmware_on_GigabotHX:MOST (accessed on 19 Jan 2017)

[52] IC3D Digital Platform. Available online: https://www.ic3dprinters.com/index.html (accessed on 19 Jan 2017)

[53] RAMPS 1.4. Available online: http://reprap.org/wiki/RAMPS_1.4 (accessed on 23 Jan 2017)

[54] Pololu A4988 Stepper Motor Drive Carrier. Available online: https://www.pololu.com/product/1182 (accessed 24 Jan 2017)

[55] Arduino Mega Board 2560. Available online: https://www.arduino.cc/en/Main/ArduinoBoardMega2560 (accessed on 24 Jan 2017)

[56] KiCad - PcbNew. Available online: http://kicad-pcb.org/discover/pcbnew/ (accessed 24 Jan 2017)

[57] Slic3r. Available online: http://slic3r.org/ (accessed on 19 Jan 2017)

[58] eSUN - PETG Technical Data Sheet. Available online: http://www.esun3d.net/products/176.html (accessed on 19 Jan 2017) 
[59] Gizmo Dorks - PP Technical Data Sheet. Available online:

http://gizmodorks.com/polypropylene-3d-printer-filament/ (accessed on 19 Jan 2017)

[60] Cura. Available online: https://ultimaker.com/en/products/cura-software (accessed on 23 Jan 2017)

[61] Petersen, E.E.; Pearce, J. Emergence of Home Manufacturing in the Developed World: Return on Investment for Open-Source 3-D Printers. Technologies $2017,5,7$.

[62] Laplume, A.; Anzalone, G.C.; Pearce, J.M. Open-source, self-replicating 3-D printer factory for small-business manufacturing. The International Journal of Advanced Manufacturing Technology, 2016 85(1-4), pp.633-642.

[63] Kreiger, M.; Pearce, J.M. Environmental impacts of distributed manufacturing from 3-D printing of polymer components and products. In MRS Proceedings. Cambridge University Press 2013, Vol. 1492, pp. 85-90

[64] Kreiger, M.; Pearce, J.M. Environmental life cycle analysis of distributed threedimensional printing and conventional manufacturing of polymer products. ACS Sustainable Chemistry \& Engineering 2013, 1(12), pp.1511-1519.

[65] Wittbrodt, B.T.; Glover, A.G.; Laureto, J. ; Anzalone, G.C.; Oppliger, D. ; Irwin, J.L. and Pearce, J.M. Life-cycle economic analysis of distributed manufacturing with open-source 3-D printers. Mechatronics 2013, 23(6), pp.713-726.

[66] Rayna, T.; Striukova, L. From rapid prototyping to home fabrication: How 3D printing is changing business model innovation. Technological Forecasting and Social Change, 102, pp.214-224.

[67] Bak, D. Rapid prototyping or rapid production? 3D printing processes move industry towards the latter. Assembly Automation 2016, 23(4), pp.340-345.

[68] Hergel, J.; Lefebvre, S. Clean color: Improving multi-filament 3D prints: Clean color: Improving multi-filament 3D prints. Computer Graphics Forum 2014, 33 (2), 469-478 DOI: 10.1111/cgf.12318.

[69] Ali, M. H.; Mir-Nasiri, N.; Ko, W. L. Multi-nozzle extrusion system for 3D printer and its control mechanism. The International Journal of Advanced Manufacturing Technology 2016, 86 (1-4), 999-1010 DOI: 10.1007/s00170015-8205-9. 
[70] Abilgaziyev, A.; Kulzhan, T.; Raissov, N.; Ali, M. H.; Match, W. L. K.; Mir-Nasiri, $\mathrm{N}$. Design and development of multi-nozzle extrusion system for 3D printer. IEEE 2015; pp 1-5.

[71] Song, X.; Pan, Y.; Chen, Y. Development of a Low-Cost Parallel Kinematic Machine for Multidirectional Additive Manufacturing. Journal of Manufacturing Science and Engineering 2015, 137 (2), 021005 DOI: 10.1115/1.4028897.

[72] Autodesk Project Escher. Available online: http://projectescher.com/ (accessed on 24 Jan 2017)

[73] Titan Robotics - Cronus 3D Printer. Available online: http://www.titan3drobotics.com/the-cronus/ (accessed on 24 Jan 2017)

[74] Baumers, M. Economic aspects of additive manufacturing: benefits, costs and energy consumption. Doctor of Philosophy, Loughborough University, Leicestershire, UK, 2012. Available online:

https://dspace.Iboro.ac.uk/2134/10768 (accessed on 4 April 2017)

[75] Chernov, N.; Stoyan, Y.; Romanova, T. Mathematical model and efficient algorithms for object packing problem. Computational Geometry 2010, 43 (5), 535-553 DOI: 10.1016/j.comgeo.2009.12.003.

[76] Bennell, J.; Scheithauer, G.; Stoyan, Y.; Romanova, T. Tools of mathematical modeling of arbitrary object packing problems. Annals of Operations Research 2010, 179 (1), 343-368 DOI: 10.1007/s10479-008-0456-5.

[77] Chernov, N.; Stoyan, Y.; Romanova, T.; Pankratov, A. Phi-Functions for 2D Objects Formed by Line Segments and Circular Arcs. Advances in Operations Research 2012, 2012, 1-26 DOI: 10.1155/2012/346358.

[78] Markforged Composite 3D Printer. Available online: https://markforged.com/why-markforged/ (accessed 24 Jan 2017)

[79] MOST Athena Delta - End Effector. Available Online: http://www.appropedia.org/Athena_Effector_Assembly (accessed on 24 Jan 2017) 


\section{5 - Future Work and Conclusions}

\subsection{Overview}

The work derived in this document further expands upon the usefulness of RepRap materials and technology to engineered solutions. Continued expansion in this realm is of great advancement to the open source and sustainability communities. Furthermore, the development of open source engineered materials and processing solutions provides tools for future researchers to improve RepRap technology. Development in this area lessens the cost of research and allows for collaborative development as it accessible everywhere.

\subsection{Conclusions}

Upon completion of the three case studies discussed the following conclusions are drawn.

\subsubsection{LLDPE Laser Welding}

- Weld protocols are quantified by identification of adequate incident laser linear energy density (Coulombs/mm). Methodology developed allows for the weldment of two and three layered LLDPE sheeting. Furthermore, proper selection of linear energy density allows for penetration depth $(\mathrm{mm})$ control during welding.

- Linear energy density and weld width develop a linear correlation (i.e. increased linear energy density increases the resultant weld width.

- Cross-head speeds of 10 and $20 \mathrm{~mm} / \mathrm{s}$ are quantified. Incident laser current settings for 10 and $20 \mathrm{~mm} / \mathrm{s}$ speeds are 8.5 and $10.5 \mathrm{~A}$, respectively. In these identified regions two layers of LLDPE are to be joined while not including the tertiary layer.

- $\quad$ Sustained peak load (Ibf) is quantified for two and three layer welds. Raw (i.e. non weld) LLDPE sheeting is utilized as a baseline measuring at $26.2 \mathrm{lbf}$. 
Weldments analyzed range from $19.6 \mathrm{lbf}(10 \mathrm{~mm} / \mathrm{s}$ at $5.5 \mathrm{~A})$ to $25.7 \mathrm{lbf}$ $(20 \mathrm{~mm} / \mathrm{s}$ at $9.5 \mathrm{~A})$.

\subsubsection{Polymer - Metal Composite Materials}

- Thermal conductivities of multiple polymer metal composites are characterized. Analyzed composites include ColorFabb CopperFill, ColorFabb BronzeFill, Proto Pasta Magnetic Iron PLA and Proto Pasta Stainless Steel PLA. Identified thermal conductivities were measured as $0.4381,0.5460,0.2943$ and $0.3907 \mathrm{~W} / \mathrm{m} \cdot \mathrm{K}$, respectively.

- The identified thermal conductivities do not correlate to common published models relevant to the research endeavor. Currently, authors suggest this deviation to result from the difficult quantification of air void fraction present within the sample via Image] and/or Archimedes density methods.

- Copper, bronze, magnetic iron, and stainless steel additions to a PLA polymer matrix were shown to increase the thermal conductivity of the bulk by 81.28 , $98.81,45.66$ and $71.55 \%$, respectively.

- Secondary processes such as hot isostatic pressing (HIP) were found to be ineffective at reducing apparent porosity.

- Back scattered scanning electron microscopy images identify metallic filler particle morphology. ImageJ allowed for determination of nominal particle size (i.e. nominal particle diameter). CopperFill and BronzeFill measured a nominal diameter of $15.5 \mu \mathrm{m}$ and $13.7 \mu \mathrm{m}$, respectively. While Magnetic Iron PLA and Stainless Steel PLA measured a nominal ferret diameter of $8.5 \mu \mathrm{m}$ and $9.3 \mu \mathrm{m}$, respectively. Secondary analytical techniques revealed contradictory results. Utilizing a spherical approximation CopperFill and BronzeFill resulted in a nominal particle diameter of $18.0 \mu \mathrm{m}$ and $18.5 \mu \mathrm{m}$, respectively. While Magnetic Iron PLA and Stainless Steel PLA resulted in a nominal ferret diameter of $43.9 \mu \mathrm{m}$ and $38.0 \mu \mathrm{m}$, respectively.

- Qualitative EDS chemical analysis determined major alloying elements within the metallic constituents of the polymer-metal composites. No significant surfaces oxides (i.e. hindrance to thermal transfer) were identified in the analysis. 


\subsubsection{Polymer - Metal Composite Gigabot Printer}

- Multi-head (x5) printing system reduces manufacturing time. Simple primitive objects were shown to be decreased by $420 \%$ and $438 \%$ based upon in-fill percentages.

- Energy consumption for single extruder printing a single primitive object was 0.01 to $0.03 \mathrm{kWh}$ depending upon in-fill percentages. Meanwhile, the embodied energy of all motors utilized for multi-head printing consumed 0.03 to $0.06 \mathrm{kWh}$ pending in-fill percentages.

- Dimensionally stable components are manufactured with a maximum measured dimensional deviation of $0.18 \mathrm{~mm}$ from nominal on a single axis.

- Resultant composite systems were realized by manufacturing operations performed on the Gigabot. Specifically, PETG and 1000 series aluminum composites were successfully manufactured for further investigation.

- Large nozzle diameter $(1.0 \mathrm{~mm})$ PETG print processing parameters were determined.

- Novel wire wrapping processes including printing / manufacturing along with extensive software tool chain were developed. Software packages utilized include; OpenSCAD, Slic3r, LibreOffice and Franklin.

\subsection{Future Work}

The work presented in this document experimentally research the application of RepRap printers and materials to thermal management solutions. Aspects of this research which should be explored further are described.

\subsubsection{LLDPE Laser Welding}

- The work discussed should be practically applied to thermal management solutions. Specifically, further analysis should investigate the manufacturing of multi-layered (greater than 3 layers) and multi-channeled (greater than 2 channels) heat exchangers.

- Modification of the RepRap system should occur to more accurately control the optical laser focal point. Current experiments are conducted localized to 
the focal point. Significant increases in LLDPE layers deviates from the focal point thus degrading the incident laser intensity. Decreased laser intensity can directly correlate to inadequate layer adhesion.

- Manufacturing processes should be developed to insure a uniform incident LLDPE layer. Specifically, the appearance of "bubbles" and/or creases in the applied layer can lead to decreased weld quality (e.g. a non-uniform weld thickness)

- Future manufacturing process improvement should be certain to retain a high-level of cleanliness on utilized LLDPE sheeting. The appearance of dust and/or hand oils were shown to decrease the weld quality, however, the effects were never formally investigated.

\subsubsection{Polymer - Metal Composite Materials}

- Proper quantification of air void fraction is required to continue this research. Methods offered in this section should be readily investigated.

- Increased volume fraction of metallic constituents' materials should be developed. As the adopted models suggest, increased volume fraction and reduction in air void fraction could allow for an engineered material for thermal management applications.

- Custom manufactured filaments (i.e. readily available polymers and metallic constituents) should be researched heavily. Processes should include material fabrication, filament manufacturing, print parameter, printed component mechanical and materials characterization and practical engineering applications should be assessed.

\subsubsection{Polymer - Metal Composite Gigabot Printer}

- Similar systems, machines and methods need to be developed for other material systems. Specifically, investigation should include carbon fiber and fiber glass material embedment.

- Applicability for the placement of secondary localized strengthening mechanisms should be explored. The increased mechanical properties of common printed polymers (i.e. PLA, ABS, PETG) could provide greater use as 
an engineered material. Strengthening mechanisms could include fiber composite materials and/or metallic materials.

- Interlayer adhesion and/or bonding of embedded materials requires further quantification. Susceptibility to delamination or porosity will significantly hinder mechanical properties and mass flow characteristics.

- Design hot ends and feed mechanisms derived specifically for secondary feed stock materials (e.g. non-polymer 3D printing filaments). As such, precise temperature and feed rate control should be readily available for the secondary materials.

- Advance printer control firmware for greater process control during wrapping operations. Ideally, operators require greater than 10 NEMA 17 motor control and greater programing ability outside of standard slicing / gcode operations.

- Larger than NEMA 17 motors should be investigated for effectiveness on the metal composite Gigabot. Motor sizes greater than those utilized will provide greater power and lessen the likelihood of positioning loss. 